\title{
The Cross-Section of Credit Risk Premia and Equity Returns
}

Friewald, Nils; Wagner, Christian; Zechner, Josef

Document Version

Accepted author manuscript

Published in:

Journal of Finance

DOI:

10.1111/jofi.12143

Publication date:

2014

License

Unspecified

Citation for published version (APA):

Friewald, N., Wagner, C., \& Zechner, J. (2014). The Cross-Section of Credit Risk Premia and Equity Returns. Journal of Finance, 69(6), 2419-2469. https://doi.org/10.1111/jofi.12143

Link to publication in CBS Research Portal

\section{General rights}

Copyright and moral rights for the publications made accessible in the public portal are retained by the authors and/or other copyright owners and it is a condition of accessing publications that users recognise and abide by the legal requirements associated with these rights.

Take down policy

If you believe that this document breaches copyright please contact us (research.lib@cbs.dk) providing details, and we will remove access to the work immediately and investigate your claim. 


\section{The Cross-Section of Credit Risk Premia and Equity Returns Nils Friewald, Christian Wagner, and Josef Zechner \\ Journal article (Post print version)}

This is the peer reviewed version of the following article: The Cross-Section of Credit Risk Premia and Equity Returns. / Friewald, Nils; Wagner, Christian; Zechner, Josef. In: Journal of Finance, Vol. 69, No. 6, 2014, p. 2419-2469, which has been published in final form at http://dx.doi.org/10.1111/jofi.12143.

This article may be used for non-commercial purposes in accordance with Wiley Terms and Conditions for Self-Archiving.

Uploaded to Research@CBS: June २०17 


\title{
The Cross-Section of
}

\section{Credit Risk Premia and Equity Returns}

\author{
Nils Friewald, Christian Wagner, and Josef Zechner*
}

May 3, 2013

Journal of Finance, forthcoming

\begin{abstract}
We explore the link between a firm's stock returns and its credit risk using a simple insight from structural models following Merton (1974): risk premia on equity and credit instruments are related because all claims on assets must earn the same compensation per unit of risk. Consistent with theory, we find that firms' stock returns increase with credit risk premia estimated from CDS spreads. Credit risk premia contain information not captured by physical or by riskneutral default probabilities alone. This sheds new light on the "distress puzzle", i.e. the lack of a positive relation between equity returns and default probabilities reported in previous studies.
\end{abstract}

The RELATION BETWEen firms' default risk and their equity risk premia is subject of an intense debate in finance. While some studies conclude that default risk is reflected in higher equity risk premia, others identify a "distress puzzle", showing that high measures of distress risk coincide with

\footnotetext{
${ }^{*}$ Nils Friewald and Josef Zechner are at the Department of Finance, Accounting and Statistics at WU Vienna University of Economics and Business. Christian Wagner is at the Department of Finance at Copenhagen Business School. We thank Rui Albuquerque, Doron Avramov, Jennie Bai, Tobias Berg, Nina Boyarchenko, Michael Brandt, Nicole Branger, Michael Brennan, Haibo Chen, Pierre Collin-Dufresne, Andreas Danis, Patrick Gagliardini, Andrea Gamba, Lorenzo Garlappi, Amit Goyal, Mark Grinblatt, Charles Jones, Miriam Marra, Elena-Claudia Moise, Caren Yinxia Nielsen, Ali Ozdagli, Juliusz Radwanski, Lucio Sarno, Paul Schneider, Clemens Sialm, Leopold Sögner, Pinar Uysal, Toni Whited and participants at the Swissquote Conference on Asset Management 2011 at EPFL, the CAPR \& NFI Workshop on "Time-Varying Expected Returns" at the Norwegian Business School (BI), the joint ECB and BoE Workshop on "Asset pricing models in the aftermath of the financial crisis", the European Winter Finance Summit 2012, the Swiss Society for Financial Market Research (SGF) Conference 2012, the German Finance Association (DGF) Meeting 2012, the Western Finance Association (WFA) Meetings 2012, the European Finance Association (EFA) Meeting 2012, as well as seminar participants at Cass Business School, Humboldt Universität Berlin, Leibniz Universität Hannover, University of Gothenburg, University of Lund, University of Piraeus, Warwick Business School, and WU Vienna for helpful comments. We are especially indebted to Campbell Harvey (the editor), an anonymous referee, and an anonymous associate editor for their extensive comments that have greatly helped to improve the paper.
} 
anomalously low equity risk premia. These studies all use either physical or risk-neutral default probabilities to sort firms into portfolios with different credit risk.

We approach this issue from a novel angle by studying the link between equity and credit markets. Structural models following Merton (1974) imply that the market price of risk (the Sharpe ratio) must be the same for all contingent claims written on a firm's assets. Hence, risk premia in equity and credit markets must be related. We derive the relation between a firm's expected excess returns on equity and credit default swaps (CDS), revealing that equity risk premia and equity Sharpe ratios depend on, both, physical and risk-neutral default expectations. Thus, sorting firms into portfolios using only either physical or risk-neutral default probabilities may not be sufficiently informative about expected stock returns. This is consistent with the mixed evidence on whether equity returns are positively, negatively, or not related to distress risk. In particular, the distress puzzle (see, e.g., Dichev, 1998; Campbell, Hilscher, and Szilagyi, 2008) emerges if firms, in the cross-section, differ by their expected asset return and/or the volatility of assets.

Guided by the implications of the model, our empirical strategy is to estimate risk premia and then relate them to subsequent equity excess returns of U.S. firms from 2001 to 2010. We estimate firm-specific measures of credit risk premia from the CDS forward curve following the ideas of Cochrane and Piazzesi (2005) and, first, show that these measures are related to risk premia implied by affine term structure models (ATSM). ${ }^{1}$ Next, we use these estimated risk premia to sort firms into portfolios at the end of each month and document a strong positive relation between credit risk premia and equity excess returns. Stock returns decrease from the portfolio of firms with highest to the portfolio of firms with lowest credit risk premia. At the same time, there are no monotonic cross-portfolio patterns related to firms' size, book-to-market ratios, risk-neutral or physical default probabilities, liquidity of their CDS contracts, or their conditional coskewness with the market. Buying high and selling low credit risk premium firms generates positive excess returns with CAPM-, Fama and French (1993)-, and Carhart (1997)-alphas being significantly positive while the factor loadings are generally not significantly different from zero. CDS-implied risk premia, thus, convey information that is priced in equity markets but neither captured by common measures of distress risk nor by traditional risk factors. To take a closer look at the

\footnotetext{
${ }^{1}$ For easier readability, we refer to risk premia estimated from the CDS forward curve as credit market-implied risk premia or simply as credit risk premia.
} 
relation between credit risk premia and various firm characteristics, we double sort portfolios using size, book-to-market, default probabilities, CDS liquidity, and conditional coskewness. The high minus low credit risk premium portfolio continues to earn significant alphas after controlling for these characteristics with excess returns being highest for small firms, value stocks, and firms with high default probabilities.

Our results are robust to splitting the full sample period (01/2001 to 04/2010) into pre-crisis $(01 / 2001$ to $06 / 2007)$ and crisis $(07 / 2007$ to $04 / 2010)$ sub-samples. The conclusions are identical for both periods, with the quantitative results being similar but more pronounced during the crisis. Our findings do not depend on whether we calculate equally- or value-weighted portfolio returns and they remain unchanged when excluding financial and utility firms from the sample. Furthermore, our conclusions are not altered when estimating the parameters using full-sample information or out-of-sample. All these results confirm and strengthen our findings on the relation between estimates of credit risk premia and subsequent equity returns.

Relation to Literature The empirical evidence on whether default risk is priced in stock returns is mixed. Some papers find a positive relation between default risk and equity returns. Vassalou and Xing (2004) construct a market-based measure for the physical default probability using the Merton (1974) model and find that distressed stocks earn higher returns. Chava and Purnanandam (2010) estimate expected returns using implied cost of capital and also find that they are positively related to default risk. However, there are numerous papers documenting a negative relation between a firm's default probability and its return on equity and the literature refers to this empirical finding as the "distress anomaly" or the "distress puzzle". For instance, Dichev (1998) uses the Altman (1968) Z-score and the Ohlson (1980) O-score to measure default risk and reports a negative relation to stock returns. More recently, Campbell, Hilscher, and Szilagyi (2008) use a dynamic panel regression approach that incorporates accounting and market data, such as past stock returns and standard deviations as well as returns in excess of the market. They find that firms with high distress risk deliver abnormally low returns. Related, Avramov et al. (2009) argue that the distress puzzle is most pronounced for worst-rated stocks around rating downgrades. Anginer and Yildizhan (2010) use corporate yield spreads to measure risk-neutral default probabilities and find that, neither a firm's default risk is priced in equity markets nor that firms with high distress risk earn anomalous 
low returns. Altogether, there is equivocal evidence to whether a firm's equity returns are positively, negatively, or at all related to estimates of its physical or risk-neutral default probability. Attempts to reconcile these apparently incompatible empirical patterns with theoretical models use arguments such as shareholder recovery (e.g., Garlappi, Shu, and Yan, 2008; Garlappi and Yan, 2011), exposure to systematic risk (e.g., Ozdagli, 2012), and/or long-run risk (e.g., Avramov, Cederburg, and Hore, $2012) .^{2}$

As an increasing cross-section and time-series of CDS data have become available, a few papers have explored (particular) relations between equity and CDS markets. Acharya and Johnson (2007) find that, under circumstances consistent with the use of non-public information by informed banks, recent increases in CDS spreads predict negative stock returns. Ni and Pan (2011) show that stock returns become predictable in the presence of short sale bans because negative information in CDS markets gets only slowly incorporated into equity prices. Han and Zhou (2011) find that the slope of the term structure of CDS spreads negatively predicts stock returns. Similar to the aforementioned papers, they argue that this predictability emerges from slow information diffusion but that it cannot be explained by standard risk factors or default risk. All of these papers investigate the (informational) lead-lag linkages between CDS and equity markets in a rather general way. In contrast, we directly exploit CDS data to estimate risk premia, guided by the theoretical relation between equity and CDS excess returns implied by the structural framework of Merton (1974).

Similar to our paper, Campello, Chen, and Zhang (2008) also exploit the link between risk premia on different corporate securities. They construct firm-specific measures of expected equity returns using corporate bond yield spreads, recovery rates, and default transition matrices. The main objective of their paper is to explore whether these return expectations are systematically related to factor loadings. While our paper relies on a similar underlying intuition, our objective is different. We are interested in the relation between expected excess returns on CDS contracts

\footnotetext{
${ }^{2}$ Garlappi, Shu, and Yan (2008) show that default probabilities are generally not positively related to expected stock returns when there is bargaining between shareholders and creditors in the event of default. Extending this framework, Garlappi and Yan (2011) explicitly account for leverage, and allow for strategic default of shareholders to recover part of the residual firm value upon the resolution of financial distress. Hackbarth, Haselmann, and Schoenherr (2013) argue that the resulting default risk premium is positive but has decreased and become insignificant after the bankruptcy reform act of 1978. Taking a different perspective, Ozdagli (2012) argues that the anomaly is due to firms' heterogeneity with respect to cash flow and growth exposure to systematic risk and concludes that stock returns should increase with risk-neutral default probabilities. Avramov, Cederburg, and Hore (2012) show that a negative relation between expected stock returns and credit risk arises out of a long-run risk economy because firms with high default risk have lower systematic risk and, hence, low expected returns.
} 
and subsequently realized equity excess returns to explore the pricing of credit risk in the equity market.

The remainder of the paper is organized as follows. We derive the relation between expected returns on equity and CDS spreads in the Merton (1974) framework and discuss implications for the distress puzzle in Section I. Building on the insights from the structural model, we show in Section II how to extract credit risk premia from the CDS forward curve and we discuss the estimation of risk premia using affine term structure models. In Section III, we describe the data, report our core empirical results, and present various robustness checks. Section IV concludes. The Appendix describes technical details and the separate Internet Appendix reports additional empirical results.

\section{Structural Framework for Credit Risk and Equity Returns}

We utilize a simple Merton framework to illustrate that information incorporated in the market for a firm's credit instruments, such as credit default swaps, must be related to expected returns on its equity. Since equity and CDS contracts are both claims on the same assets, the compensation per unit of risk on both must equal the firm's market price of risk (i.e. the Sharpe ratio) implied by the asset value process. We first derive the link between equity risk premia and the dynamics of CDS spreads to show that a firm's expected excess returns and Sharpe ratios in equity and credit markets are a function of, both, the firm's physical and its risk-neutral default expectations. Thus, exclusively relying on the firm's CDS spreads directly observable in the market or on estimates of it's physical default probability is not sufficient to understand the relation between a firm's credit risk and its equity returns. Using these insights from the model, we formulate CDS-implied measures of the firm's market price of risk and risk premia that we apply in our empirical analysis of the relation between equity returns and credit risk. Recognizing that risk premia are related to, both, physical and risk-neutral default probabilities, we then discuss how the "distress puzzle", i.e. the lack of a positive relation between equity returns and default probabilities, is perfectly consistent with a structural framework. 


\section{A. Risk Premia in Credit and Equity Markets}

In the model of Merton (1974), the asset value is governed by a geometric Brownian motion with drift $\mu$ and volatility $\sigma$. Denoting the constant riskless interest rate by $r$, the firm's expected asset excess return per unit of volatility is given by

$$
\lambda \equiv \frac{\mu-r}{\sigma} .
$$

We refer to $\lambda$ as the firm's asset Sharpe ratio or the firm's market price of risk. ${ }^{3}$ It is easy to show that the above structural framework implies that the instantaneous expected excess return per unit of risk for any claim on a firm's assets must equal $\lambda$ and that its expected excess return is, thus, given by the product of $\lambda$ and the claim's volatility.

We are interested in the relation between two particular claims on a firm's assets: equity and CDS contracts. Consider first the equity claim. Interpreting the firm's debt as a zero-coupon bond with face value $D$ and time-to-maturity $T$, equity represents a European call option on the firm's assets with strike equal to $D$ and maturity $T$. The instantaneous expected excess return on equity $\left(\mu_{E}-r\right)$ and the instantaneous equity volatility $\left(\sigma_{E}\right)$ are therefore given by ${ }^{4}$

$$
\begin{aligned}
\mu_{E}-r & =(\mu-r)\left[\frac{V}{E} E_{V}\right], \\
\sigma_{E} & =\sigma\left[\frac{V}{E} E_{V}\right],
\end{aligned}
$$

where $E_{V}$ denotes the partial derivative of $E$ with respect to $V$, i.e. the call option delta with $E_{V}>0$. Combining equations (2) and (3) shows that the equity Sharpe ratio equals the firm's market price of risk, i.e. $\lambda_{E} \equiv \frac{\mu_{E}-r}{\sigma_{E}}=\lambda$.

To derive the CDS return characteristics, we note that a European put option on the firm's assets (also with strike $D$ and maturity $T$ ) represents a hedge against default risk by compensating bondholders for the loss given default. Consider a $T$-year CDS contract that offers credit insurance in exchange for periodic premium payments, the CDS spread, $S^{T}$, which the protection buyer pays

\footnotetext{
${ }^{3}$ We use the term "market price of risk" for easier readability. Of course, in the framework that we use in this paper, all firms are subject to the same stochastic discount factor that determines the market(-wide) price of risk, $\lambda_{M}$. The firm's market price of risk $\lambda$ is a function of $\lambda_{M}$; for instance in the CAPM framework, we have $\lambda=\lambda_{M} \cdot \rho_{M}$, where $\rho_{M}$ denotes the correlation between the firm's stock and the market returns.

${ }^{4}$ For ease of notation we suppress all time subscripts. We provide the details for the derivation of Eqs. (2) and (3) in Appendix A.
} 
until default occurs or the contract expires. Since default can only occur at maturity in the Merton framework, a $T$-year CDS contract offering credit protection must have the same present value as the put option. Assuming continuous premium payments, the CDS spread for such a contract can be computed as

$$
S^{T}=A^{T} \cdot P \quad \text { with } \quad A^{T} \equiv \frac{r}{1-e^{-r T}}
$$

where $A^{T}$ denotes the annuity factor and $P$ is the value of a European put option on assets. ${ }^{5}$ It follows that the CDS spread dynamics are determined by the put dynamics and because the put option is inversely related to the firm value, the same is true for the CDS spread. We define the expected CDS excess return as the difference between the drifts under the physical probability measure $\mathbb{P}, \mu_{S}^{\mathbb{P}}$, and under the risk-neutral probability measure $\mathbb{Q}, \mu_{S}^{\mathbb{Q}} \cdot 6$

This CDS excess return captures differences between physical and risk-neutral default expectations which, in general, arise when investors do not only care about the expected loss in the event of default but, additionally, demand a risk premium for the uncertainty related to default. Accounting for the market convention to quote constant time-to-maturity CDS spreads, we get for the instantaneous expected CDS excess return $\left(\mu_{S}^{\mathbb{P}}-\mu_{S}^{\mathbb{Q}}\right)$ and CDS spread volatility $\sigma_{S}$, respectively,

$$
\begin{aligned}
\mu_{S}^{\mathbb{P}}-\mu_{S}^{\mathbb{Q}} & =(\mu-r)\left[\frac{S_{V}^{T}}{S^{T}}\right], \\
\sigma_{S} & =\sigma\left[\frac{\left|S_{V}^{T}\right|}{S^{T}}\right],
\end{aligned}
$$

where $S_{V}^{T}$ refers to the partial derivative of $S^{T}$ with respect to $V$, i.e. the (scaled) put option delta and $S_{V}^{T}<0 .{ }^{7}$ Combining Eqs. (5) and (6) shows that the CDS Sharpe ratio equals the negative of the firm's market price of risk, i.e. $\lambda_{S} \equiv \frac{\mu_{S}^{\mathbb{P}}-\mu_{S}^{\mathbb{Q}}}{\sigma_{S}}=-\lambda$.

\footnotetext{
${ }^{5}$ For the calculation of the CDS spread we use a European put option with the payoff scaled by the firm's asset value. At any given point in time, $t$, instead of using the put (embedded in the bond) with payoff $\max \left(D-V_{t+T}, 0\right)$, we consider a put option with payoff $\max \left(D / V_{t+T}-1,0\right)$. Scaling the payoff ensures that CDS spreads are comparable across firms with different size.

${ }^{6}$ The risk-neutral drift of the $S^{T}$-process does not need to be equal to $r$ because the CDS spread itself is not a traded asset (whereas the CDS contract is).

${ }^{7}$ Unlike for put options which have a fixed maturity date, quoted CDS spreads in the market refer to a constant time-to-maturity (e.g., 5-year tenor). Thus, market CDS spreads are a function of the underlying asset value $V$, but not explicitly of time $t$. Furthermore, note that the absence of $V$ in Eqs. (5) and (6) comes from the fact that the payoff of the put is scaled by $V$.
} 
Thus, credit-implied market prices of risk are informative for equity Sharpe ratios because

$$
\lambda_{E}=-\lambda_{S}
$$

From Eqs. (2) and (5), we see that expected excess returns in equity and CDS markets are inversely related because of the claims' converse relation to the value of assets as reflected by $E_{V}>0$ and $S_{V}^{T}<0$. Expressing the equity risk premium in terms of the expected CDS excess return yields

$$
\begin{aligned}
\left(\mu_{E}-r\right) & =-\lambda_{S} \cdot \sigma_{E} \\
& =-\left(\mu_{S}^{\mathbb{P}}-\mu_{S}^{\mathbb{Q}}\right) \cdot\left[S^{T} \cdot \frac{V}{E} \cdot \frac{E_{V}}{\left|S_{V}^{T}\right|}\right] .
\end{aligned}
$$

Building on these insights, we define the following measures for the CDS-implied market price of risk and for CDS-implied risk premia that we estimate in the empirical analysis at time $t$ for discrete prediction horizons $\tau$. To test the implication of Eq. (7), we estimate $\lambda$ from CDS spreads using the insight above that $\lambda=-\lambda_{S}=-\frac{\mu_{S}^{\mathbb{P}}-\mu_{S}^{\mathbb{Q}}}{\sigma_{S}}$. We define the credit-implied market price of risk $\left(M P R_{t+\tau}^{T}\right)$ as

$$
M P R_{t+\tau}^{T} \equiv \frac{\log \mathbb{E}_{t}^{\mathbb{Q}}\left[S_{t+\tau}^{T}\right]-\log \mathbb{E}_{t}^{\mathbb{P}}\left[S_{t+\tau}^{T}\right]}{\sqrt{\int_{t}^{t+\tau} \sigma_{S, u}^{2} d u}}
$$

where $\mathbb{E}_{t}^{\mathbb{Q}}\left[S_{t+\tau}^{T}\right]$ and $\mathbb{E}_{t}^{\mathbb{P}}\left[S_{t+\tau}^{T}\right]$ denote the conditional time- $t$ expectations of the future CDS spread under the $\mathbb{Q}$ and $\mathbb{P}$-measure, respectively, and the denominator refers to the volatility of the CDS spread across the interval $[t, t+\tau]$.

To measure the implied equity risk premium $\left(E R P_{t+\tau}^{T}\right)$ consistent with Eq. (8), we multiply the market price of risk with equity volatility:

$$
E R P_{t+\tau}^{T} \equiv M P R_{t+\tau}^{T} \cdot \sqrt{\int_{t}^{t+\tau} \sigma_{E, u}^{2} d u}
$$

We also explore the cross-sectional relation between equity excess returns (and Sharpe ratios) and risk premia in CDS markets by only focusing on the elements in the numerator of $M P R_{t+\tau}$. Taking this focus, we only need to estimate expected CDS spreads but avoid having to estimate 
the volatility of CDS spreads and, in contrast to sorting firms on the basis of $E R P_{t+\tau}^{T}$ defined in equation (11), exclusively rely on credit market information. While it is an empirical question whether disregarding information on volatility alters our findings as compared to using $M P R_{t+\tau}^{T}$ or $E R P_{t+\tau}^{T}$, an analysis of common patterns in equity and credit risk premia is certainly interesting per se. We define the relative risk premium $\left(\right.$ rel. $\left.R P_{t+\tau}^{T}\right)$ by the numerator of $M P R_{t+\tau}^{T}$ in $(10)$, which represents the first term in Eq. (9),

$$
\text { rel.RP } P_{t+\tau}^{T} \equiv \log \mathbb{E}_{t}^{\mathbb{Q}}\left[S_{t+\tau}^{T}\right]-\log \mathbb{E}_{t}^{\mathbb{P}}\left[S_{t+\tau}^{T}\right]
$$

Note that rel.RP $P_{t+\tau}^{T}$ is independent of the credit spread level since it reflects the CDS excess change relative to $S_{t+\tau}^{T}$. To analyze whether the level of credit risk matters, we take the spread level explicitly into account by defining the risk premium $R P_{t+\tau}^{T}$ as the absolute difference between $\mathbb{Q}$ - and $\mathbb{P}$-expectations of future CDS spreads:

$$
R P_{t+\tau}^{T} \equiv \mathbb{E}_{t}^{\mathbb{Q}}\left[S_{t+\tau}^{T}\right]-\mathbb{E}_{t}^{\mathbb{P}}\left[S_{t+\tau}^{T}\right]
$$

We describe in Section II how we use CDS data to implement Eqs. (10) to (13) empirically.

\section{B. Equity Risk Premia and Default Probabilities: A Distress Puzzle?}

In light of the recent debate on whether default risk is positively, negatively, or not at all priced in stock returns, we take a closer look at the relation between the firm's return on equity and its probability of default in our structural framework. Since debt is modeled as a zero-coupon bond with face value $D$ and time-to-maturity $T$, the default probabilities (i.e. the probability that $\left.V_{t+T}<D\right)$ under the physical and risk-neutral measure, $P D_{t}^{\mathbb{P}}$ and $P D_{t}^{\mathbb{Q}}$, are given by

$$
\begin{aligned}
& P D_{t}^{\mathbb{P}}=\Phi\left(-\frac{\log \left(V_{t} / D\right)+\left(\mu-\frac{1}{2} \sigma^{2}\right) T}{\sigma \sqrt{T}}\right), \\
& P D_{t}^{\mathbb{Q}}=\Phi\left(-\frac{\log \left(V_{t} / D\right)+\left(r-\frac{1}{2} \sigma^{2}\right) T}{\sigma \sqrt{T}}\right),
\end{aligned}
$$

where $\Phi$ is the standard normal cumulative distribution function. Combining Eqs. (14) and (15) implies a specific relation between a firm's risk-neutral and its physical default probability (see, 
e.g., Duffie and Singleton, 2003, p. 119f) and that $\lambda$ can be expressed as

$$
\lambda=\left(\Phi^{-1}\left(P D_{t}^{\mathbb{Q}}\right)-\Phi^{-1}\left(P D_{t}^{\mathbb{P}}\right)\right) \frac{1}{\sqrt{T}}
$$

where $\Phi^{-1}$ is the inverse of $\Phi$. This relation shows that the compensation per unit of risk is associated with, both, the firm's risk-neutral and its physical default probability and that $\lambda$ increases with the difference in (the $\Phi^{-1}$ of) $P D_{t}^{\mathbb{Q}}$ and $P D_{t}^{\mathbb{P}}$. As mentioned above, such differences account for risk premia that investors demand beyond the expected loss given default. Hence, cross-sectional differences in $\lambda$ are related to the cross-section of differences between $P D_{t}^{\mathbb{Q}}$ and $P D_{t}^{\mathbb{P}} .8$

Since the expected return on equity is $\left(\mu_{E}-r\right)=\lambda \cdot \sigma_{E}$ (see Eqs. (2) and (3)), it is related to the difference between (transformations of) $P D_{t}^{\mathbb{Q}}$ and $P D_{t}^{\mathbb{P}}$ as well. While the credit-implied risk premium measures that we propose above incorporate both $\mathbb{P}$ - and $\mathbb{Q}$-expectations about future credit spreads (thereby inferring information about the relation between physical and riskneutral default probabilities), ranking firms based on either $P D_{t}^{\mathbb{P}}$ or $P D_{t}^{\mathbb{Q}}$ alone is not sufficiently informative to infer equity risk premia. Eq. (2) implies that, ceteris paribus, the expected equity return increases in $\mu$, decreases in $\sigma$, and increases in leverage $L \equiv D / V$, i.e., we have $\frac{\partial\left(\mu_{E}-r\right)}{\partial \mu}>0$, $\frac{\partial\left(\mu_{E}-r\right)}{\partial \sigma}<0$, and $\frac{\partial\left(\mu_{E}-r\right)}{\partial L}>0$. From Eq. (14), we see that $P D_{t}^{\mathbb{P}}$ decreases in $\mu$, increases in $\sigma$, and increases in $L$, i.e. $\frac{\partial P D_{t}^{\mathbb{P}}}{\partial \mu}<0, \frac{\partial P D_{t}^{\mathbb{P}}}{\partial \sigma}>0$, and $\frac{\partial P D_{t}^{\mathbb{P}}}{\partial L}>0$. As a consequence, the cross-sectional relation between firms' $P D_{t}^{\mathbb{P}}$ and stock returns depends on the determinants of cross-firm differences in $\mu, \sigma$, and $L$. If firms, other things equal, differ by their $\mu$, then firms with higher $P D_{t}^{\mathbb{P}}$ have lower equity returns. The same is true when firms differ by $\sigma$. Only when $L$ drives cross-sectional differences, the relation between stock returns and $P D_{t}^{\mathbb{P}}$ is positive. Analogous implications can be formulated for $P D_{t}^{\mathbb{Q}}$ which is insensitive to $\mu\left(\frac{\partial P D_{t}^{\mathbb{Q}}}{\partial \mu}=0\right)$ and increases in $\sigma\left(\frac{\partial P D_{t}^{\mathbb{Q}}}{\partial \sigma}>0\right)$ as well as in $L\left(\frac{\partial P D_{t}^{\mathbb{Q}}}{\partial L}>0\right)$, similar to $P D_{t}^{\mathbb{P}}$.

Empirical findings documenting a negative relation between equity returns and $P D_{t}^{\mathbb{P}}$ (see, e.g., Dichev, 1998; Campbell, Hilscher, and Szilagyi, 2008) can, thus, be fully consistent with the Merton model. Similarly, evidence that there is no significant relation between firms' $P D_{t}^{\mathbb{Q}}$ and equity returns (see, e.g., Anginer and Yildizhan, 2010) may also be in line with the structural framework.

\footnotetext{
${ }^{8}$ It is worth noting that leverage $(L \equiv D / V)$ has no impact on $\lambda$. Furthermore, the riskless rate $r$ is the same for all firms. We also assume that maturity $T$ is equal accross firms because we use CDS contracts with identical maturities for all entities in our empirical analysis.
} 
The combination of these findings suggests that cross-sectional differences in $\mu$ may be an important driver behind the cross-section of (expected) equity returns, because $P D_{t}^{\mathbb{P}}$ is negatively related to $\mu$ while $P D_{t}^{\mathbb{Q}}$ does not depend on $\mu$, and both probabilities share the same comparative statics with respect to $L$ and $\sigma$. Furthermore, because $\lambda_{E}$ increases with $\mu$, decreases with $\sigma$, and does not depend on $L$, it follows that, ceteris paribus, firms with higher $P D_{t}^{\mathbb{P}}$ have lower equity excess returns per unit of risk. The empirical results in Campbell, Hilscher, and Szilagyi (2008) indeed suggest that equity Sharpe ratios decrease with distress risk. Moreover, the finding of a positive relation between default risk and equity returns, as documented by, e.g., Vassalou and Xing (2004), is consistent with the structural framework as well.

Thus, the mixed evidence in the literature may in fact result from exclusively using measures of $P D_{t}^{\mathbb{P}}$ or $P D_{t}^{\mathbb{Q}}$ while equity risk premia are related to both physical and risk-neutral probabilities of default. In contrast, the CDS-implied measures of credit risk premia that we propose above are designed to simultaneously account for risk-neutral and physical default information. We describe their empirical implementation in the next section.

\section{Using CDS Spreads to Estimate Credit Risk Premia}

This section lays out how we estimate credit risk premia from the term structure of CDS spreads. Our usage of CDS data is motivated by previous research documenting that CDS spreads represent more timely market information and are less contaminated by tax and liquidity effects than corporate bond yield spreads. ${ }^{9}$

To estimate the CDS-implied market price of risk and risk premia defined in the previous section, we need to estimate differences (in the logs of) risk-neutral and physical expectations of future CDS spreads. We do so by drawing on concepts established in the fixed income literature

\footnotetext{
${ }^{9}$ Using CDS data offers several advantages as compared to corporate bond yield spreads. First, CDS contracts are standardized and comparable across reference companies. Second, issuing a CDS on a particular firm does not change the firm's capital structure and CDS maturities can be chosen independently of the firm's debt maturity structure. Third, empirical evidence shows that corporate bonds earn an expected excess return even after accounting for the likelihood of default because of priced tax and liquidity effects as well as risk premia that compensate for bearing credit risk; see, e.g., Elton et al. (2001), Huang and Huang (2012), Driessen (2005), Longstaff, Mithal, and Neis (2005), and Ericsson, Reneby, and Wang (2007). Berndt et al. (2008) use CDS spreads to estimate risk premia because empirical research suggests that CDS spreads represent fresher market prices than corporate yield spreads (see, e.g., Blanco, Brennan, and Marsh, 2005). Hence, the difference in their estimates of risk-neutral and physical default intensities should allow to obtain a clean measure of credit risk premia. Other aspects that might potentially affect measures of credit risk premia, both using CDS spreads and yield spreads, are microstructure issues and counterparty credit risk. Arora, Gandhi, and Longstaff (2012) find that counterparty credit risk is priced but that its magnitude is small.
} 
and follow two empirical strategies. First, we construct simple firm-specific measures of credit risk premia from the term structure of CDS spreads. For each firm, we derive this measure as a linear combination of forward CDS spreads, following the approach that Cochrane and Piazzesi (2005) apply to the bond market. Second, we use an affine term structure model (ATSM) along the lines of Pan and Singleton (2008) to explicitly model the $\mathbb{Q}$ - and $\mathbb{P}$-measure dynamics of a firm's default process and compute risk premia from model-implied CDS spreads.

\section{A. Extracting Credit Risk Premia from the CDS Forward Curve}

We first note that, for a given prediction horizon $\tau$, the forward CDS spread $\left(F_{t}^{\tau \times T}\right)$ contracted at time $t$ and being effective from time $t+\tau$ for $T$ periods contains information about the expected future $T$-year CDS spread at time $t+\tau$. Since the structural model in Section I is based on deterministic interest rates, the firm's forward CDS spread represents the risk-neutral expectation of its future CDS spread, ${ }^{10}$

$$
\mathbb{E}_{t}^{\mathbb{Q}}\left[S_{t+\tau}^{T}\right]=F_{t}^{\tau \times T}
$$

and, hence, can be directly extracted from the term structure of CDS spreads. ${ }^{11}$ If credit market participants demand compensation for bearing risk, forward CDS spreads comprise the $\mathbb{P}$-expected future CDS spread plus the risk premium defined in Eq. (13),

$$
F_{t}^{\tau \times T}=\mathbb{E}_{t}^{\mathbb{P}}\left[S_{t+\tau}^{T}\right]+R P_{t+\tau}^{T}
$$

The expected change in the CDS spread in excess of the forward-implied change thus defines the risk premium,

$$
\mathbb{E}_{t}^{\mathbb{P}}\left[R X_{t+\tau}^{T}\right] \equiv \mathbb{E}_{t}^{\mathbb{P}}\left[S_{t+\tau}^{T}\right]-F_{t}^{\tau \times T}=-R P_{t+\tau}^{T}
$$

\footnotetext{
${ }^{10}$ More generally, the forward spread is the expectation of the future spot spread under the forward measure $\mathbb{Q}^{\tau}$ that uses the riskless $\tau$-period zero bond as the numeraire. In the absence of interest rate risk, such as in our framework, the forward measure $\mathbb{Q}^{\tau}$ coincides with the spot measure $\mathbb{Q}$ (using the bank account as the numeraire). While we maintain the assumption of deterministic interest rates for the moment, we relax it later. In the robustness analysis, we show that this assumption is not restrictive from an empirical perspective because the correlation between the riskless rate and CDS spreads is very low. Furthermore, our results are virtually unchanged when re-estimating forward CDS spreads under the assumption of the riskless rate being zero, see Section III.C.5. Moreover, we estimate fully-fledged dynamic term structure models as described in Section II.B.

${ }^{11}$ Compared to obtaining forward rates in the bond market, extracting forward CDS spreads from the spot CDS curve is more involved, for example since it requires assumptions about recovery rates. For computational details see B.
} 
where the minus sign on the right-hand side is in accordance with the inverse relation between equity excess returns and CDS markets. Analogously, the (relative) risk premium as defined in Eq. (12) is given by

$$
\text { rel.RP } P_{t+\tau}^{T} \equiv \log F_{t}^{\tau \times T}-\log \mathbb{E}_{t}^{\mathbb{P}}\left[S_{t+\tau}^{T}\right]
$$

which corresponds to the numerator of the CDS Sharpe ratio and, thus, of the credit-implied market price of risk defined in Eq. (10).

To estimate credit risk premia, we draw on concepts established in the fixed income literature. In particular, our approach is motivated by Cochrane and Piazzesi (2005) who extract a single factor from the term structure of forward interest rates to estimate bond risk premia. Relying on the same approach, namely that forward rates contain information about future excess returns, we construct firm-specific measures of credit risk premia from the term structure of forward CDS spreads. For each firm, we start by calculating the cross-maturity average of observed CDS Sharpe ratios $\left(\overline{S R}_{t+\tau}\right)$, CDS excess returns $\left(\overline{r e l . R X}_{t+\tau}\right)$, and excess changes $\left(\overline{R X}_{t+\tau}\right)$ for contracts with maturities $T_{k} \in T=\{1,3,5,7\},{ }^{12}$

$$
\overline{S R}_{t+\tau} \equiv \frac{1}{4} \sum_{T_{k} \in T} \frac{r e l . R X_{t+\tau}^{T_{k}}}{S D_{t+\tau}}, \quad \overline{r e l . R X}_{t+\tau} \equiv \frac{1}{4} \sum_{T_{k} \in T} \text { rel.RX } X_{t+\tau}^{T_{k}}, \quad \overline{R X}_{t+\tau} \equiv \frac{1}{4} \sum_{T_{k} \in T} R X_{t+\tau}^{T_{k}}
$$

where

$$
\text { rel. } R X_{t+\tau}^{T_{k}} \equiv \log S_{t+\tau}^{T_{k}}-\log F_{t}^{\tau \times T_{k}}, \quad R X_{t+\tau}^{T_{k}} \equiv S_{t+\tau}^{T_{k}}-F_{t}^{\tau \times T_{k}},
$$

and $S D_{t+\tau}$ refers to the sample standard deviation of daily CDS spread returns between $t$ and $t+\tau$. For each of these cross-maturity averages, we estimate the common component across $T_{k}$ by regressing $\overline{S R}_{t+\tau}, \overline{r e l . R X}_{t+\tau}$, and $\overline{R X}_{t+\tau}$, on the term structure of forward CDS spreads, respectively. We define the firm's CDS term structure to be represented by the current 1-year CDS spread and forward CDS spreads of contracts starting in 1, 3, 5, and 7 years and being effective for 1 year and define the vector $\mathbf{F}_{\mathbf{t}}=\left(1, S_{t}^{1}, F_{t}^{1 \times 1}, F_{t}^{3 \times 1}, F_{t}^{5 \times 1}, F_{t}^{7 \times 1}\right)$. We denote the corresponding

\footnotetext{
${ }^{12}$ We choose this set of maturities for CDS excess returns and also the CDS term structure, because forward CDS spreads corresponding to these maturities can be calculated using the canonical CDS maturities of 1, 3, 5, 7, and 10 years.
} 
vector of regression parameters by $\gamma^{j}=\left(\gamma_{0}^{j}, \gamma_{1}^{j}, \gamma_{2}^{j}, \gamma_{3}^{j}, \gamma_{4}^{j}, \gamma_{5}^{j}\right)$ where $j \in J=\{S R$, rel.RX, $R X\} .^{13}$ Using these regressions, we obtain estimates for the CDS-implied market price of risk and risk premia as defined in Eqs. (10) to (13) which reflect time- $t$ conditional expectations. We get

$$
\begin{aligned}
\widehat{M P R}_{t+\tau} & =-\left(\gamma^{S \boldsymbol{R}}\right)^{\top} \mathbf{F}_{\mathbf{t}} \\
\widehat{E R P}_{t+\tau} & =-\left(\gamma^{\boldsymbol{S R}}\right)^{\top} \mathbf{F}_{\mathbf{t}} \cdot \widehat{\sigma}_{E, t, \tau}, \\
\widehat{r e l . R P}_{t+\tau} & =-\left(\gamma^{r e l . \boldsymbol{R} \boldsymbol{X}}\right)^{\top} \mathbf{F}_{\mathbf{t}} \\
\widehat{R P P}_{t+\tau} & =-\left(\gamma^{\boldsymbol{R} \boldsymbol{X}}\right)^{\top} \mathbf{F}_{\mathbf{t}}
\end{aligned}
$$

where, in Eq. (24), $\widehat{\sigma}_{E, t, \tau}$ denotes the time- $t$ conditional equity volatility estimated as the sample standard deviation of daily equity returns from $t-\tau$ to $t{ }^{14}$

The estimates in Eqs. (23) to (26) are expectations conditional on CDS term structure information that is available at time $t$. In our empirical analysis, we first directly follow Cochrane and Piazzesi (2005) to estimate the parameters using full sample information, but we also estimate $\gamma^{j}$ using information up to time $t$ only. We then sort firms into portfolios based on their estimated market prices of risk and risk premia to explore whether the cross-sectional implications of the structural model are confirmed by the data.

\section{B. Estimating Credit Risk Premia with Affine Term Structure Models}

The firm-specific credit measures discussed above are easy to estimate from the term structure of CDS spreads and represent information about differences between $\mathbb{Q}$ - and $\mathbb{P}$-expectations. They are not, however, based on an explicit model of the firm's default process under the $\mathbb{Q}$ - and $\mathbb{P}$ measure which could then be used to extract the risk premium from model-implied CDS spreads. In order to perform such a model-based identification of risk premia, we use an affine term structure model (ATSM) for CDS spreads as proposed in Pan and Singleton (2008) for sovereign CDS and

\footnotetext{
${ }^{13}$ Thus, the regression specification for $R X$ (and analogously for rel.RX and $S R$ ) is given by

$$
\begin{aligned}
\overline{R X}_{t+\tau} & =\gamma_{0}^{R X}+\gamma_{1}^{R X} S_{t}^{1}+\gamma_{2}^{R X} F_{t}^{1 \times 1}+\gamma_{3}^{R X} F_{t}^{3 \times 1}+\gamma_{4}^{R X} F_{t}^{5 \times 1}+\gamma_{5}^{R X} F_{t}^{7 \times 1}+\varepsilon_{t+\tau}^{R X} \\
& =\left(\gamma^{R X}\right)^{\top} \mathbf{F}_{\mathbf{t}}+\varepsilon_{t+\tau}^{R X},
\end{aligned}
$$

${ }^{14}$ When estimating CDS and equity volatility, we have also experimented with a variety of other estimation specifications (different lengths of the rolling windows, weighting schemes, etc.) and find that the choice does not have a material impact on our conclusions with respect to the link between CDS and equity markets.
} 
recently applied to US corporate CDS by, e.g., Schneider, Sögner, and Veža (2010).

To estimate a firm's credit risk premium with an ATSM, we model the dynamics of the riskless short rate and the firm's default intensity governing the prices of the firm's corporate bonds. We model the riskless rate and the firm's default intensity with two latent factors each and use for both an essentially affine market price of risk specification to account for risk premia. For details of the ATSM specification and the estimation procedure, we refer to C. Given the estimation results, we compute the model-implied $T$-year CDS spreads under the $\mathbb{Q}$-measure $\left(\widehat{S}_{t}^{T}\right)$ and the implied "pseudo-CDS spreads" under the $\mathbb{P}$-measure $\left(\widehat{S}_{t}^{T, \mathbb{P}}\right)$. Following Pan and Singleton (2008), we define the ATSM-implied credit risk premium as

$$
\widehat{A R P}_{t}^{T} \equiv\left(\widehat{S}_{t}^{T}-\widehat{S}_{t}^{T, \mathbb{P}}\right) / \widehat{S}_{t}^{T, \mathbb{P}}
$$

which has also been used in other recent work that extracts risk premia from CDS spreads (see, e.g., Berndt et al., 2008). It is an empirical question, to what extent our measures of credit risk defined in Section II.A convey the same (equity-relevant) information as ATSM-implied credit risk premia.

\section{Empirical Analysis}

\section{A. Data}

We obtain daily CDS spreads for 675 USD denominated contracts of US based obligors from Markit for the period from January 2, 2001 to April 26, 2010. We only use the five canonical CDS maturities of $1,3,5,7$, and 10 years since these are most frequently quoted and traded. The protection payment may be triggered by several different restructuring events, ranging from no-restructuring to full-restructuring. We include contracts that adopt the modified-restructuring (MR) clause, which was the market convention before the introduction of the CDS Big Bang protocol in April 2009, and contracts that adopt the no-restructuring (NR) clause, which has been the market standard since the changes of the protocol took place. Markit also provides the number of contributors for firms' 5-year CDS contracts which we use as a proxy for liquidity. To ensure sufficient data for the estimation of the affine term structure models, we require that the percentage 
of missing spreads in each firm's panel must not exceed 15\%. We calculate forward CDS spreads using the survival curve fitted to the CDS term structure and discount factors computed from US Libor money market deposits (with maturities of 1, 3, 6, and 9 months) and interest rate swaps (with maturities of $1,2,3,4,5,7$, and 10 years) obtained from Datastream. The bootstrap procedure follows standard industry practice; Feldhütter and Lando (2008) show that swap rates are the best parsimonious proxy for riskless rates

For our analysis of the link between stock and CDS markets, we obtain daily equity data from the Center for Research in Security Prices (CRSP) and monthly firm fundamentals and credit ratings from Compustat of Standard \& Poor's. ${ }^{15}$ We exclude firms for which stock data is not available (in most cases these are privately-held firms or non-listed subsidiaries) and also apply a filter to remove stale price observations, where we define prices to be stale when we observe equal prices on at least five consecutive days. In such a case, we only consider the first of these observations and classify subsequent observations as not available. We compute the firm's market value by the product of the stock price and the number of publicly held shares. The book-to-market value is determined by Compustat data item "Common/Ordinary Equity Total" (CEQQ) divided by the product of data item "Common Shares Outstanding" (CSHOQ) and the stock's price. To compute the firm's distance-to-default (see the robustness checks in Section III.C.5) we obtain book values of liabilities using the Compustat annual files. To estimate the firm's notional debt value we follow the literature and assume that it consists of short-term and long-term debt: for short-term debt we use Compustat data item "Long-Term Debt Due in One Year" (DD1) which represents the current portion of long-term debt. For long-term debt we use the Compustat data item "Long-Term Debt - Total" (DLTT). As a further proxy for distress risk we rely on a firm's credit rating which we obtain from Compustat using the data item "Domestic Long Term Issuer Credit Rating" (SPLTICRM-S\&P).

Merging all data sets and applying the aforementioned data filters leaves us with 838,632 joint observations of CDS spreads, stock prices, firm characteristics, and credit ratings for a total of 491 firms in the period from January 2, 2001 to April 26, 2010. The standard risk factors in our asset

\footnotetext{
${ }^{15}$ We obtain the data through Wharton Research Data Services (WRDS). We merge equity data obtained from CRSP with firm characteristics from Compustat using CRSP/Compustat Merged Database (CCM). The resulting data set is then combined with the CDS data obtained from Markit. The link between Markit's ticker symbols and CUSIPs is established using Markit's US corporate bond data which provides a time series of valid links between tickers and CUSIPs.
} 
pricing tests and the riskless return, are obtained from Kenneth French's website. ${ }^{16}$

\section{B. Descriptive Statistics}

We start by summarizing various descriptive statistics for the CDS data in Table I. The left column summarizes results for the full sample (01/2001 to 04/2010), the middle for the pre-crisis period (01/2001 to 06/2007), and the right for the crisis period (07/2007 to 04/2010). The statistics are calculated based on monthly data for all firms in the sample.

The summary statistics reveal big differences before and during the crisis. The mean level of CDS spreads has been approximately 120 basis points higher during the crisis as compared to before and the average standard deviation has (more than) doubled. While the term structure is almost always upward sloping before the crisis (with slope being defined as the $T$-year minus the 1-year CDS spread), one frequently observes inverted shapes during the crisis. This is also reflected in forward-implied CDS spread changes (i.e. $\left.F_{t}^{\tau \times T}-S_{t}^{T}\right)$. Changes in CDS spreads $\left(S_{t+\tau}^{T}-S_{t}^{T}\right)$ are on average negative prior to July 2007 while after the start of the crisis changes have a positive mean, are larger in absolute terms, and more volatile. Excess changes in CDS spreads $\left(R X_{t+\tau}^{T}\right.$, see Eq. (19)) tend to be negative prior to the crisis but positive during the crisis. This suggests that forward CDS spreads overestimated future CDS spreads in the first part of our sample but underestimated subsequent spreads in the latter part, which provides a first indication for the presence of time-varying risk premia. Considering the sub-sample results also reveals that risk premia are the driving force behind CDS spread changes, being the larger component in average spread changes (in the crisis up to ten times). Furthermore, the volatility of spread changes is almost entirely driven by the volatility of $R X_{t+\tau}^{T}$. We find similar results for forward-implied CDS returns $\left(\log F_{t}^{\tau \times T}-\log S_{t}^{T}\right)$, realized CDS returns $\left(\log S_{t+\tau}^{T}-\log S_{t}^{T}\right)$, and CDS excess returns $\left(\right.$ rel. $\left.R X_{t+\tau}^{T}\right)$.

\section{Credit Risk Premia and Equity Returns}

We now explore the cross-sectional relation between firms' stock returns and credit marketimplied risk premia by conducting portfolio sorts. At the end of each month, we assign firms to quintile portfolios from high risk premium firms (portfolio P1) to low risk premium firms (portfolio

\footnotetext{
${ }^{16}$ http://mba.tuck.dartmouth.edu/pages/faculty/ken.french/
} 
P5). We compute equally- and value weighted portfolio excess returns and Sharpe ratios and also analyze how these are related to traditional risk factors, default probabilities, CDS liquidity, and conditional coskewness. We do so using the CDS forward-implied measures of credit risk as well as credit risk premia estimated with ATSMs. Subsequently, we control for firm characteristics, report results for out-of-sample parameter estimation, and summarize various robustness checks that corroborate our findings.

\section{C.1. CDS Forward-Implied Measures of Credit Risk Premia}

We use all four credit market-based estimates motivated in Section I.A and defined in Eqs. (10) to (13): the firm's CDS-implied market price of risk $\left(\widehat{M P R}_{t+\tau}\right)$, its equity risk premium $\left(\widehat{E R P}_{t+\tau}\right)$, its relative credit risk premium $\left(\widehat{\text { rel.RP }}_{t+\tau}\right)$, and its credit risk premium $\left(\widehat{R P}_{t+\tau}\right)$. The results in Tables II to $\mathrm{V}$ show that using either of the four estimates leads to qualitatively identical conclusions. There is a strong positive relation of stock returns and Sharpe ratios to firms' CDS-implied market prices of risk and CDS-implied risk premia: in accordance with our structural model, we find that equity excess returns and Sharpe ratios decrease from the portfolio of firms with highest credit risk premia (P1) to the portfolio of firms with lowest credit risk premia (P5). Buying portfolio P1 and selling portfolio P5 results in a highly significant excess return, independent of the particular estimate used and the return weighting scheme applied.

Before evaluating the equity performance of portfolios in detail, we take a look at portfolio characteristics in terms of common measures of distress risk and other variables that previous research identifies to convey information for stock returns. We thereby gauge the relation of credit risk measures to these characteristics to detect whether the performance of our portfolios might be attributed to these characteristics. The results reveal that there is generally no direct relation to and very little dispersion in other characteristics that could potentially explain the cross-section of equity returns across portfolios P1 to P5. More specifically, we find that estimates are neither monotonically related to credit ratings nor to the level of the 5-year CDS spread ( $S 5)$, which serve as proxies for a firm's physical and risk-neutral default probability, respectively. ${ }^{17,18}$ Instead we

\footnotetext{
${ }^{17}$ We assign integer numbers to the $\mathrm{S} \& \mathrm{P}$ credit ratings, i.e. $\mathrm{AAA}=1, \mathrm{AA}+=2, \ldots, \mathrm{C}=21$.

${ }^{18}$ The CDS spread is a combination of risk-neutral default probability and recovery rate. We follow the majority of the literature and assume a constant recovery rate of $40 \%$ across all firms, thus, ranking firms by their CDS spread is equivalent to ranking them by their risk-neutral default probability.
} 
find, from portfolio P1 to P5, that default probabilities exhibit a U-shape pattern. Similarly, there is generally no monotonic pattern across portfolios related to firm size $(M V)$ and book-to-market ratios $(B M)$, rather, portfolios $\mathrm{P} 1$ and $\mathrm{P} 5$ are dominated by smaller stocks and value firms whereas portfolios P2 to P4 contain comparably bigger firms and growth stocks. In other words, firms with highest credit risk premia in absolute terms have high default probabilities, are small in size, and have high book-to-market ratios. Thus, our estimates of credit risk premia convey equity-relevant information that is priced in the cross-section of stock returns but this information is different from that incorporated in common measures of distress risk. Furthermore, there is no evidence that the portfolios directly reflect differences in conditional coskewness (which we measure as in Harvey and Siddique, 2000) or in the liquidity of firm's 5-year CDS contracts (measured by the number of contributors reported by Markit). Given the very small dispersion and non-monotonic patterns across portfolios, our measures of credit risk obviously convey different information than these characteristics.

Panels A and B of Tables II to V report the equity performance of equally- and value-weighted portfolios, respectively. We present detailed results for portfolios P1 to P5 and the P1-P5 portfolio for the full sample as well as the high minus low credit risk portfolio performance for pre-crisis $(01 / 2001$ to $06 / 2007)$ and crisis $(07 / 2007$ to $04 / 2010)$ sub-samples. Our results are qualitatively identical for all four measures of credit risk. In the full sample, there is a sharp (mostly monotonic) decrease in equity returns when moving from higher to lower credit risk premium portfolios. ${ }^{19}$ All high minus low risk premium portfolios earn significantly positive excess returns and high Sharpe ratios, with results being more pronounced for equally-weighted portfolios. Going long P1 and short P5 earns highest equity excess returns when we sort firms using $\widehat{R P}_{t+\tau}$, yielding a monthly excess return of $2.63 \%$ and $1.75 \%$ for equally- and value-weighted portfolios, respectively, with corresponding (annualized) Sharpe ratios of 2.08 and 1.45. On the contrary, sorting firms based on $\widehat{M P R}_{t+\tau}$ yields the lowest P1-P5 return differentials with $1.24 \%$ and $0.90 \%$ per month and Sharpe ratios of 1.32 and 0.77 for equally- and value-weighted portfolios, respectively. When we control for traditional risk factors using the CAPM, the Fama and French (1993) three-factor model, and the four-factor extension of Carhart (1997), we find P1-P5 alphas that are significantly positive

\footnotetext{
${ }^{19}$ Non-monotonic patterns in returns are driven by the crisis sub-sample, as can be seen for instance by comparing the pre-crisis and crisis results in the Internet Appendix.
} 
and even higher than the mean excess returns. ${ }^{20}$ We also find, consistent with the portfolio characteristics discussed above, that there is typically no monotonic pattern in loadings on the market factor, small-firm factor SMB, and the value factor HML across portfolios P1 to P5. The factor loadings of the high minus low credit risk portfolio are mostly either not significant or significantly negative. Overall, these results suggest that our measures of credit risk convey information that is not captured by traditional risk factors.

Our results are robust across pre-crisis and crisis sub-samples, leading to identical conclusions for both sub-periods with results being more pronounced in the crisis period. For instance in Table V, we report equally-weighted (value-weighted) excess returns of buying high and selling low credit risk premium firms of $2.68 \%(2.67 \%)$ and $5.53 \%$ (4.16\%) per month prior to and during the crisis, respectively. All factor model alphas are highly significant, with factor loadings being mostly negative or insignificant before the crisis and all loadings being insignificant in the crisis.

Since our findings suggest that the strong link between equity and credit markets is particularly pronounced during the recent financial crisis, which covers a sizeable fraction of our sample, we verify that our results are robust to excluding financial firms (SIC codes 6000-6999) and utility firms (SIC codes 4900-4999) from the sample. Table VI shows that results for $\widehat{R P}_{t+\tau}$ are basically unchanged in the pre-crisis period. In the crisis period, we find that the high minus low risk premium return drops from $5.53 \%$ to $4.31 \%$ per month for equally-weighted portfolios and from $4.16 \%$ to $3.76 \%$ for value-weighted portfolios. Thus, the relation between credit risk premia and stock returns appears to have been particularly strong for financial and utility firms during the crisis but also exists for other firms since returns and factor model alphas remain highly significant.

Overall, our results suggest that CDS spreads contain information about equity risk premia that is conveyed by all four market price of risk and risk premium estimates but not embedded in common measures of distress risk. The relation between equity excess returns and Sharpe ratios to credit risk premia is strong and -consistent with the structural framework- positive: the higher a firm's credit risk premium (credit Sharpe ratio), the higher the firm's equity returns (equity Sharpe ratio).

\footnotetext{
${ }^{20}$ Throughout the paper, we judge significance using conventional statistical significance cutoffs. In a recent paper, Harvey, Liu, and Zhu (2013) argue that a $t$-ratio of 3.0 (or a corresponding $p$-value of $0.27 \%$ ) should be viewed as indication of significance for newly discovered factors.
} 


\section{C.2. Affine Model-Implied Credit Risk Premia}

We report analogous results for using ATSM credit risk premia calculated from model-implied 5year CDS spreads under the $\mathbb{Q}$ - and $\mathbb{P}$-measure (see Section II.B) in Table VII. The equally-weighted (value-weighted) returns for buying high and selling low credit risk premium firms are marginally significant at $0.47 \%(0.62 \%)$ per month. ${ }^{21}$ Similar to the firm-specific credit risk measures estimated from the CDS forward curve, we find that the factor model alphas are higher than the mean excess returns, they are highly significant, and the long-short portfolio returns load negatively on the three Fama-French factors. Also in line with the results for the CDS forward-implied measures above, there is little dispersion and typically no monotonic relation to other portfolio characteristics. Interestingly, we find firms to be bigger and to have better ratings in the higher credit risk premium portfolios.

The results of using the credit risk measures and ATSM-implied risk premia allow for the same conclusions with portfolios sharing similar properties, thereby suggesting that the credit risk measures indeed capture information about risk premia as identified by the ATSMs. In a series of checks, we find that the credit risk premium measure $\widehat{R P}_{t+\tau}$ exhibits the closest relation to the affine risk premium $\widehat{A R P}_{t}^{5}$; across firms, the medians (averages) of pairwise correlations are 0.38 (0.29) and when we regress $\widehat{R P}_{t+\tau}$ on the corresponding affine risk premium we find $R^{2}$ s of 0.19 (0.24) with $t$-statistics of 3.09 (3.21) for the slope coefficient.

While $\widehat{R P}_{t+\tau}$ (partly) captures the information in ATSM risk premia, it obviously contains comparably higher predictive ability for firms' stock returns. This result potentially reflects analogous findings from the bond literature where ATSMs do not necessarily have high predictive power for excess returns. For instance, Cochrane and Piazzesi (2005) argue that the predictability they find is not spanned by standard affine term structure models. Similarly, Duffee (2011) argues that there is a hidden factor that has predictive power but is unspanned by ATSMs. Since the focus of this paper is to establish the relation between credit and equity markets and not the modeling of (the term structure of) CDS spreads per se, we leave this issue for future research. Given the

\footnotetext{
${ }^{21}$ The estimation results show that the affine models fit the CDS data well. Across firms, the mean pricing error of the 5-year CDS spreads is 2.3 basis points (bp) with a standard deviation of $26.8 \mathrm{bp}$. These values are very reasonable given that our models are estimated on daily data over the full sample period from 2001 to 2010, i.e. the estimation has to match data in the relatively tranquil period prior to the crisis as well as the peak of the financial crisis. While we do not estimate separate models for pre-crisis and crisis sub-samples due to insufficient data, we see from our full sample estimates that pricing errors are substantially smaller prior to the crisis with the mean pricing error of 5-year CDS spreads being $0.8 \mathrm{bp}$ and with a standard deviation of $14.4 \mathrm{bp}$.
} 
results above, we focus on $\widehat{R P}_{t+\tau}$ as a measure of credit risk in our subsequent analysis. ${ }^{22}$

\section{C.3. Controlling for Firm Characteristics}

To gain deeper insights into the relation between firm characteristics and the pricing of credit risk premia in equity returns, we conduct a sequential portfolio sort analysis for the full sample period. We first sort firms into tercile portfolios based on common measures of distress risk as well as a proxy for CDS market liquidity and firms' conditional coskewness of stock returns with the market. In a second step, we form three sub-portfolios using firms' credit risk premium estimates and compute the excess returns for buying high and selling low credit risk premium firms. ${ }^{23}$

Controlling for Size and Book-to-Market Panel A of Table VIII reports results for sorting firms, first, into tercile portfolios based on their size (P1.*, P2.*, P3.*) and, subsequently, into three sub-portfolios based on credit risk premia $\left(\mathrm{P}^{*} .1, \mathrm{P}^{*} .2, \mathrm{P}^{*} .3\right)$. We find that credit risk premia are priced in all size portfolios, i.e. the $\mathrm{P}^{*} .1-\mathrm{P}^{*} .3$ returns are highly significant for small, medium, and big firms, with this effect being most pronounced in the small firm portfolio. For value-weighted returns, the four-factor alphas of the long-short portfolios decrease from $2.91 \%$ per month for small firms to $0.70 \%$ for big firms. The factor model alphas are significant but there are no pronounced patterns related to factor loadings. Next, we control for book-to-market ratios and present results in Panel B. Similar to the results for firm size, we find that the pricing effect is significant in all book-to-market portfolios. The four-factor alpha of the value-weighted $\mathrm{P}^{*} .1-\mathrm{P}^{*} .3$ return decreases from $2.12 \%$ per month for value firms to $0.86 \%$ for growth firms.

Our finding that the price of credit risk in equity returns decreases with size and increases with book-to-market is consistent with the non-monotonic relation of $M V$ and $B M$ to credit marketimplied risk premia reported above. Furthermore, they are in line with the general notion that small firms and value firms earn comparably higher stock returns (because these firms are exposed to higher distress risk) than bigger firms or firms with lower $B M$. Nevertheless, the finding that credit risk premia are significantly priced in all size and book-to-market portfolios strengthens our argument that credit risk premia estimated from CDS spreads contain information not captured

\footnotetext{
${ }^{22}$ This choice is also motivated by practical considerations as the relatively short data period as well as computational issues are prohibitive for the use of ATSMs for, e.g., generating out-of-sample forecasts.

${ }^{23}$ All results presented in this section are robust across pre-crisis and crisis periods. Results are not reported to conserve space but available from the authors upon request.
} 
by size and book-to-market.

Controlling for Default Probabilities Next, we take a closer look at the relation between equity returns and credit risk premia when we control for the probability of default. We use credit ratings and the 5-year CDS spreads as proxies for physical and risk-neutral default probabilities, respectively. ${ }^{24}$ In Table IX, we find that the magnitude of credit risk premia priced in equity returns increases with the default probability. For value-weighted returns, the four-factor alpha decreases from $2.64 \%$ per month to $0.76 \%$ for firms with bad compared to good credit ratings and from $2.88 \%$ per month to $0.17 \%$ for firms with high compared to low CDS spread levels. The long-short returns are significant in all default probability portfolios for both proxies and return weighting schemes, with the single exception being the value-weighted differential in the portfolio with lowest CDS spread firms.

Controlling for CDS Liquidity and Conditional Coskewness Furthermore, we control for liquidity in CDS markets using the number of contributors reported by Markit, i.e. the number of market participants that provide a quote for the firm's 5-year CDS contract. ${ }^{25}$ The results in Panel A of Table X suggest that credit risk premia are significantly priced in all liquidity portfolios. The four-factor alphas of the high-low credit risk premium strategy increase with the number of contributors, for value-weighted returns from $0.66 \%$ to $1.74 \%$ per month. The effects are much more pronounced in the equally-weighted portfolios. Finding that the credit risk premium effect increases with liquidity suggests that credit risk premia estimated from CDS spreads do not reflect liquidity premia in CDS markets. On the contrary, it appears that the link between equity and CDS markets is stronger when the firm's contract is more liquid. In a robustness analysis using an alternative data set (sourced from Credit Market Analytics (CMA)), we use CDS bid-ask spreads as a proxy for liquidity and also find that the pricing effect of credit risk premia is inversely related to bid-ask spreads. This suggests that credit risk premia increase with liquidity and decrease with transaction costs.

In Panel B, we control for conditional coskewness of firms' stock returns with the market using

\footnotetext{
${ }^{24}$ Results are very similar when using the distance-to-default $(D D)$ instead of credit ratings; see the robustness checks in Section III.C.5.

${ }^{25}$ For a discussion of the number of contributors as a measure of liquidity in CDS markets and other proxies see, e.g., Qiu and Yu (2012).
} 
the measure of Harvey and Siddique (2000). P1.* to P3.* contain firms with the most negative to most positive coskewness. For value-weighted portfolios, we find a U-shape pattern with the fourfactor alpha of buying high and selling low-risk premium firms being $0.57 \%$ (not significant) for P2.* while the P.1* and P3.* alphas are significant with $0.98 \%$ and $1.03 \%$, respectively. This pattern suggests that, the returns of credit risk premium sorted portfolios cannot be directly attributed to coskewness. On the other hand, we find for equally-weighted portfolios that all four-factor alphas are significant and decrease from $1.86 \%$ in $\mathrm{P} 1 .^{*}$ to $1.35 \%$ in $\mathrm{P} 3 .^{*}$. This result suggests that the credit risk premium effect is most pronounced among firms with returns that are left skewed.

\section{C.4. Out-of-Sample Parameter Estimation}

So far, to generate time- $t$ conditional credit risk premia we only use the CDS term structure information available at time $t$ but estimation of the parameters $\gamma$ is based on full sample information; in doing so, we exactly follow Cochrane and Piazzesi (2005). Now, we also estimate the parameters conditional on the time- $t$ information set only. The out-of-sample results reinforce our findings and also alleviate potential concerns that look-ahead bias could have an impact on our conclusions.

To generate out-of-sample forecasts, we estimate predictive regressions using the approach described in Section II.A with monthly as well as with weekly data. We apply different sampling schemes (rolling and expanding windows) to estimate the conditional mean or conditional quantiles of the risk premium distribution (using ordinary least squares (OLS) or quantile regressions (QR), respectively). ${ }^{26}$ Furthermore, we account for potential changes in the data generating process using standard intercept corrections. ${ }^{27}$ Using the risk premium forecasts, we sort firms into either quintile

\footnotetext{
${ }^{26}$ Our motivation to use quantile regressions is based on the observation that the distribution of credit risk premia is asymmetric. Typically, when we sort portfolios by credit risk premia, the return difference between the medium and the lowest credit risk premium portfolio is larger (in absolute terms) than the corresponding difference to the high risk premium portfolio. Accordingly, we set the quantile to be estimated in the regression to $20 \%$ when we use quintile portfolios and to $10 \%$ when we use decile portfolios.

${ }^{27}$ We implement the intercept correction as follows. Using the regression model $\overline{R X}_{t+\tau}=\left(\gamma^{R \boldsymbol{X}}\right)^{\top} \mathbf{F}_{\mathbf{t}}+\varepsilon_{t+\tau}^{R X}$, we have that $\mathbb{E}_{t}^{\mathbb{P}}\left[\overline{R X}_{t+\tau}\right]=\left(\boldsymbol{\gamma}^{\boldsymbol{R X}}\right)^{\top} \mathbf{F}_{\mathbf{t}}$ and we define the forecast error $\nu_{t+\tau} \equiv \overline{R X}_{t+\tau}-\mathbb{E}_{t}^{\mathbb{P}}\left[\overline{R X}_{t+\tau}\right]$. We rewrite the conditional expectation of the next period's excess return as

$$
\mathbb{E}_{t+\tau}^{\mathbb{P}}\left[\overline{R X}_{t+2 \tau}\right]=\left(\gamma^{R \boldsymbol{X}}\right)^{\top} \mathbf{F}_{\mathbf{t}+\tau}=\mathbb{E}_{t}^{\mathbb{P}}\left[\overline{R X}_{t+\tau}\right]+\left(\gamma^{\boldsymbol{R X}}\right)^{\top}\left(\mathbf{F}_{\mathbf{t}+\tau}-\mathbf{F}_{t}\right)
$$

Thus, to compute the forecast for the excess return from $t+\tau$ to $t+2 \tau$, we replace last period's expectation, $\mathbb{E}_{t}^{\mathbb{P}}\left[\overline{R X}_{t+\tau}\right]$, by the observed realized excess return, $\overline{R X}_{t+\tau}$, in Eq. (28), hence correcting the intercept by the forecast error. For discussions on such uses of intercept corrections in forecasting see, e.g., the survey of Clements and Hendry (2006) and other chapters in Elliot, Granger, and Timmermann (2006).
} 
or decile portfolios.

We report detailed results in Table XI, for monthly data in Panel A and for weekly data in Panel B. We compute the excess returns of buying high and selling low credit risk premium firms using an expanding window with initial length of one year and a rolling one-year window for the forecast estimation, respectively. Since data is available from January 2001, the out-of-sample period, thus, covers January 2002 to April 2010. At the monthly frequency, the annualized four-factor alphas are all positive but mostly not or only marginally significant. The annualized alpha estimates range from $3.35 \%$ to $5.77 \%$ when using OLS forecasts and from $0.95 \%$ to $8.36 \%$ when using QR forecasts. At the weekly frequency, the corresponding annualized alpha estimates are all highly significant and range from $9.18 \%$ to $16.36 \%$ when using OLS forecasts and from $8.97 \%$ to $17.17 \%$ when using QR forecasts. Furthermore, all long-short risk premium portfolio returns exhibit a negative correlation with corresponding long-short $M V$ and $B M$ portfolio returns. These results once more suggest that risk premia estimated from CDS data convey information for equity risk premia that is not captured by traditional risk factors like size and book-to-market.

We plot cumulative risk-adjusted excess returns of buying high and selling low risk premium firms in Figure 1. Using weekly data, we compute the cumulative four-factor alphas and present results for quintile portfolios in Panel A and for decile portfolios in Panel B. The plots illustrate that the long-short risk premium strategy is highly profitable, independent of the forecast specification and irrespective of the number of portfolios used. The graphs reveal that the strategy generates a positive performance throughout the out-of-sample period and it appears to perform particularly well during the recent crisis (when size and book-to-market conveyed little information about stock returns). The out-of-sample results, thus, confirm our conclusion that there is a strong positive relation between credit risk premia and equity returns. The facts that our results get stronger when using decile instead of quintile portfolios and weekly instead of monthly frequency further corroborate our findings. We leave it for future research to further exploit the link between equity and credit markets using more sophisticated econometric techniques for out-of-sample forecasting.

\section{C.5. Robustness Checks}

We conduct a variety of robustness checks to further corroborate our findings. In this subsection, we summarize the results of these checks which show that our conclusions remain unchanged when 
taking a closer look at sub-sample periods, assuming zero interest rates in the estimation of credit risk premia, and that using physical or risk-neutral default probabilities only, is not sufficiently informative to understand the cross-section of firms' stock returns. The corresponding tables are delegated to the Internet Appendix to save space.

Pre-Crisis and Crisis Sub-Samples We already know from Table V that a long-short strategy based on our credit risk premium measure yields significant abnormal returns, both, prior to the crisis $(01 / 2001$ to $06 / 2007)$ and during the crisis $(07 / 2007$ to $04 / 2010)$, with equity excess returns being higher in the latter period. In the Internet Appendix, we provide detailed results for the two sub-samples, showing that credit risk premia reach substantially higher (absolute) values during the crisis. While the difference between raw equity excess returns of buying P1 and selling P5 prior and during the crisis is relatively large, the difference between the four-factor model alphas is much smaller. Furthermore, all patterns with respect to portfolio characteristics are similar in both sub-samples, confirming that our credit risk premium measures are not monotonically related to size, book-to-market, default probabilities, as well as to proxies for liquidity and coskewness. Similarly, we find that results are also robust over sub-samples when using the alternative credit risk measures defined in Section I.A.

Relevance of Interest Rate Risk When motivating our empirical approach to measure credit risk premia from the CDS forward curve, we assumed that the riskless rate is non-stochastic such that the forward measure $\mathbb{Q}^{\tau}$ coincides with the spot measure $\mathbb{Q}$ (see Eq. 17). Without this assumption, expectations under the two measures are only equal under certain conditions, in particular when there is no correlation between riskless interest rates and default intensities. In line with previous research (see, e.g., the discussion and related references in Schneider, Sögner, and Veža, 2010), we find that the correlations between interest rates and CDS spreads are close to zero in our data: across firms and spread maturities, the average correlation is -0.057 with a standard deviation of 0.140 . This suggests that, both, assuming forward CDS spreads to represent riskneutral expectations in Section II.A and the processes of the riskless short interest rate and default intensity to be independent in Section II.B are justified by the data. To provide further support for this claim, we repeat the empirical analysis with credit risk measures estimated from forward CDS curves constructed under the assumption of zero riskless rates and find differences in results 
to be negligible. For details, see the Internet Appendix.

Default Probabilities and Equity Returns Prior research focuses on sorting firms into portfolios using measures either of a firm's physical or its risk-neutral probability of default and provides mixed evidence on the pricing of distress risk in equity returns. Our structural framework implies that equity risk premia are related to default information under both probability measures and that exclusively considering only one of them might not be sufficiently informative. We also discussed in Section I.B that structural models are consistent with, both, a negative relation between default probabilities and equity returns (the distress puzzle as reported, e.g., in Dichev, 1998; Campbell, Hilscher, and Szilagyi, 2008) as well as a positive relation (e.g., in Vassalou and Xing, 2004), depending on the underlying characteristics driving firm differences. We now present empirical results to show these claims are supported by our data.

We sort firms into quintile portfolios based on 5-year CDS spreads as a proxy for risk-neutral default probability and on credit ratings as well as on distances-to-default (following the procedure of Vassalou and Xing, 2004) as proxies for physical default probabilities, respectively. From the results reported in the Internet Appendix, we first notice that all three default probability measures are monotonically related to each other as well as to size and to book-to-market. While results are not clear-cut when considering raw excess returns and CAPM-alphas, we find that the multi-factor model alphas of buying firms with high and selling firms with low CDS spreads are significantly negative. Qualitatively, we get a similar finding when using credit ratings, but the quantitative results are less significant. Using the distance-to-default, we find a negative but not significant relation. Thus, using either of the proxies for a firm's probability of default, our results resemble the findings of previous research that identifies a "distress puzzle": firms with high distress risk earn low returns. These results are consistent with a structural framework that allows for such a negative relation but at the same time implies a positive relation between credit risk premia and expected equity returns.

Other Checks (not reported in the paper) As a further robustness check, we also conduct the core empirical analysis using decile instead of quintile portfolios. The results are qualitatively the same as those reported and quantitatively somewhat more pronounced when calculating high minus low returns of the decile portfolios. Furthermore, we also repeat the analysis when excluding 
firms with stock prices being less than one dollar to account for potential liquidity issues. Doing so virtually has no effect on our results on the link between credit risk premia and equity returns. As a final robustness check, we repeat the whole empirical analysis using CDS data from Datastream (the source is Credit Market Analytics (CMA)) for the period January 2004 to June 2010 and come to the same conclusions as with Markit data used in this paper.

\section{Conclusion}

In a Merton (1974) framework the market price of risk is the same for all contingent claims written on a firm's assets. We exploit this result by estimating risk premia from firms' CDS forward curves and test whether these firm-specific measures of credit risk are related to subsequent equity excess returns. Our empirical results strongly support this hypothesis. We find that equity returns and equity Sharpe ratios decrease from the high to the low credit risk premium portfolio and that this pattern cannot be explained by common measures of firms' distress risk, size, book-to-market ratios, CDS liquidity, or conditional coskewness. Buying high and selling low credit risk premium firms generates positive alpha after controlling for standard risk factors. Credit risk premia are priced in all size, book-to-market, and default probability portfolios with equity excess returns being highest for small firms, value stocks, and firms with high probability of default. The term structure of CDS spreads, thus, contains risk premium information that is relevant for pricing stocks but is not captured by traditional risk factors. Our results are robust across sub-samples (pre-crisis period until July 2007 and crisis period from July 2007), return weighting schemes (equally- and value-weighted), information sets for parameter estimation (full sample and out-of-sample), and sampling frequency (monthly and weekly).

Our analysis also generates insights for the "distress puzzle" - the finding that firms with high distress risk earn anomalously low equity risk premia (see, e.g., Campbell, Hilscher, and Szilagyi, 2008). We show that the distress puzzle is perfectly consistent with structural models and find that empirically firms with the highest physical or risk-neutral default probabilities earn the lowest equity returns. These findings complement our results documenting that there is a strong positive relation between credit risk premia and subsequent equity returns.

There are various dimensions along which our work could be extended. Providing an economic 
interpretation for the CDS risk factor that we identify seems an important next step. From a methodological perspective, it is also interesting to explore whether using more sophisticated econometric techniques for modeling CDS spreads would enhance predictability in CDS markets, thereby possibly strengthening the link between credit and equity markets. More generally, understanding common risk premia in equity and credit markets is important, for instance, when analyzing the interplay between institutional and regulatory features of both markets or when specifying models that jointly price equity and credit instruments. 


\section{Appendix A. Instantaneous Expected Return and Volatility}

In the following we derive the instantaneous expected return and volatility on the equity claim given by Eqs. (2) and (3). In the structural framework of Merton (1974), the dynamics of the asset value $V$ under the $\mathbb{P}$ - and $\mathbb{Q}$-measure are

$$
\begin{aligned}
& d V=\mu V d t+\sigma V d W^{\mathbb{P}}, \\
& d V=r V d t+\sigma V d W^{\mathbb{Q}} .
\end{aligned}
$$

Applying Itô's lemma under both measures we get

$$
\begin{aligned}
\frac{d E}{E} & =\frac{E_{t}+\mu V E_{V}+\frac{1}{2} \sigma^{2} V^{2} E_{V V}}{E}+\sigma \frac{E_{V} V}{E} d W^{\mathbb{P}}, \\
\frac{d E}{E} & =\frac{E_{t}+r V E_{V}+\frac{1}{2} \sigma^{2} V^{2} E_{V V}}{E}+\sigma \frac{E_{V} V}{E} d W^{\mathbb{Q}} .
\end{aligned}
$$

The instantaneous expected return on equity under the $\mathbb{P}$-measure, $\mu_{E}$, is

$$
\mu_{E} \equiv \mathbb{E}^{\mathbb{P}}\left[\frac{d E}{E}\right]=\frac{E_{t}+\mu V E_{V}+\frac{1}{2} \sigma^{2} V^{2} E_{V V}}{E} .
$$

Because under the $\mathbb{Q}$-measure $\mathbb{E}^{\mathbb{Q}}\left[\frac{d E}{E}\right]=r$, it follows from Eqs. (A4) and (A5) that the instantaneous excess return is

$$
\mu_{E}-r=(\mu-r)\left[\frac{V}{E} E_{V}\right]
$$

which is Eq. (2) in the paper. Eq. (3) follows immediately from Eqs. (A3) and (A4) by applying Girsanov's theorem, i.e.

$$
\sigma_{E}=\sqrt{\mathbb{V}^{\mathbb{P}}\left(\frac{d E}{E}\right)}=\sqrt{\mathbb{V}^{\mathbb{Q}}\left(\frac{d E}{E}\right)}=\sigma\left[\frac{V}{E} E_{V}\right] .
$$

The instantaneous expected return and volatility for CDS spreads are obtained analogously. 


\section{Appendix B. Valuation of Credit Default Swaps}

CDS Pricing A CDS contract with time-to-maturity $T$ comprises two legs: a protection leg which corresponds to a contingent payment following a credit event and a premium leg which refers to a stream of risky premium payments. The value of the protection leg $\left(\operatorname{Prot}_{t}^{T}\right)$ at time $t$ is given as

$$
\operatorname{Prot}_{t}^{T}=(1-R) \int_{t}^{t+T} \mathbb{E}_{t}^{\mathbb{Q}}\left[\eta_{u} \exp \left(-\int_{t}^{u}\left(r_{s}+\eta_{s}\right) d s\right)\right] d u
$$

where $R$ is the recovery rate of the defaulted obligation, $r$ the continuously compounded riskless short rate and $\eta$ the default intensity. The premium leg $\left(\operatorname{Prem}_{t}^{T}\right)$ is given by the product of the annual contract premium, i.e. the CDS spread $S_{t}^{T}$, and the time $t$ present value of a credit risky annuity $\mathrm{RPV}_{t}^{T}$ starting at $t$ with time-to-maturity $T$, i.e.

$$
\operatorname{Prem}_{t}^{T}=S_{t}^{T} \cdot \mathrm{RPV}_{t}^{T}
$$

where $\mathrm{RPV}_{t}^{T}$ is defined as

$$
\begin{aligned}
\operatorname{RPV}_{t}^{T} & \equiv \sum_{n=1}^{N} \delta\left(t_{n-1}, t_{n}\right) \mathbb{E}_{t}^{\mathbb{Q}}\left[\exp \left(-\int_{t}^{t_{n}}\left(r_{s}+\eta_{s}\right) d s\right)\right] \\
& +\sum_{n=1}^{N} \int_{t_{n-1}}^{t_{n}} \delta\left(t_{n-1}, u\right) \mathbb{E}_{t}^{\mathbb{Q}}\left[\eta_{u} \exp \left(-\int_{t}^{u}\left(r_{s}+\eta_{s}\right) d s\right)\right] d u
\end{aligned}
$$

Here we use the notation that $t_{0}=t$ and $t_{N}=t+T$ with $N$ referring to the number of premium payments during the life of the CDS contract. The term $\delta\left(t_{n-1}, t_{n}\right)$ refers to the day-count fraction between two consecutive premium payment dates $t_{n-1}$ and $t_{n} \cdot{ }^{28}$ The first part of Eq. (B3) refers to the expected present value of the risky premium payments made conditional on surviving up to the payment dates while the second part corresponds to the amount of premium that has accrued from the previous premium payment date to the default time. Since the price of a CDS contract is zero at inception the difference between both legs must be zero. Hence, the premium of a newly issued CDS contract with time-to-maturity $T$ is determined by

$$
S_{t}^{T}=\frac{(1-R) \int_{t}^{t+T} \mathbb{E}_{t}^{\mathbb{Q}}\left[\eta_{u} \exp \left(-\int_{t}^{u}\left(r_{s}+\eta_{s}\right) d s\right)\right] d u}{\operatorname{RPV}_{t}^{T}} .
$$

\footnotetext{
${ }^{28}$ The day count convention that usually applies for CDS contracts is actual/360.
} 
Computation of Forward CDS Spreads A forward $C D S$ is a contract that provides protection against default of a reference obligation for a future time period of length $T$ starting at a forward date $t+\tau, \tau>0$. The forward premium is fixed today at contract inception. From a today's perspective, market participants should be indifferent between trading a $\tau+T$-period spot contract or a combination of spot and forward contracts covering the same period of time. Hence, we get

$$
S_{t}^{\tau+T} \cdot \mathrm{RPV}_{t}^{\tau+T}=S_{t}^{\tau} \cdot \mathrm{RPV}_{t}^{\tau}+F_{t}^{\tau \times T} \cdot \mathrm{RPV}_{t}^{\tau \times T}
$$

In other words, the time- $t$ value of a credit risky stream of forward spreads of length $T$ starting at $t+\tau$ is equal to the difference of the risky annuity $\mathrm{RPV}_{t}^{\tau+T}$ that starts today with time-to-maturity of $\tau+T$ and the annuity $\operatorname{RPV}_{t}^{\tau}$ that lasts from today to $t+\tau$, each weighted by their corresponding spot spreads. We assume determinstic interest rates and default intensities to compute forward CDS spreads. We bootstrap default intensities from on-the-run CDS contracts assuming a recovery rate $R$ of 0.40 .

\section{Appendix C. Affine Term Structure Model}

Let the time- $t$ price of a defaultable zero-coupon bond with $T$ years to maturity be given by

$$
P(t, T)=\mathbb{E}_{t}^{\mathbb{Q}}\left[\exp \left(-\int_{t}^{t+T}\left(r_{s}+\eta_{s}\right) d s\right)\right]
$$

where $r$ is the riskless short rate and $\eta$ is the default intensity. We model the riskless short rate using an affine model with two latent factors. The first factor can be interpreted as the riskless short rate and the second as its stochastic long-run mean. The $\mathbb{Q}$-dynamics are given by:

$$
\begin{aligned}
d r_{t} & =\kappa_{r}^{\mathbb{Q}}\left(m_{t}-r_{t}\right) d t+\sigma_{r} \sqrt{r_{t}} d W_{r}^{\mathbb{Q}}(t), \\
d m_{t} & =\left(\zeta_{m}-\kappa_{m}^{\mathbb{Q}} m_{t}\right) d t+\sigma_{m} \sqrt{m_{t}} d W_{m}^{\mathbb{Q}}(t) .
\end{aligned}
$$

To model the firm's default intensity we also use a two-factor affine model, with the two factors aimed at capturing the short-term and the the long-term behavior, respectively: 


$$
\begin{aligned}
& d \eta_{t}=\kappa_{\eta}^{\mathbb{Q}}\left(\gamma_{t}-\eta_{t}\right) d t+\sigma_{\eta} \sqrt{\eta_{t}} d W_{\eta}^{\mathbb{Q}}(t) \\
& d \gamma_{t}=\left(\zeta_{\gamma}-\kappa_{\gamma}^{\mathbb{Q}} \gamma_{t}\right) d t+\sigma_{\gamma} \sqrt{\gamma_{t}} d W_{\gamma}^{\mathbb{Q}}(t)
\end{aligned}
$$

In line with previous research we find that the correlation between the riskless short rate and CDS spreads are close to zero (see Section III.C.5) and therefore abstain from modeling dependence between riskless and default state variables. For both, the riskless and the intensity model, we use an essentially affine market price of risk specification to account for risk premia. Combining Eqs. (C2) and (C3), we have a four-factor model for the default risk-adjusted short rate $r+\eta$.

Our empirical implementation to estimate the model follows Schneider, Sögner, and Veža (2010) and we refer the reader to Section IV of their article for details on the Bayesian estimation methodology with Markov Chain Monte Carlo techniques. ${ }^{29}$ For each firm, we estimate the four-factor model for the default risk-adjusted short rate in two stages. First, we estimate the riskless model in Eq. (C2) once on a panel of riskless zero-yields. We use daily data on riskless zero yields, which we bootstrap from money market Libors with maturities of 1, 3, 6, and 9 months and swap rates with maturities of $1,2,3,4,5,7$, and 10 years. Subsequently, we estimate the default risk model in Eq. (C3) conditionally on the parameters and state variables obtained for the riskless model in the first stage. The point estimates for, both, the riskless and default risk models are obtained as the multivariate medians of the posterior distributions.

Using the estimation results, we obtain the firm's model-implied $T$-year CDS spread $\widehat{S}_{t}^{T}$ by applying the valuation formula in Eq. (B4). To compute the "pseudo-spread" under the $\mathbb{P}$-measure $\widehat{S}_{t}^{T, \mathbb{P}}$, we use the same formula but with all expectations taken under the $\mathbb{P}$ - instead of the $\mathbb{Q}$ measure. Using the model-implied spreads under both measures, we compute the ATSM-implied credit risk premium as defined in Eq. (27) following Pan and Singleton (2008).

\footnotetext{
${ }^{29}$ We are very grateful to Paul Schneider for his guidance on the empirical implementation of the ATSMs.
} 


\section{REFERENCES}

Acharya, Viral V., and Timothy C. Johnson, 2007, Insider trading in credit derivatives, Journal of Financial Economics 84, 110-141.

Altman, Edward I., 1968, Financial ratios, discriminant analysis and the prediction of corporate bankruptcy, The Journal of Finance 23, 589-609.

Andrews, Donald W.K., 1991, Heteroskedasticity and autocorrelation consistent covariance matrix estimation, Econometrica 59, 817-858.

Anginer, Deniz, and Celim Yildizhan, 2010, Is there a distress risk anomaly? Corporate bond spread as a proxy for default risk, Working Paper, World Bank and University of Georgia.

Arora, Navneet, Priyank Gandhi, and Francis A. Longstaff, 2012, Counterparty credit risk and the credit default swap market, Journal of Financial Economics 103, 280-293.

Avramov, Doron, Scott Cederburg, and Satadru Hore, 2012, Cross-sectional asset pricing puzzles: An equilibirum perspective, Working Paper, Hebrew University of Jerusalem, University of Arizona and Federal Reserve Bank of Boston.

Avramov, Doron, Tarun Chordia, Gergana Jostova, and Alexander Philipov, 2009, Credit ratings and the cross-section of stock returns, Journal of Financial Markets 12, 469-499.

Berndt, Antje, Rohan Douglas, Darrell Duffie, Mark Ferguson, and David Schranz, 2008, Measuring default risk premia form default swap rates and EDFs, Working paper, Carnegie Mellon University, Cornell University and Stanford University.

Blanco, Roberto, Simon Brennan, and Ian W. Marsh, 2005, An empirical analysis of the dynamic relation between investment-grade bonds and credit default swaps, Journal of Finance 60:5, $2255-2281$.

Campbell, John Y., Jens Hilscher, and Jan Szilagyi, 2008, In search of distress risk, The Journal of Finance 63, 2899-2939.

Campello, Murillo, Long Chen, and Lu Zhang, 2008, Expected returns, yield spreads, and asset pricing tests, Review of Financial Studies 21, 1297-1338. 
Carhart, Mark, 1997, On persistence in mutual fund performance, Journal of Finance 52, 57-82.

Chava, Sundheer, and Amiyatosh Purnanandam, 2010, Is default risk negatively related to stock returns?, Review of Financial Studies 23, 2523-2559.

Clements, Michael P., and David F. Hendry, 2006, Forecasting with breaks in data processes, in Graham Elliot, Clive W. J. Granger, and Allan Timmermann, ed.: Handbook of Economic Forecasting . pp. 605-657 (Elsevier North Holland).

Cochrane, John H., and Monika Piazzesi, 2005, Bond risk premia, American Economic Review 95, $138-160$.

Dichev, Ilia D., 1998, Is the risk of bankruptcy a systematic risk?, The Journal of Finance 53, $1131-1147$.

Driessen, Joost, 2005, Is default event risk priced in corporate bonds?, Review of Financial Studies $18,165-195$.

Duffee, Gregory R., 2011, Information in (and not in) the term structure, Review of Financial Studies 24, 2895-2934.

Duffie, Darrel, and Kenneth J. Singleton, 2003, Credit Risk - Pricing, Measurement, and Management (Princeton University Press) first edn.

Elliot, Graham, Clive W. J. Granger, and Allan Timmermann, 2006, Handbook of Economic Forecasting (Elsevier North-Holland).

Elton, Edwin J., Martin J. Gruber, Deepak Agrawal, and Christopher Mann, 2001, Explaining the rate spread on corporate bonds, Journal of Finance 56, 247-278.

Ericsson, Jan, Joel Reneby, and Hao Wang, 2007, Can structural models price default risk? Evidence from bond and credit derivative markets, Working paper, McGill University, Swedish Institute for Financial Research (SIFR), Stockholm School of Economics and Tsinghua University.

Fama, Eugene F., and Kenneth R. French, 1993, Common risk factors in the returns on stocks and bonds, Journal of Financial Economics 33, 3-56. 
Feldhütter, Peter, and David Lando, 2008, Decomposing swap spreads, Journal of Financial Economics 88, 375-405.

Garlappi, Lorenzo, Tao Shu, and Hong Yan, 2008, Default risk, shareholder advantage, and stock returns, Review of Financial Studies 21, 2743-2778.

Garlappi, Lorenzo, and Hong Yan, 2011, Financial distress and the cross section of equity returns, Journal of Finance 66, 789-822.

Hackbarth, Dirk, Rainer Haselmann, and David Schoenherr, 2013, Distress risk, stock returns, and the 1978 bankruptcy reform act, Working paper, University of Illionois at Urbana-Champaign, Bonn University, and London Business School.

Han, Bing, and Yi Zhou, 2011, Term structure of credit default swap spreads and cross-section of stock returns, McCombs Research Paper Series No. FIN-01-11, University of Texas at Austin and Florida State University.

Harvey, Campbell R., Yan Liu, and Heqing Zhu, 2013, ... and the cross-section of expected returns, Working paper, Duke University.

Harvey, Campbell R., and Akhtar Siddique, 2000, Conditional skewness in asset pricing tests, Journal of Finance LV, 1263-1295.

Huang, Jing-Zhi, and Ming Huang, 2012, How much of the corporate-treasury yield spread is due to credit risk?, Review of Asset Pricing Studies 2, 153-202.

Longstaff, Francis A., Sanjay Mithal, and Eric Neis, 2005, Corporate yield spreads: Default risk or liquidity? New evidence from the credit default swap market, Journal of Finance 60, 2213-2253.

Merton, Robert, 1974, On the pricing of corporate debt: The risk structure of interest rates, Journal of Finance 29, 449-470.

Newey, Whitney K., and Kenneth D. West, 1987, A simple positive semi-definite, heteroscedasticity and autorcorrelation consitent covariance matrix, Econometrica 55, 703-708.

Ni, Sophie X., and Jun Pan, 2011, Trading puts and cds on stocks with short sale ban, Working paper, Hong Kong University of Science and Technology and Massachusetts. 
Ohlson, James A., 1980, Financial ratios and the probabilistic prediction of bankruptcy, Journal of Accounting Research 18, 109-131.

Ozdagli, Ali K., 2012, Distressed, but not risky: Reconciling the empirical relationship between financial distress, market-based risk indicators, and stock returns (and more), Working paper, Federal Reserve Bank of Boston.

Pan, Jun, and Kenneth J. Singleton, 2008, Default and recovery implicit in the term structure of sovereign CDS spreads, Journal of Finance 63, 2345-2384.

Qiu, Jiaping, and Fan Yu, 2012, Endogenous liquidity in credit derivatives, Journal of Financial Economics 103, 611-631.

Schneider, Paul, Leopold Sögner, and Tanja Veža, 2010, The economic role of jumps and recovery rates in the market for corporate default risk, Journal of Financial and Quantitative Analysis $45,1517-1547$.

Vassalou, Maria, and Yuhang Xing, 2004, Default risk in equity returns, The Journal of Finance 59, 831-868. 
Table I: Descriptives Statistics for CDS Spreads

This table presents summary statistics for CDS spreads for the sample periods and spread maturities $T$ given in the column headers. Data is sampled at a monthly frequency corresponding to the prediction horizon $\tau$ of one month. We summarize descriptive statistics for levels of CDS spreads $\left(S_{t}^{T}\right)$, slopes of the CDS term structure defined as the $T$-year minus the 1-year CDS spread $\left(S_{t}^{T}-S_{t}^{1}\right)$, forward-implied CDS spread changes $\left(F_{t}^{\tau \times T}-S_{t}^{T}\right)$, realized changes in CDS spreads $\left(S_{t+\tau}^{T}-S_{t}^{T}\right)$, excess changes in CDS spreads $\left(R X_{t+\tau}^{T}\right)$, forward-implied returns in CDS spreads $\left(\log F_{t}^{\tau \times T}-\log S_{t}^{T}\right)$, realized returns in CDS spreads $\left(\log S_{t+\tau}^{T}-\log S_{t}^{T}\right)$, and CDS excess returns (rel. $R X_{t+\tau}^{T}$ ). We report, across firms, the means, standard deviations, and $5 \%$ and $95 \%$ quantiles. Results are based on a data set comprising joint observations of CDS spreads, stock prices, firm characteristics, and S\&P credit ratings for the full time period (01/2001-04/2010), the pre-crisis period (01/2001-06/2007) and the crisis period (07/2007-04/2010).

\begin{tabular}{|c|c|c|c|c|c|c|c|c|c|c|c|c|}
\hline & \multicolumn{4}{|c|}{ Full Period: 01/2001-04/2010 } & \multicolumn{4}{|c|}{ Pre-Crisis: $01 / 2001-06 / 2007$} & \multicolumn{4}{|c|}{ Crisis: $07 / 2007-04 / 2010$} \\
\hline & $T=1$ & $T=3$ & $T=5$ & $T=7$ & $T=1$ & $T=3$ & $T=5$ & $T=7$ & $T=1$ & $T=3$ & $T=5$ & $T=7$ \\
\hline \multicolumn{13}{|c|}{$C D S$ Spreads $\left(S_{t}^{T}\right)$ in basis points } \\
\hline mean & 105.67 & 126.91 & 143.84 & 148.73 & 66.25 & 86.32 & 104.19 & 109.95 & 180.60 & 206.06 & 223.96 & 223.22 \\
\hline sd & 274.71 & 251.52 & 237.77 & 225.04 & 151.88 & 154.32 & 154.25 & 148.37 & 408.07 & 361.54 & 336.32 & 311.77 \\
\hline q05 & 4.35 & 10.11 & 16.72 & 21.97 & 3.75 & 8.75 & 14.61 & 19.50 & 7.71 & 17.88 & 28.09 & 34.25 \\
\hline q95 & 443.12 & 487.50 & 521.14 & 516.73 & 291.70 & 335.00 & 373.70 & 376.34 & 714.85 & 755.37 & 777.21 & 750.30 \\
\hline \multicolumn{13}{|c|}{ CDS Slopes $\left(S_{t}^{T}-S_{t}^{1}\right)$ in basis points } \\
\hline mean & & 21.00 & 37.80 & 43.45 & & 18.23 & 34.54 & 43.73 & & 26.27 & 43.99 & 42.92 \\
\hline sd & & 71.74 & 100.13 & 115.51 & & 34.78 & 54.79 & 62.08 & & 112.13 & 152.72 & 176.21 \\
\hline q05 & & -1.90 & -2.82 & -6.98 & & 0.26 & 2.14 & 3.96 & & -19.17 & -38.93 & -68.34 \\
\hline q95 & & 97.73 & 164.15 & 181.69 & & 69.48 & 126.59 & 150.98 & & 148.41 & 223.28 & 229.42 \\
\hline \multicolumn{13}{|c|}{ Forward-Implied Changes in CDS Spreads $\left(F_{t}^{\tau \times T}-S_{t}^{T}\right)$ in basis points } \\
\hline mean & 2.45 & 1.75 & 0.98 & 0.87 & 2.17 & 1.67 & 1.14 & 1.07 & 2.98 & 1.90 & 0.64 & 0.48 \\
\hline sd & 10.63 & 6.45 & 5.11 & 4.60 & 4.36 & 2.86 & 1.90 & 1.67 & 17.07 & 10.34 & 8.46 & 7.49 \\
\hline q05 & -0.25 & -0.31 & -0.52 & -0.41 & 0.01 & -0.00 & -0.02 & 0.04 & -2.37 & -2.15 & -2.71 & -2.42 \\
\hline q95 & 11.78 & 7.95 & 4.67 & 3.90 & 8.30 & 6.25 & 4.03 & 3.49 & 18.23 & 10.72 & 5.89 & 4.86 \\
\hline \multicolumn{13}{|c|}{ Changes in CDS Spreads $\left(S_{t+\tau}^{T}-S_{t}^{T}\right)$ in basis points } \\
\hline mean & 0.85 & 1.00 & 1.16 & 1.33 & -1.43 & -1.36 & -1.12 & -0.65 & 4.33 & 4.46 & 4.41 & 3.74 \\
\hline sd & 102.16 & 78.11 & 68.99 & 64.71 & 43.03 & 37.88 & 36.47 & 34.81 & 162.60 & 122.44 & 107.29 & 98.44 \\
\hline q05 & -51.46 & -48.22 & -47.83 & -47.28 & -32.87 & -31.61 & -32.42 & -31.82 & -88.40 & -85.43 & -82.82 & -80.83 \\
\hline q95 & 48.75 & 50.52 & 52.16 & 51.58 & 22.77 & 23.59 & 28.00 & 28.51 & 103.03 & 98.58 & 92.94 & 88.67 \\
\hline \multicolumn{13}{|c|}{ Excess Changes in CDS Spreads $\left(R X_{t+\tau}^{T}\right)$ in basis points } \\
\hline mean & $\begin{array}{l}-1.69 \\
\end{array}$ & -0.83 & 0.11 & 0.39 & -3.62 & -3.06 & -2.28 & -1.74 & 1.17 & 2.39 & 3.60 & 3.09 \\
\hline sd & 100.36 & 77.35 & 68.42 & 64.19 & 42.56 & 37.71 & 36.37 & 34.70 & 159.64 & 121.17 & 106.28 & 97.56 \\
\hline q05 & -55.98 & -51.44 & -49.26 & -48.76 & -37.33 & -34.62 & -34.61 & -33.22 & -95.24 & -90.09 & -83.70 & -81.24 \\
\hline q95 & 43.30 & 46.83 & 50.15 & 50.45 & 18.62 & 21.03 & 26.08 & 26.87 & 96.14 & 94.39 & 91.86 & 87.54 \\
\hline \multicolumn{13}{|c|}{ Forward-Implied Returns in CDS Spreads $\left(\log F_{t}^{\tau \times T}-\log S_{t}^{T}\right)$ in percentage points } \\
\hline mean & 8.54 & 3.58 & 1.72 & 1.31 & 9.53 & 3.98 & 1.98 & 1.52 & 6.67 & 2.81 & 1.21 & 0.90 \\
\hline sd & 7.46 & 2.55 & 1.36 & 0.93 & 7.75 & 2.62 & 1.34 & 0.85 & 6.48 & 2.23 & 1.25 & 0.95 \\
\hline q05 & -0.17 & -0.14 & -0.23 & -0.17 & 0.01 & -0.00 & -0.01 & 0.03 & -0.82 & -0.59 & -0.71 & -0.65 \\
\hline q95 & 21.38 & 7.69 & 3.99 & 2.63 & 22.30 & 7.97 & 4.15 & 2.71 & 18.73 & 6.62 & 3.31 & 2.31 \\
\hline \multicolumn{13}{|c|}{$C D S$ Returns $\left(\log S_{t+\tau}^{T}-\log S_{t}^{T}\right)$ in percentage points } \\
\hline mean & 0.15 & 0.26 & 0.33 & 0.44 & -2.82 & -1.84 & -1.24 & -0.79 & 4.05 & 2.85 & 2.19 & 1.68 \\
\hline sd & 34.25 & 24.06 & 20.75 & 19.55 & 30.40 & 20.08 & 17.40 & 16.21 & 38.95 & 28.70 & 24.80 & 23.65 \\
\hline q05 & -52.87 & -35.38 & -29.67 & -28.74 & -51.51 & -31.39 & -26.24 & -24.27 & -56.43 & -43.56 & -37.90 & -37.56 \\
\hline q95 & 57.75 & 41.43 & 35.66 & 33.35 & 45.46 & 30.77 & 26.38 & 25.51 & 71.72 & 51.56 & 44.52 & 40.76 \\
\hline \multicolumn{13}{|c|}{$C D S$ Excess Returns (rel.R $R X_{t+\tau}^{T}$ ) in percentage points } \\
\hline mean & -8.52 & -3.37 & -1.42 & -0.89 & -12.45 & -5.85 & -3.22 & -2.33 & -2.65 & 0.03 & 0.97 & 0.76 \\
\hline sd & 33.18 & 23.80 & 20.63 & 19.47 & 29.38 & 19.89 & 17.31 & 16.14 & 37.52 & 28.31 & 24.65 & 23.55 \\
\hline q05 & -59.91 & -38.10 & -31.10 & -29.58 & -59.55 & -35.01 & -27.70 & -25.57 & -61.73 & -45.78 & -39.04 & -38.08 \\
\hline q95 & 46.69 & 37.25 & 33.83 & 31.92 & 33.39 & 26.46 & 24.49 & 23.86 & 61.50 & 48.34 & 43.18 & 39.68 \\
\hline
\end{tabular}


Table II: Returns on Stock Portfolios sorted by CDS-Implied Market Prices of Risk

We sort stocks based on firms' estimates of their CDS-implied market price of risk $\left(\widehat{M P R}_{t+\tau}\right)$ into quintile portfolios and calculate equally- and value-weighted excess returns in Panel $A(B)$. P1 contains firms with highest CDS-implied market prices of risk, P5 the ones with lowest. P1-P5 presents results for going long P1 and short P5. Portfolio Characteristics summarizes portfolio means of the market value $(M V)$, book-to-market $(B M)$, 5-year CDS spread ( 55$)$, credit rating (Rating), number of CDS contributors reported by Markit (Liquid), and conditional coskewness with the market portfolio (Coskew) following Harvey and Siddique (2000). We assign integer numbers to the $\mathrm{S} \& \mathrm{P}$ credit ratings, i.e. $\mathrm{AAA}=1, \mathrm{AA}+=2, \ldots, \mathrm{C}=21$. Portfolio Returns reports monthly means and standard deviations of excess returns along with annualized Sharpe ratios. Asset Pricing reports alpha estimates of regressing excess returns on the market $(M K T)$, as well as the three $(M K T, S M B, H M L)$ and four $(M K T, S M B, H M L, U M D)$ FamaFrench factors. Values in parentheses are $t$-statistics based on HAC standard errors using Newey and West (1987) with optimal truncation lag chosen as suggested by Andrews (1991). Results are based on a data set comprising joint observations of CDS spreads, stock prices, firm characteristics, and S\&P credit ratings for the full time period (01/2001-04/2010), the pre-crisis period (01/2001-06/2007) and the crisis period (07/2007-04/2010).

\begin{tabular}{|c|c|c|c|c|c|c|c|c|}
\hline & \multicolumn{6}{|c|}{ Full Period } & \multirow{2}{*}{$\begin{array}{c}\text { Pre-Crisis } \\
\text { P1-P5 }\end{array}$} & \multirow{2}{*}{$\begin{array}{c}\text { Crisis } \\
\text { P1-P5 }\end{array}$} \\
\hline & $\mathrm{P} 1$ & $\mathrm{P} 2$ & P3 & P4 & P5 & P1-P5 & & \\
\hline \multicolumn{9}{|c|}{ Sort Variable: CDS-Implied Market Price of Risk $\left(\widehat{M P R}_{t+\tau}\right)$} \\
\hline mean & 159.94 & 4.61 & 3.29 & 2.01 & -53.48 & & & \\
\hline \multicolumn{9}{|c|}{ Portfolio Characteristics } \\
\hline$M V$ & 13.41 & 19.14 & 22.19 & 30.33 & 23.85 & & & \\
\hline$B M$ & 0.65 & 0.64 & 0.63 & 0.62 & 0.68 & & & \\
\hline$S 5$ & 138.25 & 123.26 & 116.34 & 128.01 & 184.12 & & & \\
\hline Rating & 8.66 & 8.34 & 8.07 & 7.77 & 8.32 & & & \\
\hline Liquid & 6.76 & 8.80 & 8.75 & 8.34 & 6.91 & & & \\
\hline Coskew & -3.76 & -4.43 & -3.01 & -4.80 & -3.05 & & & \\
\hline
\end{tabular}

Panel A: Equally-Weighted Portfolios

\begin{tabular}{|c|c|c|c|c|c|c|c|c|}
\hline \multicolumn{9}{|c|}{$1.54^{* * *}$} \\
\hline & $(0.31)$ & $(0.40)$ & $(-0.28)$ & $(-0.49)$ & $(-1.20)$ & $(4.36)$ & (5.61) & $(6.20)$ \\
\hline sd & 6.33 & 6.08 & 5.84 & 5.97 & 7.35 & 3.24 & 3.12 & 3.56 \\
\hline $\mathrm{SR}$ & 0.14 & 0.16 & -0.12 & -0.20 & -0.47 & 1.32 & 1.71 & 3.44 \\
\hline \multicolumn{9}{|c|}{ Asset Pricing } \\
\hline \multirow[t]{2}{*}{ CAPM $\alpha$} & 0.16 & 0.19 & -0.28 & $-0.43^{*}$ & $-1.09^{* * *}$ & $1.25^{\text {*** }}$ & $1.52^{* * *}$ & $3.48^{* * *}$ \\
\hline & $(0.83)$ & $(0.90)$ & $(-1.24)$ & $(-1.72)$ & $(-4.54)$ & $(3.69)$ & $(4.89)$ & $(5.38)$ \\
\hline 3 -fac $\alpha$ & -0.05 & -0.08 & $-0.57^{* * *}$ & $-0.68^{* * *}$ & $-1.54^{* * *}$ & $1.49^{* * *}$ & $2.10^{* * *}$ & $3.41^{* * *}$ \\
\hline \multirow{2}{*}{4 -fac $\alpha$} & $\begin{array}{c}(-0.33) \\
-0.04\end{array}$ & $\begin{array}{c}(-0.39) \\
-0.08\end{array}$ & $\begin{array}{l}(-3.95) \\
-0.57^{* * *}\end{array}$ & $\begin{array}{l}(-3.31) \\
-0.68^{* * *}\end{array}$ & $\begin{array}{l}(-7.39) \\
-1.52^{* * *}\end{array}$ & $\begin{array}{l}(5.81) \\
1.48^{* * *}\end{array}$ & $\begin{array}{l}(7.79) \\
2.09^{* * *}\end{array}$ & $\begin{array}{l}(5.33) \\
3.37^{* * *}\end{array}$ \\
\hline & $(-0.19)$ & $(-0.39)$ & $(-3.11)$ & $(-3.11)$ & $(-7.08)$ & $(4.93)$ & $(6.19)$ & $(6.57)$ \\
\hline \multirow[t]{2}{*}{ MKT } & $1.21^{* * *}$ & $1.12^{* * *}$ & $1.06^{* * *}$ & $1.12^{* * *}$ & $1.32^{* * *}$ & $-0.12^{*}$ & -0.13 & -0.16 \\
\hline & $(20.25)$ & $(16.00)$ & $(18.88)$ & $(21.17)$ & $(19.63)$ & $(-1.74)$ & $(-1.23)$ & $(-1.29)$ \\
\hline \multirow[t]{2}{*}{ SMB } & $0.16^{* * *}$ & $0.17^{* * *}$ & $0.18^{* * *}$ & 0.06 & $0.18^{* *}$ & -0.01 & -0.05 & 0.18 \\
\hline & $(2.82)$ & $(2.81)$ & $(4.13)$ & $(1.55)$ & $(2.01)$ & $(-0.11)$ & $(-0.22)$ & $(0.59)$ \\
\hline \multirow[t]{2}{*}{ HML } & $0.23^{* * *}$ & $0.35^{* * *}$ & $0.38^{* * *}$ & $0.39^{* * *}$ & $0.66^{* * *}$ & $-0.43^{* * *}$ & $-0.60^{* * *}$ & -0.19 \\
\hline & $(3.08)$ & $(3.39)$ & $(4.53)$ & $(6.27)$ & $(7.03)$ & $(-3.82)$ & $(-5.18)$ & $(-0.59)$ \\
\hline
\end{tabular}

Panel B: Value-Weighted Portfolios

\begin{tabular}{|c|c|c|c|c|c|c|c|c|}
\hline mean & $\begin{array}{c}-0.23 \\
(-0.31)\end{array}$ & $\begin{array}{c}-0.23 \\
(-0.37)\end{array}$ & $\begin{array}{c}-0.32 \\
(-0.56)\end{array}$ & $\begin{array}{c}-0.70 \\
(-1.15)\end{array}$ & $\begin{array}{c}-1.14^{*} \\
(-1.72)\end{array}$ & $\begin{array}{l}0.90^{* *} \\
(2.29)\end{array}$ & $\begin{array}{l}1.69^{* * *} \\
(5.89)\end{array}$ & $\begin{array}{c}2.05 \\
(1.43)\end{array}$ \\
\hline sd & 5.73 & 5.51 & 4.90 & 4.79 & 5.72 & 4.09 & 3.09 & 5.71 \\
\hline SR & -0.14 & -0.14 & -0.23 & -0.50 & -0.69 & 0.77 & 1.90 & 1.25 \\
\hline \multicolumn{9}{|c|}{ Asset Pricing } \\
\hline CAPM $\alpha$ & $\begin{array}{c}-0.31 \\
(-1.27)\end{array}$ & $\begin{array}{c}-0.30 \\
(-1.24)\end{array}$ & $\begin{array}{l}-0.39^{* * *} \\
(-2.59)\end{array}$ & $\begin{array}{l}-0.76^{* * *} \\
(-4.93)\end{array}$ & $\begin{array}{l}-1.21^{* * *} \\
(-3.96)\end{array}$ & $\begin{array}{c}0.90^{*} \\
(1.90)\end{array}$ & $\begin{array}{l}1.65^{* * *} \\
(5.53)\end{array}$ & $\begin{array}{c}2.02 \\
(1.61)\end{array}$ \\
\hline 3 -fac $\alpha$ & $\begin{array}{c}-0.19 \\
(-0.86)\end{array}$ & $\begin{array}{c}-0.33 \\
(-1.46)\end{array}$ & $\begin{array}{l}-0.44^{* * *} \\
(-3.34)\end{array}$ & $\begin{array}{l}-0.75^{* * *} \\
(-6.53)\end{array}$ & $\begin{array}{l}-1.30^{* * *} \\
(-4.85)\end{array}$ & $\begin{array}{l}1.11^{* *} \\
(2.47)\end{array}$ & $\begin{array}{l}1.95^{* * *} \\
(6.16)\end{array}$ & $\begin{array}{l}1.92^{* *} \\
(2.02)\end{array}$ \\
\hline 4-fac $\alpha$ & $\begin{array}{c}-0.21 \\
(-1.05) \\
\end{array}$ & $\begin{array}{c}-0.35 \\
(-1.46) \\
\end{array}$ & $\begin{array}{l}-0.45^{* * *} \\
(-3.28) \\
\end{array}$ & $\begin{array}{l}-0.75^{* * *} \\
(-4.13) \\
\end{array}$ & $\begin{array}{l}-1.29^{* * *} \\
(-3.90)\end{array}$ & $\begin{array}{l}1.08^{* *} \\
(2.36)\end{array}$ & $\begin{array}{l}1.94^{* * *} \\
(4.67)\end{array}$ & $\begin{array}{l}1.84^{* *} \\
(2.12)\end{array}$ \\
\hline MKT & $\begin{array}{l}1.08^{* * *} \\
(8.13)\end{array}$ & $\begin{array}{c}1.04^{* * *} \\
(11.93)\end{array}$ & $\begin{array}{c}0.93^{* * *} \\
(16.25)\end{array}$ & $\begin{array}{c}0.92^{\text {*** }} \\
(17.88)\end{array}$ & $\begin{array}{c}1.07^{* * *} \\
(26.60)\end{array}$ & $\begin{array}{c}0.01 \\
(0.06)\end{array}$ & $\begin{array}{c}-0.03 \\
(-0.33)\end{array}$ & $\begin{array}{c}0.11 \\
(0.42)\end{array}$ \\
\hline SMB & $\begin{array}{c}-0.08 \\
(-1.12)\end{array}$ & $\begin{array}{c}-0.10 \\
(-1.14)\end{array}$ & $\begin{array}{c}-0.08 \\
(-1.28)\end{array}$ & $\begin{array}{c}-0.11 \\
(-1.09)\end{array}$ & $\begin{array}{l}-0.28^{* * *} \\
(-4.04)\end{array}$ & $\begin{array}{c}0.20 \\
(1.46)\end{array}$ & $\begin{array}{c}0.20 \\
(1.04)\end{array}$ & $\begin{array}{c}0.37 \\
(1.04)\end{array}$ \\
\hline HML & $\begin{array}{l}-0.15^{* *} \\
(-2.02)\end{array}$ & $\begin{array}{c}0.13^{*} \\
(1.78)\end{array}$ & $\begin{array}{c}0.16^{*} \\
(1.83)\end{array}$ & $\begin{array}{c}0.07 \\
(0.94)\end{array}$ & $\begin{array}{l}0.39^{* * *} \\
(2.99)\end{array}$ & $\begin{array}{l}-0.54^{* * *} \\
(-2.73)\end{array}$ & $\begin{array}{l}-0.43^{* * *} \\
(-2.83)\end{array}$ & $\begin{array}{c}-1.04^{*} \\
(-1.99)\end{array}$ \\
\hline
\end{tabular}




\section{Table III: Returns on Stock Portfolios sorted by CDS-Implied Equity Risk Premia}

We sort stocks based on firms' estimates of their CDS-implied equity risk premium $\left(\widehat{E R P}_{t+\tau}\right)$ into quintile portfolios and calculate equally- and value-weighted excess returns in Panel $A(B) . \mathrm{P} 1$ contains firms with highest CDS-implied equity risk premia, P5 the ones with lowest. P1-P5 presents results for going long P1 and short P5. Portfolio Characteristics summarizes portfolio means of the market value $(M V)$, book-to-market $(B M)$, 5-year CDS spread (S5), credit rating (Rating), number of CDS contributors reported by Markit (Liquid), and conditional coskewness with the market portfolio (Coskew) following Harvey and Siddique (2000). We assign integer numbers to the $\mathrm{S} \& \mathrm{P}$ credit ratings, i.e. $\mathrm{AAA}=1, \mathrm{AA}+=2, \ldots, \mathrm{C}=21$. Portfolio Returns reports monthly means and standard deviations of excess returns along with annualized Sharpe ratios. Asset Pricing reports alpha estimates of regressing excess returns on the market $(M K T)$, as well as the three $(M K T, S M B, H M L)$ and four $(M K T, S M B, H M L, U M D)$ FamaFrench factors. Values in parentheses are $t$-statistics based on HAC standard errors using Newey and West (1987) with optimal truncation lag chosen as suggested by Andrews (1991). Results are based on a data set comprising joint observations of CDS spreads, stock prices, firm characteristics, and S\&P credit ratings for the full time period (01/2001-04/2010), the pre-crisis period (01/2001-06/2007) and the crisis period (07/2007-04/2010).

\begin{tabular}{|c|c|c|c|c|c|c|c|c|}
\hline & \multicolumn{6}{|c|}{ Full Period } & \multirow{2}{*}{$\begin{array}{c}\text { Pre-Crisis } \\
\text { P1-P5 }\end{array}$} & \multirow{2}{*}{$\begin{array}{l}\text { Crisis } \\
\text { P1-P5 }\end{array}$} \\
\hline & $\mathrm{P} 1$ & $\mathrm{P} 2$ & P3 & $\mathrm{P} 4$ & P5 & $\mathrm{P} 1-\mathrm{P} 5$ & & \\
\hline \multicolumn{9}{|c|}{ Sort Variable: CDS-Implied Equity Risk Premium $\left(\widehat{E R P}_{t+\tau}\right)$} \\
\hline mean & 3.09 & 0.09 & 0.06 & 0.03 & -1.44 & & & \\
\hline \multicolumn{9}{|c|}{ Portfolio Characteristics } \\
\hline$M V$ & 11.73 & 17.41 & 21.18 & 29.56 & 27.75 & & & \\
\hline$B M$ & 0.70 & 0.65 & 0.61 & 0.59 & 0.67 & & & \\
\hline$S 5$ & 185.25 & 128.81 & 104.96 & 99.94 & 172.04 & & & \\
\hline Rating & 9.11 & 8.57 & 8.04 & 7.55 & 7.97 & & & \\
\hline Liquid & 6.65 & 8.83 & 8.77 & 8.46 & 7.09 & & & \\
\hline Coskew & -3.42 & -4.15 & -3.84 & -4.22 & -3.51 & & & \\
\hline
\end{tabular}

Panel A: Equally-Weighted Portfolios

\begin{tabular}{|c|c|c|c|c|c|c|c|c|}
\hline mean & $\begin{array}{c}0.47 \\
(0.48)\end{array}$ & $\begin{array}{c}0.06 \\
(0.08)\end{array}$ & $\begin{array}{c}-0.07 \\
(-0.10)\end{array}$ & $\begin{array}{c}-0.17 \\
(-0.28)\end{array}$ & $\begin{array}{c}-1.05 \\
(-1.24)\end{array}$ & $\begin{array}{l}1^{1.51^{* * *}} \\
(4.99)\end{array}$ & $\begin{array}{l}1.78^{* * *} \\
(5.98)\end{array}$ & $\begin{array}{c}4.69^{* * *} \\
(6.18)\end{array}$ \\
\hline sd & 7.66 & 6.03 & 5.25 & 4.92 & 7.43 & 3.23 & 2.70 & 4.21 \\
\hline SR & 0.21 & 0.04 & -0.05 & -0.12 & -0.49 & 1.62 & 2.28 & 3.86 \\
\hline \multicolumn{9}{|c|}{ Asset Pricing } \\
\hline CAPM $\alpha$ & $\begin{array}{c}0.21 \\
(0.87)\end{array}$ & $\begin{array}{c}-0.14 \\
(-0.70)\end{array}$ & $\begin{array}{c}-0.24 \\
(-1.03)\end{array}$ & $\begin{array}{c}-0.33^{*} \\
(-1.76)\end{array}$ & $\begin{array}{l}-1.28^{* * *} \\
(-5.04)\end{array}$ & $\begin{array}{l}1.49^{* * *} \\
(4.71)\end{array}$ & $\begin{array}{l}1.70^{* * *} \\
(4.95)\end{array}$ & $\begin{array}{c}4.68^{* * *} \\
(5.38)\end{array}$ \\
\hline 3 -fac $\alpha$ & $\begin{array}{c}-0.09 \\
(-0.44)\end{array}$ & $\begin{array}{l}-0.34^{* *} \\
(-2.11)\end{array}$ & $\begin{array}{l}-0.49^{* * *} \\
(-2.50)\end{array}$ & $\begin{array}{l}-0.51^{* * *} \\
(-3.69)\end{array}$ & $\begin{array}{l}-1.63^{* * *} \\
(-7.35)\end{array}$ & $\begin{array}{l}1.54^{* * *} \\
(5.12)\end{array}$ & $\begin{array}{l}1.88^{* * *} \\
(5.13)\end{array}$ & $\begin{array}{l}4.51^{* * *} \\
(4.90)\end{array}$ \\
\hline 4 -fac $\alpha$ & $\begin{array}{l}-0.06 \\
(-0.28)\end{array}$ & $\begin{array}{l}-0.34 \\
(-1.50)\end{array}$ & $\begin{array}{l}-0.50^{* * *} \\
(-2.59)\end{array}$ & $\begin{array}{l}-0.51^{* * *} \\
(-3.72)\end{array}$ & $\begin{array}{l}-1.61^{* * *} \\
(-6.64)\end{array}$ & $\begin{array}{l}1.54^{* * *} \\
(5.44)\end{array}$ & $\begin{array}{l}1.87^{* * *} \\
(5.48)\end{array}$ & $\begin{array}{l}4.31^{* * *} \\
(6.40)\end{array}$ \\
\hline $\mathrm{MKT}$ & $\begin{array}{c}1.43^{* * *} \\
(18.61)\end{array}$ & $\begin{array}{c}1.13^{* * *} \\
(15.34)\end{array}$ & $\begin{array}{c}0.94^{* * *} \\
(15.63)\end{array}$ & $\begin{array}{c}0.92^{* * *} \\
(24.10)\end{array}$ & $\begin{array}{c}1.33^{* * *} \\
(16.27)\end{array}$ & $\begin{array}{c}0.10 \\
(1.56)\end{array}$ & $\begin{array}{c}0.07 \\
(0.83)\end{array}$ & $\begin{array}{c}-0.09 \\
(-1.46)\end{array}$ \\
\hline SMB & $\begin{array}{l}0.32^{* * *} \\
(9.28)\end{array}$ & $\begin{array}{l}0.22^{* * *} \\
(3.56)\end{array}$ & $\begin{array}{c}0.09^{* *} \\
(1.98)\end{array}$ & $\begin{array}{c}0.04 \\
(0.89)\end{array}$ & $\begin{array}{c}0.10 \\
(1.20)\end{array}$ & $\begin{array}{l}0.22^{* * *} \\
(2.70)\end{array}$ & $\begin{array}{c}0.20 \\
(1.34)\end{array}$ & $\begin{array}{c}0.37^{* *} \\
(2.11)\end{array}$ \\
\hline HML & $\begin{array}{l}0.35^{* * *} \\
(5.69)\end{array}$ & $\begin{array}{l}0.24^{* *} \\
(2.02)\end{array}$ & $\begin{array}{l}0.48^{* * *} \\
(4.67)\end{array}$ & $\begin{array}{l}0.40^{* * *} \\
(6.41)\end{array}$ & $\begin{array}{l}0.70^{* * *} \\
(8.73)\end{array}$ & $\begin{array}{l}-0.35^{* * *} \\
(-2.88)\end{array}$ & $\begin{array}{l}-0.36^{* * *} \\
(-2.92)\end{array}$ & $\begin{array}{c}-0.07 \\
(-0.26)\end{array}$ \\
\hline
\end{tabular}

Panel B: Value-Weighted Portfolios

\begin{tabular}{|c|c|c|c|c|c|c|c|c|}
\hline mean & $\begin{array}{c}-0.02 \\
(-0.02)\end{array}$ & $\begin{array}{c}-0.30 \\
(-0.46)\end{array}$ & $\begin{array}{c}-0.33 \\
(-0.60)\end{array}$ & $\begin{array}{c}-0.46 \\
(-0.87)\end{array}$ & $\begin{array}{c}-1.16 \\
(-1.63)\end{array}$ & $\begin{array}{l}1.14^{* *} \\
(2.24)\end{array}$ & $\begin{array}{l}1.72^{* * *} \\
(3.91)\end{array}$ & $\begin{array}{l}3.37^{* * *} \\
(2.62)\end{array}$ \\
\hline sd & 6.90 & 5.65 & 4.57 & 4.10 & 5.75 & 4.41 & 3.35 & 5.65 \\
\hline SR & -0.01 & -0.19 & -0.25 & -0.39 & -0.70 & 0.90 & 1.78 & 2.07 \\
\hline \multicolumn{9}{|c|}{ Asset Pricing } \\
\hline CAPM $\alpha$ & $\begin{array}{c}-0.25 \\
(-0.90)\end{array}$ & $\begin{array}{l}-0.49^{* * *} \\
(-3.29)\end{array}$ & $\begin{array}{l}-0.47^{* * *} \\
(-2.85)\end{array}$ & $\begin{array}{l}-0.59^{* * *} \\
(-3.66)\end{array}$ & $\begin{array}{l}-1.34^{* * *} \\
(-4.23)\end{array}$ & $\begin{array}{l}1.09^{* *} \\
(2.33)\end{array}$ & $\begin{array}{l}1.63^{* * *} \\
(3.44)\end{array}$ & $\begin{array}{l}3.37^{* * *} \\
(2.74)\end{array}$ \\
\hline 3 -fac $\alpha$ & $\begin{array}{l}-0.23 \\
(-1.12)\end{array}$ & $\begin{array}{l}-0.46^{* * *} \\
(-2.90)\end{array}$ & $\begin{array}{l}-0.51^{* * *} \\
(-3.85)\end{array}$ & $\begin{array}{l}-0.59^{* * *} \\
(-4.27)\end{array}$ & $\begin{array}{l}-1.38^{* * *} \\
(-4.42)\end{array}$ & $\begin{array}{l}1.14^{* * *} \\
(2.63)\end{array}$ & $\begin{array}{l}1.57^{* * *} \\
(3.16)\end{array}$ & $\begin{array}{l}3.38^{* * *} \\
(3.55)\end{array}$ \\
\hline $4-f a c \alpha$ & $\begin{array}{l}-0.24 \\
(-1.07)\end{array}$ & $\begin{array}{l}-0.47^{* * *} \\
(-2.92)\end{array}$ & $\begin{array}{l}-0.53^{* * *} \\
(-4.27)\end{array}$ & $\begin{array}{l}-0.59^{* * *} \\
(-4.06)\end{array}$ & $\begin{array}{l}-1.37^{* * *} \\
(-4.04)\end{array}$ & $\begin{array}{l}1.13^{* * *} \\
(2.50)\end{array}$ & $\begin{array}{l}1.56^{* * * *} \\
(2.89)\end{array}$ & $\begin{array}{l}3.16^{* * *} \\
(3.05)\end{array}$ \\
\hline MKT & $\begin{array}{c}1.34^{* * *} \\
(11.38)\end{array}$ & $\begin{array}{c}1.11^{* * *} \\
(15.53)\end{array}$ & $\begin{array}{c}0.87^{* * *} \\
(19.73)\end{array}$ & $\begin{array}{c}0.78^{* * *} \\
(15.21)\end{array}$ & $\begin{array}{c}1.07^{* * *} \\
(24.88)\end{array}$ & $\begin{array}{c}0.26^{*} \\
(1.79)\end{array}$ & $\begin{array}{c}0.06 \\
(0.61)\end{array}$ & $\begin{array}{c}0.17 \\
(0.80)\end{array}$ \\
\hline SMB & $\begin{array}{c}0.01 \\
(0.15)\end{array}$ & $\begin{array}{c}0.02 \\
(0.19)\end{array}$ & $\begin{array}{l}-0.18^{* * *} \\
(-2.68)\end{array}$ & $\begin{array}{c}-0.12 \\
(-1.31)\end{array}$ & $\begin{array}{l}-0.28^{* * *} \\
(-4.14)\end{array}$ & $\begin{array}{c}0.30^{* *} \\
(1.99)\end{array}$ & $\begin{array}{l}0.45^{* * *} \\
(3.17)\end{array}$ & $\begin{array}{c}0.22 \\
(0.43)\end{array}$ \\
\hline HML & $\begin{array}{c}-0.05 \\
(-0.34)\end{array}$ & $\begin{array}{c}-0.08 \\
(-0.80)\end{array}$ & $\begin{array}{l}0.27^{* * *} \\
(4.81)\end{array}$ & $\begin{array}{c}0.11 \\
(1.55)\end{array}$ & $\begin{array}{l}0.39^{* * *} \\
(2.88)\end{array}$ & $\begin{array}{c}-0.43^{*} \\
(-1.78)\end{array}$ & $\begin{array}{l}-0.20 \\
(-0.92)\end{array}$ & $\begin{array}{c}-0.74 \\
(-1.37)\end{array}$ \\
\hline
\end{tabular}


Table IV: Returns on Stock Portfolios sorted by Relative Credit Risk Premia

We sort stocks based on firms' estimates of their relative credit risk premium $\left(\widehat{r e l . R P}_{t+\tau}\right)$ into quintile portfolios and calculate equally- and value-weighted excess returns in Panel $A(B) . \mathrm{P} 1$ contains firms with highest relative credit risk premia, P5 the ones with lowest. P1-P5 presents results for going long P1 and short P5. Portfolio Characteristics summarizes portfolio means of the market value $(M V)$, book-to-market $(B M), 5$-year CDS spread (S5), credit rating (Rating), number of CDS contributors reported by Markit (Liquid), and conditional coskewness with the market portfolio (Coskew) following Harvey and Siddique (2000). We assign integer numbers to the $\mathrm{S} \& \mathrm{P}$ credit ratings, i.e. $\mathrm{AAA}=1, \mathrm{AA}+=2, \ldots, \mathrm{C}=21$. Portfolio Returns reports monthly means and standard deviations of excess returns along with annualized Sharpe ratios. Asset Pricing reports alpha estimates of regressing excess returns on the market $(M K T)$, as well as the three $(M K T, S M B, H M L)$ and four $(M K T, S M B, H M L, U M D)$ FamaFrench factors. Values in parentheses are $t$-statistics based on HAC standard errors using Newey and West (1987) with optimal truncation lag chosen as suggested by Andrews (1991). Results are based on a data set comprising joint observations of CDS spreads, stock prices, firm characteristics, and S\&P credit ratings for the full time period (01/2001-04/2010), the pre-crisis period (01/2001-06/2007) and the crisis period (07/2007-04/2010).

\begin{tabular}{|c|c|c|c|c|c|c|c|c|}
\hline & \multicolumn{6}{|c|}{ Full Period } & \multirow{2}{*}{$\begin{array}{c}\text { Pre-Crisis } \\
\text { P1-P5 }\end{array}$} & \multirow{2}{*}{$\begin{array}{l}\text { Crisis } \\
\mathrm{P} 1-\mathrm{P} 5\end{array}$} \\
\hline & $\mathrm{P} 1$ & P2 & P3 & $\mathrm{P} 4$ & P5 & $\mathrm{P} 1-\mathrm{P} 5$ & & \\
\hline \multicolumn{9}{|c|}{ Sort Variable: Relative Credit Risk Premium (rel.RP $\left.{ }_{t+\tau}\right)$} \\
\hline mean & 13.02 & 6.36 & 3.58 & 0.91 & -5.41 & & & \\
\hline \multicolumn{9}{|c|}{ Portfolio Characteristics } \\
\hline$M V$ & 17.50 & 18.39 & 21.86 & 31.11 & 21.70 & & & \\
\hline$B M$ & 0.65 & 0.62 & 0.62 & 0.62 & 0.71 & & & \\
\hline$S 5$ & 168.32 & 122.87 & 115.10 & 116.14 & 166.77 & & & \\
\hline Rating & 8.68 & 8.34 & 8.11 & 7.84 & 8.19 & & & \\
\hline Liquid & 7.42 & 7.69 & 8.01 & 8.28 & 7.99 & & & \\
\hline Coskew & -3.30 & -4.14 & -3.41 & -4.09 & -4.19 & & & \\
\hline
\end{tabular}

Panel A: Equally-Weighted Portfolios

\begin{tabular}{|c|c|c|c|c|c|c|c|c|}
\hline mean & $\begin{array}{c}0.98 \\
(1.35)\end{array}$ & $\begin{array}{c}0.08 \\
(0.10)\end{array}$ & $\begin{array}{c}0.02 \\
(0.03)\end{array}$ & $\begin{array}{c}-0.54 \\
(-0.76)\end{array}$ & $\begin{array}{c}-1.54^{*} \\
(-1.70)\end{array}$ & $\begin{array}{l}2.52^{* * *} \\
(5.22)\end{array}$ & $\begin{array}{l}2.59^{* * *} \\
(6.61)\end{array}$ & $\begin{array}{l}5.06^{* * *} \\
(5.94)\end{array}$ \\
\hline sd & 6.51 & 5.81 & 5.80 & 6.02 & 7.45 & 3.86 & 3.47 & 4.00 \\
\hline SR & 0.52 & 0.05 & 0.01 & -0.31 & -0.72 & 2.26 & 2.59 & 4.39 \\
\hline \multicolumn{9}{|c|}{ Asset Pricing } \\
\hline CAPM $\alpha$ & $\begin{array}{l}0.89^{* * *} \\
(2.73)\end{array}$ & $\begin{array}{c}-0.00 \\
(-0.02)\end{array}$ & $\begin{array}{c}-0.06 \\
(-0.25)\end{array}$ & $\begin{array}{l}-0.63^{* * *} \\
(-2.65)\end{array}$ & $\begin{array}{l}-1.64^{* * *} \\
(-4.57)\end{array}$ & $\begin{array}{l}2.53^{* * *} \\
(5.05)\end{array}$ & $\begin{array}{l}2.60^{* * * *} \\
(6.58)\end{array}$ & $\begin{array}{l}5.00^{* * *} \\
(4.68)\end{array}$ \\
\hline $3-$ fac $\alpha$ & $\begin{array}{l}0.68^{* *} \\
(2.04)\end{array}$ & $\begin{array}{c}-0.26 \\
(-1.67)\end{array}$ & $\begin{array}{c}-0.37^{*} \\
(-1.88)\end{array}$ & $\begin{array}{l}-0.94^{* * *} \\
(-4.78)\end{array}$ & $\begin{array}{l}-2.08^{* * *} \\
(-7.96)\end{array}$ & $\begin{array}{l}2.76^{* * *} \\
(6.27)\end{array}$ & $\begin{array}{l}3.20^{* * *} \\
(8.22)\end{array}$ & $\begin{array}{l}4.75^{* * *} \\
(4.84)\end{array}$ \\
\hline 4 -fac $\alpha$ & $\begin{array}{l}0.70^{* * *} \\
(2.47)\end{array}$ & $\begin{array}{l}-0.26 \\
(-1.67)\end{array}$ & $\begin{array}{l}-0.37^{* *} \\
(-2.00)\end{array}$ & $\begin{array}{l}-0.94^{* * *} \\
(-5.24)\end{array}$ & $\begin{array}{l}-2.08^{* * *} \\
(-8.83)\end{array}$ & $\begin{array}{l}2.78^{* * *} \\
(7.00)\end{array}$ & $\begin{array}{l}3.19^{* * *} \\
(7.48)\end{array}$ & $\begin{array}{l}4.56^{* * *} \\
(8.28)\end{array}$ \\
\hline MKT & $\begin{array}{l}1.20^{* * *} \\
(20.41)\end{array}$ & $\begin{array}{c}1.06^{* * *} \\
(11.48)\end{array}$ & $\begin{array}{c}1.06^{* * *} \\
(19.57)\end{array}$ & $\begin{array}{c}1.10^{* * *} \\
(17.62)\end{array}$ & $\begin{array}{c}1.34^{* * *} \\
(15.51)\end{array}$ & $\begin{array}{c}-0.14 \\
(-1.33)\end{array}$ & $\begin{array}{l}-0.21^{* *} \\
(-2.28)\end{array}$ & $\begin{array}{c}-0.22^{*} \\
(-1.95)\end{array}$ \\
\hline SMB & $\begin{array}{l}0.19^{* *} \\
(2.42)\end{array}$ & $\begin{array}{l}0.18^{* * *} \\
(3.35)\end{array}$ & $\begin{array}{l}0.17^{\text {*** }} \\
(3.93)\end{array}$ & $\begin{array}{l}0.16^{* * *} \\
(2.50)\end{array}$ & $\begin{array}{c}0.10 \\
(1.14)\end{array}$ & $\begin{array}{c}0.09 \\
(0.77)\end{array}$ & $\begin{array}{l}-0.03 \\
(-0.17)\end{array}$ & $\begin{array}{l}0.58^{* * *} \\
(3.57)\end{array}$ \\
\hline HML & $\begin{array}{l}0.22^{* * *} \\
(2.63)\end{array}$ & $\begin{array}{l}0.30^{* * *} \\
(3.12)\end{array}$ & $\begin{array}{l}0.42^{* * *} \\
(4.72)\end{array}$ & $\begin{array}{l}0.43^{* * *} \\
(6.42)\end{array}$ & $\begin{array}{l}0.71^{* * *} \\
(9.84)\end{array}$ & $\begin{array}{l}-0.49^{* * *} \\
(-3.79)\end{array}$ & $\begin{array}{l}-0.64^{* * *} \\
(-5.14)\end{array}$ & $\begin{array}{l}-0.27 \\
(-1.21)\end{array}$ \\
\hline
\end{tabular}

Panel B: Value-Weighted Portfolios

\begin{tabular}{|c|c|c|c|c|c|c|c|c|}
\hline mean & $\begin{array}{c}0.12 \\
(0.17)\end{array}$ & $\begin{array}{c}-0.18 \\
(-0.34)\end{array}$ & $\begin{array}{c}-0.28 \\
(-0.48)\end{array}$ & $\begin{array}{c}-0.86 \\
(-1.27)\end{array}$ & $\begin{array}{c}-1.26^{*} \\
(-1.80)\end{array}$ & $\begin{array}{l}1.38^{* * *} \\
(3.31)\end{array}$ & $\begin{array}{l}2.18^{* * *} \\
(4.56)\end{array}$ & $\begin{array}{l}3.13^{* * *} \\
(3.21)\end{array}$ \\
\hline $\mathrm{sd}$ & 5.59 & 5.02 & 4.46 & 5.08 & 5.81 & 3.88 & 3.65 & 5.10 \\
\hline SR & 0.07 & -0.13 & -0.21 & -0.59 & -0.75 & 1.23 & 2.06 & 2.13 \\
\hline \multicolumn{9}{|c|}{ Asset Pricing } \\
\hline CAPM $\alpha$ & $\begin{array}{c}0.04 \\
(0.18)\end{array}$ & $\begin{array}{l}-0.25 \\
(-1.30)\end{array}$ & $\begin{array}{c}-0.34^{*} \\
(-1.94)\end{array}$ & $\begin{array}{l}-0.93^{* * *} \\
(-4.26)\end{array}$ & $\begin{array}{l}-1.34^{* * *} \\
(-4.34)\end{array}$ & $\begin{array}{l}1.38^{* * *} \\
(3.09)\end{array}$ & $\begin{array}{l}2.20^{* * *} \\
(4.79)\end{array}$ & $\begin{array}{l}3.10^{* * *} \\
(3.28)\end{array}$ \\
\hline 3 -fac $\alpha$ & $\begin{array}{c}0.08 \\
(0.41)\end{array}$ & $\begin{array}{c}-0.24 \\
(-1.23)\end{array}$ & $\begin{array}{c}-0.29^{*} \\
(-1.87)\end{array}$ & $\begin{array}{l}-0.97^{* * *} \\
(-4.44)\end{array}$ & $\begin{array}{l}-1.51^{* * *} \\
(-6.27)\end{array}$ & $\begin{array}{l}1.59^{* * *} \\
(3.70)\end{array}$ & $\begin{array}{l}2.79^{* * *} \\
(5.17)\end{array}$ & $\begin{array}{l}3.02^{* * *} \\
(5.27)\end{array}$ \\
\hline 4 -fac $\alpha$ & $\begin{array}{c}0.08 \\
(0.37) \\
\end{array}$ & $\begin{array}{c}-0.25 \\
(-1.45) \\
\end{array}$ & $\begin{array}{c}-0.29 \\
(-1.67) \\
\end{array}$ & $\begin{array}{l}-0.97^{* * *} \\
(-4.55) \\
\end{array}$ & $\begin{array}{l}-1.50^{* * *} \\
(-5.00)\end{array}$ & $\begin{array}{l}1.58^{* * *} \\
(3.42) \\
\end{array}$ & $\begin{array}{l}2.78^{* * *} \\
(5.04) \\
\end{array}$ & $\begin{array}{l}2.90^{* * *} \\
(6.15)\end{array}$ \\
\hline MKT & $\begin{array}{c}1.08^{* * *} \\
(14.67)\end{array}$ & $\begin{array}{c}0.92^{* * *} \\
(10.06)\end{array}$ & $\begin{array}{c}0.85^{* * *} \\
(14.46)\end{array}$ & $\begin{array}{c}0.98^{* * *} \\
(21.34)\end{array}$ & $\begin{array}{c}1.06^{* * *} \\
(15.43)\end{array}$ & $\begin{array}{c}0.02 \\
(0.15)\end{array}$ & $\begin{array}{l}-0.27^{* * *} \\
(-2.83)\end{array}$ & $\begin{array}{c}0.03 \\
(0.27)\end{array}$ \\
\hline SMB & $\begin{array}{c}-0.05 \\
(-0.83)\end{array}$ & $\begin{array}{c}-0.02 \\
(-0.24)\end{array}$ & $\begin{array}{l}-0.16^{* *} \\
(-2.08)\end{array}$ & $\begin{array}{l}-0.16^{* * *} \\
(-2.84)\end{array}$ & $\begin{array}{l}-0.21^{* * *} \\
(-7.90)\end{array}$ & $\begin{array}{c}0.16 \\
(1.67)\end{array}$ & $\begin{array}{l}-0.06 \\
(-0.37)\end{array}$ & $\begin{array}{c}0.28 \\
(0.87)\end{array}$ \\
\hline HML & $\begin{array}{c}-0.03 \\
(-0.48)\end{array}$ & $\begin{array}{c}-0.01 \\
(-0.09)\end{array}$ & $\begin{array}{c}0.05 \\
(0.50)\end{array}$ & $\begin{array}{c}0.20^{* *} \\
(2.37)\end{array}$ & $\begin{array}{l}0.48^{* * *} \\
(4.59)\end{array}$ & $\begin{array}{l}-0.51^{* * *} \\
(-3.06)\end{array}$ & $\begin{array}{l}-0.61^{* * *} \\
(-3.13)\end{array}$ & $\begin{array}{c}-0.71 \\
(-1.34)\end{array}$ \\
\hline
\end{tabular}


Table V: Returns on Stock Portfolios sorted by Credit Risk Premia

We sort stocks based on firms' estimates of their credit risk premium $\left(\widehat{C R P}_{t+\tau}\right)$ into quintile portfolios and calculate equally- and value-weighted excess returns in Panel $A(B)$. P1 contains firms with highest credit risk premia, P5 the ones with lowest. P1-P5 presents results for going long P1 and short P5. Portfolio Characteristics summarizes portfolio means of the market value ( $M V)$, book-to-market $(B M), 5$-year CDS spread (S5), credit rating (Rating), number of CDS contributors reported by Markit (Liquid), and conditional coskewness with the market portfolio (Coskew) following Harvey and Siddique (2000). We assign integer numbers to the $\mathrm{S} \& \mathrm{P}$ credit ratings, i.e. $\mathrm{AAA}=1, \mathrm{AA}+=2, \ldots, \mathrm{C}=21$. Portfolio Returns reports monthly means and standard deviations of excess returns along with annualized Sharpe ratios. Asset Pricing reports alpha estimates of regressing excess returns on the market $(M K T)$, as well as the three $(M K T, S M B, H M L)$ and four ( $M K T, S M B, H M L, U M D)$ Fama-French factors. Values in parentheses are $t$-statistics based on HAC standard errors using Newey and West (1987) with optimal truncation lag chosen as suggested by Andrews (1991). Results are based on a data set comprising joint observations of CDS spreads, stock prices, firm characteristics, and S\&P credit ratings for the full time period (01/2001-04/2010), the pre-crisis period (01/2001-06/2007) and the crisis period $(07 / 2007-04 / 2010)$.

\begin{tabular}{|c|c|c|c|c|c|c|c|c|}
\hline & \multicolumn{6}{|c|}{ Full Period } & \multirow{2}{*}{$\begin{array}{c}\text { Pre-Crisis } \\
\text { P1-P5 }\end{array}$} & \multirow{2}{*}{$\begin{array}{l}\text { Crisis } \\
\text { P1-P5 }\end{array}$} \\
\hline & $\mathrm{P} 1$ & $\mathrm{P} 2$ & P3 & $\mathrm{P} 4$ & P5 & $\mathrm{P} 1-\mathrm{P} 5$ & & \\
\hline \multicolumn{9}{|c|}{ Sort Variable: Credit Risk Premium $\left.\widehat{(\widehat{R P}}_{t+\tau}\right)$} \\
\hline mean & 30.65 & 4.98 & 1.20 & -2.14 & -29.52 & & & \\
\hline \multicolumn{9}{|c|}{ Portfolio Characteristics } \\
\hline$M V$ & 12.41 & 18.89 & 29.34 & 31.93 & 18.05 & & & \\
\hline$B M$ & 0.77 & 0.60 & 0.53 & 0.55 & 0.77 & & & \\
\hline$S 5$ & 251.64 & 100.02 & 67.92 & 72.17 & 196.57 & & & \\
\hline Rating & 9.71 & 8.06 & 7.19 & 7.34 & 8.85 & & & \\
\hline Liquid & 7.16 & 7.61 & 7.90 & 8.31 & 8.40 & & & \\
\hline Coskew & -3.33 & -3.72 & -4.61 & -4.78 & -2.65 & & & \\
\hline
\end{tabular}

Panel A: Equally-Weighted Portfolios

\begin{tabular}{|c|c|c|c|c|c|c|c|c|}
\hline mean & $\begin{array}{c}0.74 \\
(0.74)\end{array}$ & $\begin{array}{c}0.31 \\
(0.54)\end{array}$ & $\begin{array}{c}-0.02 \\
(-0.03)\end{array}$ & $\begin{array}{c}-0.14 \\
(-0.21)\end{array}$ & $\begin{array}{c}-1.90 \\
(-1.68)\end{array}$ & $\begin{array}{l}2.63^{* * *} \\
(4.21)\end{array}$ & $\begin{array}{l}2.68^{* * *} \\
(6.31)\end{array}$ & $\begin{array}{l}5.53^{* * *} \\
(3.94)\end{array}$ \\
\hline sd & 7.99 & 5.30 & 5.02 & 5.03 & 8.50 & 4.39 & 3.14 & 6.21 \\
\hline SR & 0.32 & 0.21 & -0.01 & -0.10 & -0.77 & 2.08 & 2.95 & 3.09 \\
\hline \multicolumn{9}{|c|}{ Asset Pricing } \\
\hline$\overline{\mathrm{CAPM}} \alpha$ & $\begin{array}{c}0.63^{*} \\
(1.89)\end{array}$ & $\begin{array}{c}0.24 \\
(1.32)\end{array}$ & $\begin{array}{l}-0.09 \\
(-0.45)\end{array}$ & $\begin{array}{l}-0.21 \\
(-0.99)\end{array}$ & $\begin{array}{l}-2.01^{* * *} \\
(-4.61)\end{array}$ & $\begin{array}{l}2.64^{* * *} \\
(4.21)\end{array}$ & $\begin{array}{l}2.68^{* * *} \\
(6.57)\end{array}$ & $\begin{array}{l}5.46^{* * *} \\
(3.18)\end{array}$ \\
\hline 3 -fac $\alpha$ & $\begin{array}{c}0.25 \\
(0.69)\end{array}$ & $\begin{array}{c}-0.04 \\
(-0.25)\end{array}$ & $\begin{array}{c}-0.24 \\
(-1.40)\end{array}$ & $\begin{array}{l}-0.42^{* *} \\
(-2.42)\end{array}$ & $\begin{array}{l}-2.52^{* * *} \\
(-7.48)\end{array}$ & $\begin{array}{l}2.77^{* * *} \\
(5.86)\end{array}$ & $\begin{array}{l}3.13^{* * *} \\
(6.08)\end{array}$ & $\begin{array}{l}5.29^{* * *} \\
(3.59)\end{array}$ \\
\hline 4 -fac $\alpha$ & $\begin{array}{c}0.29 \\
(1.02)\end{array}$ & $\begin{array}{l}-0.03 \\
(-0.20)\end{array}$ & $\begin{array}{l}-0.25 \\
(-1.57)\end{array}$ & $\begin{array}{l}-0.43^{* * *} \\
(-2.70)\end{array}$ & $\begin{array}{l}-2.52^{* * *} \\
(-6.15)\end{array}$ & $\begin{array}{l}2.82^{\text {*** }} \\
(6.68)\end{array}$ & $\begin{array}{l}3.14^{* * *} \\
(6.24)\end{array}$ & $\begin{array}{l}4.84^{* * *} \\
(7.59)\end{array}$ \\
\hline$\overline{\mathrm{MKT}}$ & $\begin{array}{c}1.43^{* * *} \\
(17.66)\end{array}$ & $\begin{array}{c}0.94^{* * *} \\
(17.35)\end{array}$ & $\begin{array}{c}0.93^{* * *} \\
(15.61)\end{array}$ & $\begin{array}{c}0.93^{* * *} \\
(15.99)\end{array}$ & $\begin{array}{c}1.53^{* * *} \\
(10.04)\end{array}$ & $\begin{array}{c}-0.10 \\
(-0.53)\end{array}$ & $\begin{array}{c}-0.19^{*} \\
(-1.72)\end{array}$ & $\begin{array}{c}-0.25 \\
(-0.92)\end{array}$ \\
\hline SMB & $\begin{array}{l}0.35^{* * *} \\
(3.81)\end{array}$ & $\begin{array}{l}0.23^{* * *} \\
(5.32)\end{array}$ & $\begin{array}{c}0.01 \\
(0.23)\end{array}$ & $\begin{array}{c}0.06 \\
(0.77)\end{array}$ & $\begin{array}{l}0.14^{* *} \\
(2.30)\end{array}$ & $\begin{array}{l}0.21^{* *} \\
(2.13)\end{array}$ & $\begin{array}{c}0.07 \\
(0.44)\end{array}$ & $\begin{array}{c}0.40 \\
(1.40)\end{array}$ \\
\hline HML & $\begin{array}{l}0.39^{* * *} \\
(3.45)\end{array}$ & $\begin{array}{l}0.31^{* * *} \\
(2.71)\end{array}$ & $\begin{array}{l}0.26^{* * *} \\
(3.50)\end{array}$ & $\begin{array}{l}0.33^{* * *} \\
(5.55)\end{array}$ & $\begin{array}{l}0.79^{* * *} \\
(7.01)\end{array}$ & $\begin{array}{l}-0.40^{* *} \\
(-2.11)\end{array}$ & $\begin{array}{l}-0.53^{* * *} \\
(-3.70)\end{array}$ & $\begin{array}{c}-0.16 \\
(-0.72)\end{array}$ \\
\hline
\end{tabular}

Panel B: Value-Weighted Portfolios

\begin{tabular}{|c|c|c|c|c|c|c|c|c|}
\hline mean & $\begin{array}{c}-0.06 \\
(-0.08)\end{array}$ & $\begin{array}{c}0.11 \\
(0.20)\end{array}$ & $\begin{array}{c}-0.48 \\
(-0.95)\end{array}$ & $\begin{array}{c}-0.48 \\
(-0.86)\end{array}$ & $\begin{array}{c}-1.81^{*} \\
(-1.79)\end{array}$ & $\begin{array}{l}1.75^{* * *} \\
(3.65)\end{array}$ & $\begin{array}{l}2.67^{* * *} \\
(4.00)\end{array}$ & $\begin{array}{l}4.16^{* * *} \\
(3.36)\end{array}$ \\
\hline sd & 6.90 & 4.76 & 4.30 & 4.34 & 7.32 & 4.16 & 3.98 & 5.79 \\
\hline SR & -0.03 & 0.08 & -0.38 & -0.39 & -0.86 & 1.45 & 2.33 & 2.49 \\
\hline \multicolumn{9}{|c|}{ Asset Pricing } \\
\hline CAPM $\alpha$ & $\begin{array}{c}-0.16 \\
(-0.60)\end{array}$ & $\begin{array}{c}0.04 \\
(0.37)\end{array}$ & $\begin{array}{l}-0.53^{* * *} \\
(-2.96)\end{array}$ & $\begin{array}{l}-0.54^{* * *} \\
(-2.67)\end{array}$ & $\begin{array}{l}-1.91^{* * *} \\
(-4.85)\end{array}$ & $\begin{array}{l}1.75^{* * *} \\
(3.28)\end{array}$ & $\begin{array}{l}2.71^{* * *} \\
(4.02)\end{array}$ & $\begin{array}{l}4.10^{* * *} \\
(3.43)\end{array}$ \\
\hline 3 -fac $\alpha$ & $\begin{array}{c}-0.26 \\
(-0.92)\end{array}$ & $\begin{array}{c}-0.07 \\
(-0.54)\end{array}$ & $\begin{array}{l}-0.49^{* * *} \\
(-3.05)\end{array}$ & $\begin{array}{l}-0.56^{* * *} \\
(-2.97)\end{array}$ & $\begin{array}{l}-2.03^{* * *} \\
(-5.44)\end{array}$ & $\begin{array}{l}1.77^{* * *} \\
(3.54)\end{array}$ & $\begin{array}{l}3.14^{* * *} \\
(3.94)\end{array}$ & $\begin{array}{l}3.93^{* * *} \\
(3.83)\end{array}$ \\
\hline 4 -fac $\alpha$ & $\begin{array}{c}-0.24 \\
(-0.90)\end{array}$ & $\begin{array}{c}-0.07 \\
(-0.54)\end{array}$ & $\begin{array}{l}-0.50^{* * *} \\
(-3.00)\end{array}$ & $\begin{array}{l}-0.57^{* * *} \\
(-3.20)\end{array}$ & $\begin{array}{l}-2.03^{* * *} \\
(-5.39)\end{array}$ & $\begin{array}{l}1.79^{* * *} \\
(3.90)\end{array}$ & $\begin{array}{l}3.14^{* * *} \\
(4.01)\end{array}$ & $\begin{array}{l}3.62^{* * *} \\
(3.99)\end{array}$ \\
\hline MKT & $\begin{array}{c}1.29^{* * *} \\
(17.83)\end{array}$ & $\begin{array}{c}0.90^{* * *} \\
(16.75)\end{array}$ & $\begin{array}{c}0.82^{* * *} \\
(21.53)\end{array}$ & $\begin{array}{c}0.80^{* * *} \\
(19.28)\end{array}$ & $\begin{array}{c}1.40^{* * *} \\
(10.94)\end{array}$ & $\begin{array}{c}-0.11 \\
(-1.07)\end{array}$ & $\begin{array}{l}-0.33^{* *} \\
(-2.18)\end{array}$ & $\begin{array}{c}-0.17 \\
(-0.90)\end{array}$ \\
\hline SMB & $\begin{array}{l}0.07^{* *} \\
(2.39)\end{array}$ & $\begin{array}{c}0.08 \\
(1.05)\end{array}$ & $\begin{array}{l}-0.20^{* * *} \\
(-2.87)\end{array}$ & $\begin{array}{c}-0.14 \\
(-1.41)\end{array}$ & $\begin{array}{l}-0.29^{* * *} \\
(-3.77)\end{array}$ & $\begin{array}{l}0.36^{* * *} \\
(2.48)\end{array}$ & $\begin{array}{c}0.13 \\
(0.80)\end{array}$ & $\begin{array}{c}0.43 \\
(0.85)\end{array}$ \\
\hline HML & $\begin{array}{l}0.12^{* * *} \\
(2.57)\end{array}$ & $\begin{array}{c}0.12 \\
(1.47)\end{array}$ & $\begin{array}{c}0.09 \\
(1.57)\end{array}$ & $\begin{array}{c}0.14^{* *} \\
(2.07)\end{array}$ & $\begin{array}{l}0.45^{* * *} \\
(4.74)\end{array}$ & $\begin{array}{c}-0.33^{*} \\
(-1.85)\end{array}$ & $\begin{array}{l}-0.53^{* *} \\
(-2.12)\end{array}$ & $\begin{array}{c}-0.41 \\
(-0.76)\end{array}$ \\
\hline
\end{tabular}


Table VI: Returns on Stock Portfolios sorted by Credit Risk Premia excluding Financials and Utilities

We sort stocks based on firms' estimates of their credit risk premium $\left(\widehat{C R P}_{t+\tau}\right)$ into quintile portfolios and calculate equallyand value-weighted excess returns in Panel $A(B)$ excluding financial and utility firms. P1 contains firms with highest credit risk premia, P5 the ones with lowest. P1-P5 presents results for going long P1 and short P5. Portfolio Characteristics summarizes portfolio means of the market value $(M V)$, book-to-market $(B M)$, 5-year CDS spread (S5), credit rating (Rating), number of CDS contributors reported by Markit (Liquid), and conditional coskewness with the market portfolio (Coskew) following Harvey and Siddique (2000). We assign integer numbers to the S\&P credit ratings, i.e. AAA $=1$, AA+=2, .., C $=21$. Portfolio Returns reports monthly means and standard deviations of excess returns along with annualized Sharpe ratios. Asset Pricing reports alpha estimates of regressing excess returns on the market $(M K T)$, as well as the three $(M K T, S M B, H M L)$ and four $(M K T$, $S M B$, $H M L, U M D)$ Fama-French factors. Values in parentheses are $t$-statistics based on HAC standard errors using Newey and West (1987) with optimal truncation lag chosen as suggested by Andrews (1991). Results are based on a data set comprising joint observations of CDS spreads, stock prices, firm characteristics, and S\&P credit ratings for the full time period (01/2001-04/2010), the pre-crisis period (01/2001-06/2007) and the crisis period (07/2007-04/2010) excluding financial (SIC codes 6000-6999) and utility firms (SIC codes 4900-4999).

\begin{tabular}{|c|c|c|c|c|c|c|c|c|}
\hline & \multicolumn{6}{|c|}{ Full Period } & \multirow{2}{*}{$\begin{array}{c}\text { Pre-Crisis } \\
\text { P1-P5 }\end{array}$} & \multirow{2}{*}{$\begin{array}{l}\text { Crisis } \\
\text { P1-P5 }\end{array}$} \\
\hline & P1 & P2 & P3 & $\mathrm{P} 4$ & P5 & P1-P5 & & \\
\hline \multicolumn{9}{|c|}{ Sort Variable: Credit Risk Premium $\left(\widehat{R P}_{t+\tau}\right)$} \\
\hline mean & 28.46 & 4.93 & 1.33 & -1.80 & -26.12 & & & \\
\hline \multicolumn{9}{|c|}{ Portfolio Characteristics } \\
\hline$M V$ & 9.36 & 19.23 & 31.84 & 32.34 & 15.15 & & & \\
\hline$B M$ & 0.70 & 0.54 & 0.46 & 0.50 & 0.67 & & & \\
\hline$S 5$ & 261.14 & 100.87 & 65.79 & 71.86 & 199.98 & & & \\
\hline Rating & 10.21 & 8.16 & 7.15 & 7.43 & 9.43 & & & \\
\hline Liquid & 7.03 & 7.71 & 8.05 & 8.34 & 8.14 & & & \\
\hline Coskew & -3.58 & -3.47 & -3.85 & -4.24 & -3.12 & & & \\
\hline
\end{tabular}

Panel A: Equally-Weighted Portfolios

\begin{tabular}{|c|c|c|c|c|c|c|c|c|}
\hline mean & $\begin{array}{c}0.74 \\
(0.79)\end{array}$ & $\begin{array}{c}0.41 \\
(0.61)\end{array}$ & $\begin{array}{c}0.11 \\
(0.19)\end{array}$ & $\begin{array}{l}-0.10 \\
(-0.14)\end{array}$ & $\begin{array}{l}-1.62 \\
(-1.55)\end{array}$ & $\begin{array}{l}2.36^{* * *} \\
(5.21)\end{array}$ & $\begin{array}{l}2.66^{* * *} \\
(6.60)\end{array}$ & $\begin{array}{l}4.31^{* * *} \\
(3.55)\end{array}$ \\
\hline sd & 8.25 & 5.59 & 5.21 & 5.14 & 8.11 & 4.25 & 3.62 & 5.48 \\
\hline SR & 0.31 & 0.25 & 0.07 & -0.07 & -0.69 & 1.93 & 2.55 & 2.72 \\
\hline \multicolumn{9}{|c|}{ Asset Pricing } \\
\hline CAPM $\alpha$ & $\begin{array}{c}0.63^{*} \\
(1.93)\end{array}$ & $\begin{array}{c}0.33 \\
(1.63)\end{array}$ & $\begin{array}{c}0.04 \\
(0.18)\end{array}$ & $\begin{array}{c}-0.17 \\
(-0.80)\end{array}$ & $\begin{array}{l}-1.73^{* * *} \\
(-4.75)\end{array}$ & $\begin{array}{l}2.36^{* * *} \\
(5.33)\end{array}$ & $\begin{array}{l}2.68^{* * *} \\
(7.17)\end{array}$ & $\begin{array}{l}4.28^{* * *} \\
(3.07)\end{array}$ \\
\hline 3 -fac $\alpha$ & $\begin{array}{c}0.21 \\
(0.68)\end{array}$ & $\begin{array}{c}0.02 \\
(0.15)\end{array}$ & $\begin{array}{c}-0.12 \\
(-0.54)\end{array}$ & $\begin{array}{l}-0.39^{* *} \\
(-1.99)\end{array}$ & $\begin{array}{l}-2.16^{* * *} \\
(-7.69)\end{array}$ & $\begin{array}{l}2.38^{* * *} \\
(5.73)\end{array}$ & $\begin{array}{l}3.04^{* * *} \\
(6.72)\end{array}$ & $\begin{array}{l}4.05^{* * *} \\
(3.12)\end{array}$ \\
\hline 4 -fac $\alpha$ & $\begin{array}{c}0.26 \\
(0.87)\end{array}$ & $\begin{array}{c}0.03 \\
(0.16)\end{array}$ & $\begin{array}{l}-0.12 \\
(-0.68)\end{array}$ & $\begin{array}{l}-0.41^{* *} \\
(-2.17)\end{array}$ & $\begin{array}{l}-2.17^{* * *} \\
(-6.76)\end{array}$ & $\begin{array}{l}2.43^{* * *} \\
(6.35)\end{array}$ & $\begin{array}{l}3.05^{* * *} \\
(6.30)\end{array}$ & $\begin{array}{l}3.65^{\text {**** }} \\
(6.37)\end{array}$ \\
\hline MKT & $\begin{array}{c}1.43^{* * *} \\
(19.28)\end{array}$ & $\begin{array}{c}0.97^{* * *} \\
(16.02)\end{array}$ & $\begin{array}{c}0.96^{* * *} \\
(14.71)\end{array}$ & $\begin{array}{c}0.93^{* * *} \\
(16.38)\end{array}$ & $\begin{array}{l}1.45^{* * *} \\
(9.12)\end{array}$ & $\begin{array}{c}-0.02 \\
(-0.12)\end{array}$ & $\begin{array}{l}-0.26^{* *} \\
(-1.98)\end{array}$ & $\begin{array}{c}-0.16 \\
(-0.53)\end{array}$ \\
\hline SMB & $\begin{array}{l}0.48^{* * *} \\
(3.66)\end{array}$ & $\begin{array}{l}0.28^{* * *} \\
(5.67)\end{array}$ & $\begin{array}{c}0.03 \\
(0.48)\end{array}$ & $\begin{array}{c}0.06 \\
(0.50)\end{array}$ & $\begin{array}{l}0.21^{* * *} \\
(2.76)\end{array}$ & $\begin{array}{c}0.27^{* *} \\
(2.39)\end{array}$ & $\begin{array}{c}0.19 \\
(0.78)\end{array}$ & $\begin{array}{c}0.50^{* *} \\
(2.04)\end{array}$ \\
\hline HML & $\begin{array}{l}0.35^{* * *} \\
(3.52)\end{array}$ & $\begin{array}{l}0.32^{* *} \\
(2.26)\end{array}$ & $\begin{array}{l}0.25^{* * *} \\
(3.54)\end{array}$ & $\begin{array}{l}0.36^{* * *} \\
(5.83)\end{array}$ & $\begin{array}{l}0.61^{* * *} \\
(3.83)\end{array}$ & $\begin{array}{l}-0.26 \\
(-1.44)\end{array}$ & $\begin{array}{l}-0.49^{* * *} \\
(-4.58)\end{array}$ & $\begin{array}{c}-0.04 \\
(-0.30)\end{array}$ \\
\hline
\end{tabular}

Panel B: Value-Weighted Portfolios

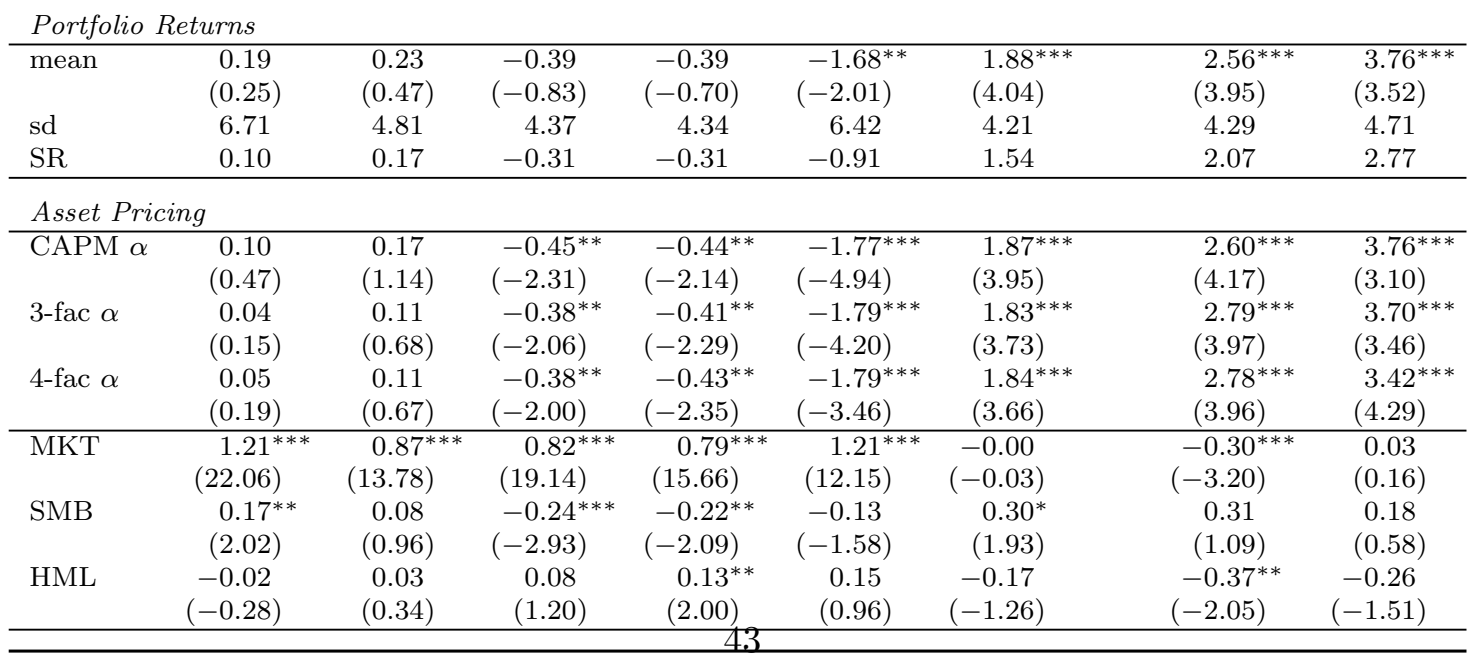




\section{Table VII: Returns on Stock Portfolios sorted by ATSM-Implied Credit Risk Premia}

We sort stocks based on firms' estimates of their ATSM credit risk premium $\left(\widehat{A R P}_{t}^{5}\right)$ calculated from model-implied 5-year CDS spreads under the $\mathbb{Q}$ - and $\mathbb{P}$-measure, respectively, into quintile portfolios and calculate equally- and value-weighted excess returns in Panel $A(B)$. P1 contains firms with highest ATSM-implied credit risk premia, P5 the ones with lowest. P1-P5 presents results for going long P1 and short P5. Portfolio Characteristics summarizes portfolio means of the market value ( $M V)$, book-to-market $(B M)$, 5-year CDS spread (S5), credit rating (Rating), number of CDS contributors reported by Markit (Liquid), and conditional coskewness with the market portfolio (Coskew) following Harvey and Siddique (2000). We assign integer numbers to the S\&P credit ratings, i.e. $\mathrm{AAA}=1, \mathrm{AA}+=2, \ldots, \mathrm{C}=21$. Portfolio Returns reports monthly means and standard deviations of excess returns along with annualized Sharpe ratios. Asset Pricing reports alpha estimates of regressing excess returns on the market ( $M K T)$, as well as the three $(M K T, S M B, H M L)$ and four $(M K T, S M B, H M L, U M D)$ Fama-French factors. Values in parentheses are $t$-statistics based on HAC standard errors using Newey and West (1987) with optimal truncation lag chosen as suggested by Andrews (1991). Results are based on a data set comprising joint observations of CDS spreads, stock prices, firm characteristics, and S\&P credit ratings for the full time period (01/2001-04/2010).

\begin{tabular}{|c|c|c|c|c|c|c|}
\hline & $\overline{\mathrm{P} 1}$ & $\overline{\mathrm{P} 2}$ & P3 & $\mathrm{P} 4$ & $\mathrm{P} 5$ & $\overline{\mathrm{P} 1-\mathrm{P} 5}$ \\
\hline \multicolumn{7}{|c|}{ Sort Variable: ATSM-Implied Credit Risk Premium $\left(\widehat{A R P}_{t}^{5}\right)$} \\
\hline mean & 109.43 & 6.64 & -28.01 & -58.91 & -83.68 & \\
\hline \multicolumn{7}{|c|}{ Portfolio Characteristics } \\
\hline$M V$ & 24.83 & 22.34 & 22.09 & 17.41 & 13.56 & \\
\hline$B M$ & 0.60 & 0.69 & 0.71 & 0.64 & 0.62 & \\
\hline$S 5$ & 105.01 & 148.38 & 139.03 & 160.46 & 152.58 & \\
\hline Rating & 7.45 & 8.17 & 8.16 & 8.78 & 9.09 & \\
\hline Liquid & 6.92 & 7.71 & 7.51 & 7.54 & 7.57 & \\
\hline Coskew & -3.42 & -4.14 & -5.22 & -3.74 & -1.91 & \\
\hline
\end{tabular}

Panel A: Equally-Weighted Portfolios

\begin{tabular}{|c|c|c|c|c|c|c|}
\hline mean & $\begin{array}{c}0.10 \\
(0.18)\end{array}$ & $\begin{array}{c}-0.30 \\
(-0.37)\end{array}$ & $\begin{array}{c}-0.02 \\
(-0.02)\end{array}$ & $\begin{array}{c}-0.17 \\
(-0.22)\end{array}$ & $\begin{array}{c}-0.36 \\
(-0.41)\end{array}$ & $\begin{array}{c}0.47^{*} \\
(1.67)\end{array}$ \\
\hline $\mathrm{sd}$ & 4.96 & 6.54 & 6.66 & 6.41 & 6.48 & 2.93 \\
\hline SR & 0.07 & -0.16 & -0.01 & -0.09 & -0.19 & 0.55 \\
\hline \multicolumn{7}{|c|}{ Asset Pricing } \\
\hline CAPM $\alpha$ & $\begin{array}{c}0.03 \\
(0.15)\end{array}$ & $\begin{array}{l}-0.39^{*} \\
(-1.88)\end{array}$ & $\begin{array}{l}-0.11 \\
(-0.55)\end{array}$ & $\begin{array}{c}-0.26 \\
(-1.10)\end{array}$ & $\begin{array}{c}-0.45 \\
(-1.63)\end{array}$ & $\begin{array}{c}0.48^{* *} \\
(2.28)\end{array}$ \\
\hline 3 -fac $\alpha$ & $\begin{array}{c}-0.19 \\
(-1.14)\end{array}$ & $\begin{array}{l}-0.72^{* * *} \\
(-5.06)\end{array}$ & $\begin{array}{l}-0.44^{* * *} \\
(-3.50)\end{array}$ & $\begin{array}{l}-0.59^{* * *} \\
(-3.16)\end{array}$ & $\begin{array}{l}-0.88^{* * *} \\
(-5.98)\end{array}$ & $\begin{array}{l}0.69^{* * * *} \\
(2.63)\end{array}$ \\
\hline 4 -fac $\alpha$ & $\begin{array}{c}-0.20 \\
(-1.18)\end{array}$ & $\begin{array}{l}-0.71^{* * *} \\
(-4.58)\end{array}$ & $\begin{array}{l}-0.42^{* * *} \\
(-2.64)\end{array}$ & $\begin{array}{l}-0.58^{* * *} \\
(-2.83)\end{array}$ & $\begin{array}{l}-0.88^{* * *} \\
(-4.20)\end{array}$ & $\begin{array}{c}0.68^{* *} \\
(2.44)\end{array}$ \\
\hline MKT & $\begin{array}{c}0.91^{* * *} \\
(15.95)\end{array}$ & $\begin{array}{c}1.23^{* * *} \\
(18.30)\end{array}$ & $\begin{array}{c}1.24^{* * *} \\
(25.88)\end{array}$ & $\begin{array}{c}1.19^{* * *} \\
(21.17)\end{array}$ & $\begin{array}{c}1.13^{* * *} \\
(10.55)\end{array}$ & $\begin{array}{l}-0.22^{* * *} \\
(-2.80)\end{array}$ \\
\hline SMB & $\begin{array}{c}0.11^{* *} \\
(1.95)\end{array}$ & $\begin{array}{l}0.10^{* *} \\
(2.43)\end{array}$ & $\begin{array}{l}0.18^{* * *} \\
(3.28)\end{array}$ & $\begin{array}{l}0.24^{* * *} \\
(5.27)\end{array}$ & $\begin{array}{l}0.34^{* * *} \\
(6.36)\end{array}$ & $\begin{array}{l}-0.23^{* *} \\
(-2.36)\end{array}$ \\
\hline HML & $\begin{array}{l}0.32^{* * *} \\
(4.65)\end{array}$ & $\begin{array}{c}0.51^{* * *} \\
(11.16)\end{array}$ & $\begin{array}{c}0.44^{* * *} \\
(11.42)\end{array}$ & $\begin{array}{l}0.38^{* * *} \\
(6.27)\end{array}$ & $\begin{array}{l}0.49^{* * *} \\
(4.22)\end{array}$ & $\begin{array}{l}-0.18^{* *} \\
(-2.26)\end{array}$ \\
\hline
\end{tabular}

Panel B: Value-Weighted Portfolios

\begin{tabular}{|c|c|c|c|c|c|c|}
\hline \multicolumn{7}{|c|}{ Portfolio Returns } \\
\hline \multirow[t]{2}{*}{ mean } & -0.13 & -0.59 & -0.50 & -0.68 & -0.75 & $0.62^{*}$ \\
\hline & $(-0.31)$ & $(-0.97)$ & $(-0.73)$ & $(-1.04)$ & $(-1.08)$ & $(1.78)$ \\
\hline sd & 3.75 & 5.13 & 5.61 & 5.26 & 5.52 & 2.95 \\
\hline $\mathrm{SR}$ & -0.12 & -0.40 & -0.31 & -0.44 & -0.47 & 0.73 \\
\hline \multicolumn{7}{|c|}{ Asset Pricing } \\
\hline \multirow[t]{2}{*}{ CAPM $\alpha$} & $-0.18^{*}$ & $-0.66^{* * *}$ & $-0.58^{* * *}$ & $-0.75^{* * *}$ & $-0.83^{* * *}$ & $0.65^{* * *}$ \\
\hline & $(-1.91)$ & $(-3.83)$ & $(-3.10)$ & $(-3.90)$ & $(-4.03)$ & $(3.27)$ \\
\hline \multirow[t]{2}{*}{3 -fac $\alpha$} & $-0.15^{* *}$ & $-0.73^{* * *}$ & $-0.67^{* * *}$ & $-0.76^{* * *}$ & $-0.91^{* * *}$ & $0.76^{* * *}$ \\
\hline & $(-2.08)$ & $(-4.59)$ & $(-3.60)$ & $(-4.06)$ & $(-4.44)$ & $(3.46)$ \\
\hline \multirow[t]{2}{*}{4 -fac $\alpha$} & -0.16 & $-0.73^{* * *}$ & $-0.67^{* * *}$ & $-0.78^{* * *}$ & $-0.92^{* * *}$ & $0.76^{* * *}$ \\
\hline & $(-1.32)$ & $(-4.52)$ & $(-2.94)$ & $(-4.37)$ & $(-5.90)$ & $(3.84)$ \\
\hline \multirow[t]{2}{*}{$\mathrm{MKT}$} & $0.74^{* * *}$ & $1.01^{* * *}$ & $1.09^{* * *}$ & $1.01^{* * *}$ & $1.03^{* * *}$ & $-0.29^{* * *}$ \\
\hline & $(27.54)$ & $(19.57)$ & $(15.67)$ & $(15.84)$ & $(8.57)$ & $(-2.96)$ \\
\hline \multirow[t]{2}{*}{ SMB } & $-0.23^{* * *}$ & $-0.19^{* * *}$ & -0.12 & -0.06 & -0.01 & $-0.22^{* *}$ \\
\hline & $(-11.76)$ & $(-5.15)$ & $(-1.43)$ & $(-0.87)$ & $(-0.17)$ & $(-2.27)$ \\
\hline \multirow[t]{2}{*}{ HML } & $0.14^{* *}$ & $0.27^{* * *}$ & $0.27^{* * *}$ & 0.07 & 0.15 & -0.01 \\
\hline & $(2.16)$ & $(3.23)$ & $(3.09)$ & $(0.98)$ & $(1.31)$ & $(-0.18)$ \\
\hline
\end{tabular}


Table VIII: Returns on Stock Portfolios sorted by Credit Risk Premia: Controlling for Size and Book-to-Market

We double-sort stocks first into three size $(M V)$ portfolios in Panel $A$ and book-to-market $(B M)$ portfolios in Panel $B$, then each of them into tercile portfolios based on firms' credit risk premia $\left(\widehat{R P}_{t+\tau}\right)$ and calculate equally- and value-weighted excess returns in Sub-Panel (1) and (2), respectively. In Panel A, P1.* contains small, P2.* medium and P3.* big firms. P*.1 contains for the respective size portfolio the firms with highest credit risk premia, $\mathrm{P}^{*} .3$ with lowest credit risk premia. In Panel $B$, P1.* contains value (high $B M), \mathrm{P} 2 .^{*}$ neutral, P3.* growth stocks. $\mathrm{P}^{*} .1$ contains for the respective book-to-market portfolio the firms with highest credit risk premia, $\mathrm{P}^{*} .3$ with lowest credit risk premia. $\mathrm{P}^{*} .1-\mathrm{P}^{*} .3$ presents results for going long $\mathrm{P}^{*} .1$ and short $\mathrm{P}^{*} .3$. Portfolio Returns reports monthly means and standard deviations of excess returns along with annualized Sharpe ratios. Values in parentheses are $t$-statistics based on HAC standard errors using Newey and West (1987) with optimal truncation lag chosen as suggested by Andrews (1991). Results are based on a data set comprising joint observations of CDS spreads, stock prices, firm characteristics, and S\&P credit ratings for the full time period (01/2001-04/2010).

Panel A: Size

\begin{tabular}{lccc}
\hline & $\mathrm{P} 1.1-\mathrm{P} 1.3$ & $\mathrm{P} 2.1-\mathrm{P} 2.3$ & $\mathrm{P} 3.1-\mathrm{P} 3.3$ \\
\hline Sort Variables & & & \\
\hline mean $M V$ & 2.88 & 9.53 & 52.55 \\
mean $\widehat{R P}_{t+\tau}$ & 1.50 & 1.36 & 0.43 \\
\hline
\end{tabular}

(1) Equally-Weighted Portfolios

\begin{tabular}{lccc} 
Portfolio Returns & \multicolumn{3}{l}{} \\
\hline mean & $2.83^{* * *}$ & $1.36^{* * *}$ & $0.88^{* * *}$ \\
& $(4.02)$ & $(4.05)$ & $(2.97)$ \\
sd & 5.44 & 3.45 & 3.13 \\
SR & 1.80 & 1.36 & 0.98 \\
\hline \multirow{2}{*}{ Asset Pricing } & & & \\
\hline CAPM $\alpha$ & $2.84^{* * *}$ & $1.38^{* * *}$ & $0.88^{* * *}$ \\
& $(4.34)$ & $(4.23)$ & $(2.73)$ \\
3-fac $\alpha$ & $3.10^{* * *}$ & $1.33^{* * *}$ & $0.97^{* * *}$ \\
& $(5.87)$ & $(4.50)$ & $(3.32)$ \\
4-fac $\alpha$ & $3.16^{* * *}$ & $1.35^{* * *}$ & $0.98^{* * *}$ \\
& $(6.75)$ & $(4.74)$ & $(3.57)$ \\
\hline MKT & -0.11 & $-0.17^{*}$ & 0.07 \\
& $(-0.43)$ & $(-1.91)$ & $(1.01)$ \\
SMB & 0.04 & 0.14 & $0.16^{*}$ \\
& $(0.39)$ & $(1.54)$ & $(1.73)$ \\
HML & $-0.50^{*}$ & -0.03 & $-0.30^{* * *}$ \\
& $(-1.85)$ & $(-0.28)$ & $(-2.61)$ \\
\hline
\end{tabular}

(2) Value-Weighted Portfolios

\begin{tabular}{lccc} 
Portfolio Returns & & \\
\hline mean & $2.65^{* * *}$ & $1.33^{* * *}$ & $0.61^{* *}$ \\
& $(3.67)$ & $(4.30)$ & $(2.01)$ \\
sd & 5.24 & 3.53 & 3.22 \\
SR & 1.76 & 1.31 & 0.66 \\
\hline \multirow{2}{*}{ Asset Pricing } & & & \\
\hline CAPM $\alpha$ & $2.66^{* * *}$ & $1.36^{* * *}$ & $0.60^{*}$ \\
\multirow{2}{*}{ 3-fac $\alpha$} & $(3.59)$ & $(4.22)$ & $(1.93)$ \\
& $2.85^{* * *}$ & $1.29^{* * *}$ & $0.70^{* * *}$ \\
4-fac $\alpha$ & $(4.25)$ & $(4.36)$ & $(2.64)$ \\
& $2.91^{* * *}$ & $1.31^{* * *}$ & $0.70^{* *}$ \\
\hline MKT & $(5.41)$ & $(4.87)$ & $(2.21)$ \\
& -0.16 & $-0.20^{* *}$ & 0.10 \\
SMB & $(-0.75)$ & $(-2.29)$ & $(1.27)$ \\
& 0.16 & $0.17^{*}$ & 0.18 \\
HML & $(1.43)$ & $(1.81)$ & $(1.59)$ \\
& $-0.46^{* *}$ & -0.03 & $-0.31^{* * *}$ \\
\hline
\end{tabular}

Panel B: Book-to-Market

\begin{tabular}{lccc}
\hline & $\mathrm{P} 1.1-\mathrm{P} 1.3$ & $\mathrm{P} 2.1-\mathrm{P} 2.3$ & $\mathrm{P} 3.1-\mathrm{P} 3.3$ \\
\hline Sort Variables & & & \\
\hline mean $B M$ & 1.18 & 0.52 & 0.24 \\
mean $\widehat{R P}_{t+\tau}$ & -0.43 & 2.28 & 1.43 \\
\hline
\end{tabular}

(1) Equally-Weighted Portfolios

\begin{tabular}{lccc}
\multicolumn{3}{l}{ Portfolio Returns } & \multicolumn{3}{l}{} \\
\hline mean & $2.48^{* * *}$ & $1.09^{* * *}$ & $1.70^{* * *}$ \\
& $(3.29)$ & $(3.42)$ & $(3.22)$ \\
sd & 5.06 & 2.85 & 4.02 \\
SR & 1.70 & 1.33 & 1.46 \\
\hline \multirow{2}{*}{ Asset Pricing } & & & \\
\hline CAPM $\alpha$ & $2.50^{* * *}$ & $1.08^{* * *}$ & $1.70^{* * *}$ \\
& $(3.28)$ & $(3.28)$ & $(3.26)$ \\
3-fac $\alpha$ & $2.68^{* * *}$ & $0.99^{* * *}$ & $1.60^{* * *}$ \\
& $(3.94)$ & $(3.08)$ & $(3.86)$ \\
4-fac $\alpha$ & $2.74^{* * *}$ & $1.01^{* * *}$ & $1.63^{* * *}$ \\
& $(6.11)$ & $(2.63)$ & $(4.18)$ \\
\hline MKT & -0.27 & 0.04 & -0.04 \\
& $(-1.42)$ & $(0.43)$ & $(-0.38)$ \\
SMB & $0.24^{*}$ & $0.17^{*}$ & $0.27^{* *}$ \\
& $(1.94)$ & $(1.77)$ & $(2.19)$ \\
HML & $-0.52^{* * *}$ & 0.01 & -0.06 \\
& $(-3.86)$ & $(0.10)$ & $(-0.45)$ \\
& & &
\end{tabular}

(2) Value-Weighted Portfolios

\begin{tabular}{lccc}
\multicolumn{3}{l}{ Portfolio Returns } & \\
\hline mean & $2.02^{* *}$ & $0.90^{* *}$ & $0.84^{* *}$ \\
& $(2.25)$ & $(2.32)$ & $(2.22)$ \\
sd & 6.38 & 3.65 & 3.73 \\
SR & 1.10 & 0.85 & 0.78 \\
\hline \multirow{2}{*}{ Asset Pricing } & & & \\
\hline CAPM $\alpha$ & $2.04^{*}$ & $0.89^{* *}$ & $0.83^{* *}$ \\
& $(1.81)$ & $(2.28)$ & $(2.19)$ \\
3-fac $\alpha$ & $2.06^{* *}$ & $0.78^{* *}$ & $0.86^{* * *}$ \\
& $(2.17)$ & $(1.94)$ & $(2.55)$ \\
4-fac $\alpha$ & $2.12^{* * *}$ & $0.79^{*}$ & $0.86^{* * *}$ \\
& $(3.25)$ & $(1.94)$ & $(2.52)$ \\
\hline MKT & -0.29 & 0.00 & 0.06 \\
& $(-1.25)$ & $(0.01)$ & $(0.93)$ \\
SMB & $0.45^{* *}$ & 0.19 & 0.21 \\
& $(2.10)$ & $(1.45)$ & $(1.57)$ \\
HML & $-0.42^{*}$ & 0.06 & $-0.24^{* * *}$ \\
& $(-1.79)$ & $(0.42)$ & $(-2.72)$ \\
\hline
\end{tabular}


Table IX:

Returns on Stock Portfolios sorted by Credit Risk Premia: Controlling for Credit Rating and CDS Spread

We double-sort stocks first into three portfolios based on their physical default probability measured by the S\&P credit rating (Rating) in Panel $A$ and on their risk-neutral default probability measured by the 5-year CDS spread (S5) in Panel B. We then sort each of them into tercile portfolios based on firms' credit risk premia $\left(\widehat{R P}_{t+\tau}\right)$ and calculate equally- and value-weighted excess returns in Sub-Panel (1) and (2), respectively. In Panel A, P1.* contains stocks of firms with lowest credit ratings, P2.* with medium and P3.* with highest. $\mathrm{P}^{*} .1$ contains for the respective credit rating portfolio the firms with highest credit risk premia, $\mathrm{P}^{*} .3$ with lowest credit risk premia. We assign integer numbers to the credit ratings, i.e. AAA $=1, \mathrm{AA}+=2, \ldots, \mathrm{C}=21 . \mathrm{In}$ Panel $B, \mathrm{P} 1{ }^{*}$ contains stocks of firms with highest 5 -year CDS spreads, P2.* with medium and P3.* with lowest. ${ }^{*} .1$ contains for the respective 5-year CDS spread portfolio the firms with highest credit risk premia, $\mathrm{P}^{*} .3$ with lowest credit risk premia. $\mathrm{P}^{*} .1-\mathrm{P}^{*} .3$ presents results for going long $\mathrm{P}^{*} .1$ and short $\mathrm{P}^{*} .3$. Portfolio Returns reports monthly means and standard deviations of excess returns along with annualized Sharpe ratios. Asset Pricing reports alpha estimates of regressing excess returns on the market $(M K T)$, as well as the three $(M K T, S M B, H M L)$ and four $(M K T, S M B, H M L, U M D)$ Fama-French factors. Values in parentheses are $t$-statistics based on HAC standard errors using Newey and West (1987) with optimal truncation lag chosen as suggested by Andrews (1991). Results are based on a data set comprising joint observations of CDS spreads, stock prices, firm characteristics, and S\&P credit ratings for the full time period (01/2001-04/2010).

Panel A: Credit Rating

\begin{tabular}{lrcc}
\hline & $\mathrm{P} 1.1-\mathrm{P} 1.3$ & $\mathrm{P} 2.1-\mathrm{P} 2.3$ & $\mathrm{P} 3.1-\mathrm{P} 3.3$ \\
\hline Sort Variables & & & \\
\hline mean Rating & 11.72 & 8.75 & 5.61 \\
mean $\widehat{R P}_{t+\tau}$ & 3.27 & 1.04 & -0.27 \\
\hline
\end{tabular}

(1) Equally-Weighted Portfolios

\begin{tabular}{lccc}
\multicolumn{4}{l}{ Portfolio Returns } \\
mean & $2.90^{* * *}$ & $1.43^{* * *}$ & $1.24^{* * *}$ \\
& $(4.62)$ & $(3.19)$ & $(2.76)$ \\
sd & 5.91 & 3.65 & 3.51 \\
SR & 1.70 & 1.36 & 1.22 \\
\hline \multirow{2}{*}{ Asset Pricing } & & & \\
\hline CAPM $\alpha$ & $2.91^{* * *}$ & $1.42^{* * *}$ & $1.25^{* * *}$ \\
& $(5.55)$ & $(3.24)$ & $(3.04)$ \\
3-fac $\alpha$ & $3.21^{* * *}$ & $1.37^{* * *}$ & $1.39^{* * *}$ \\
& $(7.04)$ & $(2.92)$ & $(3.71)$ \\
4-fac $\alpha$ & $3.27^{* * *}$ & $1.40^{* * *}$ & $1.40^{* * *}$ \\
& $(8.67)$ & $(3.37)$ & $(4.02)$ \\
\hline MKT & -0.08 & 0.06 & $-0.18^{* *}$ \\
& $(-0.33)$ & $(0.42)$ & $(-2.36)$ \\
SMB & 0.12 & 0.11 & 0.11 \\
& $(0.69)$ & $(0.99)$ & $(1.00)$ \\
HML & $-0.71^{* * *}$ & -0.01 & $-0.34^{* * *}$ \\
& $(-3.21)$ & $(-0.05)$ & $(-2.88)$ \\
\hline
\end{tabular}

(2) Value-Weighted Portfolios

\begin{tabular}{lccc}
\multicolumn{4}{l}{ Portfolio Returns } \\
mean & $2.15^{* * *}$ & $1.42^{* * *}$ & $0.72^{* *}$ \\
& $(3.30)$ & $(2.70)$ & $(2.27)$ \\
sd & 6.19 & 4.02 & 3.12 \\
SR & 1.21 & 1.22 & 0.80 \\
\hline \multirow{2}{*}{ Asset Pricing } & & & \\
\hline CAPM $\alpha$ & $2.16^{* * *}$ & $1.41^{* * *}$ & $0.72^{* *}$ \\
& $(3.83)$ & $(2.58)$ & $(2.17)$ \\
3-fac $\alpha$ & $2.58^{* * *}$ & $1.30^{* *}$ & $0.76^{* * *}$ \\
& $(4.74)$ & $(2.03)$ & $(2.57)$ \\
4-fac $\alpha$ & $2.64^{* * *}$ & $1.32^{* * *}$ & $0.76^{* * *}$ \\
& $(5.50)$ & $(2.57)$ & $(2.63)$ \\
\hline MKT & -0.03 & 0.04 & 0.01 \\
& $(-0.11)$ & $(0.36)$ & $(0.09)$ \\
SMB & 0.04 & 0.15 & $0.21^{*}$ \\
& $(0.19)$ & $(1.49)$ & $(1.73)$ \\
HML & $-0.89^{* * *}$ & 0.08 & $-0.25^{* * *}$ \\
& $(-4.13)$ & $(0.33)$ & $(-2.73)$ \\
\hline
\end{tabular}

Panel B: 5-Year CDS Spread

\begin{tabular}{|c|c|c|c|}
\hline & P1.1-P1.3 & P2.1-P2.3 & P3.1-P3.3 \\
\hline \multicolumn{4}{|c|}{ Sort Variables } \\
\hline mean $S 5$ & 301.67 & 77.51 & 35.52 \\
\hline mean $\widehat{R P}_{t+\tau}$ & 2.51 & 0.38 & 0.43 \\
\hline
\end{tabular}

(1) Equally-Weighted Portfolios

\begin{tabular}{lccc} 
Portfolio Returns & & \\
\hline mean & $3.11^{* * *}$ & $0.86^{* * *}$ & 0.19 \\
& $(4.14)$ & $(2.73)$ & $(0.85)$ \\
sd & 5.79 & 3.47 & 2.45 \\
SR & 1.86 & 0.85 & 0.27 \\
\hline \multirow{2}{*}{ Asset Pricing } & & & \\
\hline CAPM $\alpha$ & $3.13^{* * *}$ & $0.88^{* * *}$ & 0.18 \\
& $(4.12)$ & $(3.01)$ & $(0.65)$ \\
3-fac $\alpha$ & $3.55^{* * *}$ & $0.70^{* * *}$ & 0.29 \\
& $(6.91)$ & $(7.80)$ & $(1.40)$ \\
4-fac $\alpha$ & $3.61^{* * *}$ & $0.70^{*}$ & 0.29 \\
& $(7.72)$ & $(1.91)$ & $(1.03)$ \\
\hline MKT & -0.22 & $-0.18^{* *}$ & 0.05 \\
& $(-1.05)$ & $(-2.40)$ & $(0.96)$ \\
SMB & 0.09 & $0.27^{* * *}$ & 0.06 \\
& $(0.76)$ & $(5.36)$ & $(0.58)$ \\
HML & $-0.83^{* * *}$ & 0.11 & $-0.25^{* * *}$ \\
& $(-3.86)$ & $(0.94)$ & $(-3.19)$ \\
\hline
\end{tabular}

(2) Value-Weighted Portfolios

\begin{tabular}{lccc}
\multicolumn{4}{l}{ Portfolio Returns } \\
mean & $2.46^{* * *}$ & $1.27^{* * *}$ & 0.00 \\
& $(3.58)$ & $(3.36)$ & $(0.01)$ \\
sd & 6.76 & 4.54 & 2.74 \\
SR & 1.26 & 0.97 & 0.00 \\
\hline \multirow{2}{*}{ Asset Pricing } & & & \\
\hline CAPM $\alpha$ & $2.47^{* * *}$ & $1.29^{* * *}$ & -0.00 \\
& $(3.80)$ & $(3.69)$ & $(-0.01)$ \\
3-fac $\alpha$ & $2.85^{* * *}$ & $1.12^{* * *}$ & 0.18 \\
& $(3.66)$ & $(3.35)$ & $(0.78)$ \\
4-fac $\alpha$ & $2.88^{* * *}$ & $1.12^{* * *}$ & 0.17 \\
& $(4.84)$ & $(2.49)$ & $(0.72)$ \\
\hline MKT & $-0.21^{* * *}$ & $-0.18^{*}$ & 0.06 \\
& $(-4.33)$ & $(-1.71)$ & $(0.91)$ \\
SMB & $0.32^{* * *}$ & $0.37^{* * *}$ & 0.05 \\
& $(3.83)$ & $(4.99)$ & $(0.34)$ \\
HML & $-0.96^{* * *}$ & -0.01 & $-0.37^{* * *}$ \\
& $(-5.02)$ & $(-0.05)$ & $(-4.60)$ \\
\hline
\end{tabular}


Table X: Returns on Stock Portfolios sorted by Credit Risk Premia: Controlling for Liquidity and Coskewness

We double-sort stocks first into three portfolios based on their liquidity measured by the number of CDS contributors reported by Markit (Liquid) in Panel A and on their coskewness with the market portfolio (Coskew) in Panel B. We then sort each of them into tercile portfolios based on firms' credit risk premia $\left(\widehat{R P}_{t+\tau}\right)$ and calculate equally- and value-weighted excess returns in Sub-Panel (1) and (2), respectively. In Panel $A, \mathrm{P} 1 .^{*}$ contains stocks of firms with lowest numbers of contributors, P2.* with medium and P3.* with highest. $\mathrm{P}^{*} .1$ contains for the respective liquidity portfolio the firms with highest credit risk premia, $\mathrm{P}^{*} .3$ with lowest credit risk premia. In Panel B, P1.* contains stocks of firms with lowest coskewness, P2.* with medium and P3.* with highest. $\mathrm{P}^{*} .1$ contains for the respective coskewness portfolio the firms with highest credit risk premia, $\mathrm{P}^{*} .3$ with lowest credit risk premia. $\mathrm{P}^{*} .1-\mathrm{P}^{*} .3$ presents results for going long $\mathrm{P}^{*} .1$ and short $\mathrm{P}^{*} .3$. Portfolio Returns reports monthly means and standard deviations of excess returns along with annualized Sharpe ratios. Asset Pricing reports alpha estimates of regressing excess returns on the market $(M K T)$, as well as the three $(M K T, S M B, H M L)$ and four ( $M K T, S M B, H M L, U M D)$ Fama-French factors. Values in parentheses are $t$-statistics based on HAC standard errors using Newey and West (1987) with optimal truncation lag chosen as suggested by Andrews (1991). Results are based on a data set comprising joint observations of CDS spreads, stock prices, firm characteristics, and S\&P credit ratings for the full time period $(01 / 2001-04 / 2010)$.

Panel A: Liquidity

\begin{tabular}{|c|c|c|c|}
\hline & P1.1-P1.3 & P2.1-P2.3 & P3.1-P3.3 \\
\hline \multicolumn{4}{|l|}{ Sort Variables } \\
\hline mean Liquid & 4.10 & 8.26 & 12.73 \\
\hline mean $\widehat{R P}_{t+\tau}$ & 2.12 & 0.43 & 0.68 \\
\hline
\end{tabular}

(1) Equally-Weighted Portfolios

\begin{tabular}{lccc} 
Portfolio Returns & \multicolumn{3}{l}{} \\
\hline mean & $1.53^{* * *}$ & $1.87^{* * *}$ & $2.31^{* * *}$ \\
& $(6.38)$ & $(2.50)$ & $(3.28)$ \\
sd & 3.23 & 4.53 & 4.25 \\
SR & 1.64 & 1.42 & 1.89 \\
\hline \multirow{2}{*}{ Asset Pricing } & & & \\
\hline CAPM $\alpha$ & $1.54^{* * *}$ & $1.89^{* *}$ & $2.34^{* * *}$ \\
& $(5.91)$ & $(2.30)$ & $(4.42)$ \\
3-fac $\alpha$ & $1.34^{* * *}$ & $1.93^{* * *}$ & $2.42^{* * *}$ \\
& $(5.05)$ & $(2.48)$ & $(3.96)$ \\
4-fac $\alpha$ & $1.36^{* * *}$ & $1.99^{* * *}$ & $2.46^{* * *}$ \\
& $(5.18)$ & $(4.09)$ & $(4.32)$ \\
\hline MKT & -0.09 & $-0.14^{*}$ & -0.16 \\
& $(-0.85)$ & $(-1.94)$ & $(-0.73)$ \\
SMB & $0.37^{* * *}$ & 0.09 & 0.07 \\
& $(3.46)$ & $(0.60)$ & $(0.71)$ \\
HML & 0.06 & -0.21 & -0.26 \\
& $(0.33)$ & $(-1.36)$ & $(-0.93)$ \\
\hline
\end{tabular}

(2) Value-Weighted Portfolios

\begin{tabular}{lccc}
\multicolumn{4}{l}{ Portfolio Returns } \\
\hline mean & $0.96^{* * *}$ & $1.20^{* * *}$ & $1.73^{* * *}$ \\
& $(3.35)$ & $(2.56)$ & $(3.16)$ \\
sd & 3.33 & 4.08 & 4.79 \\
SR & 1.00 & 1.02 & 1.25 \\
\hline \multirow{2}{*}{ Asset Pricing } & & & \\
\hline CAPM $\alpha$ & $0.95^{* * *}$ & $1.21^{* *}$ & $1.73^{* * *}$ \\
& $(3.20)$ & $(2.27)$ & $(3.05)$ \\
3-fac $\alpha$ & $0.67^{* *}$ & $1.11^{* *}$ & $1.70^{* *}$ \\
& $(2.33)$ & $(2.42)$ & $(2.43)$ \\
4-fac $\alpha$ & $0.66^{* *}$ & $1.12^{* *}$ & $1.74^{* * *}$ \\
& $(2.42)$ & $(2.47)$ & $(3.23)$ \\
\hline MKT & -0.04 & -0.06 & -0.07 \\
& $(-0.40)$ & $(-0.52)$ & $(-0.43)$ \\
SMB & $0.48^{* * *}$ & 0.09 & $0.23^{* *}$ \\
& $(3.32)$ & $(0.49)$ & $(2.39)$ \\
HML & 0.14 & 0.14 & -0.16 \\
& $(1.03)$ & $(1.32)$ & $(-0.69)$ \\
\hline
\end{tabular}

Panel B: Coskewness

\begin{tabular}{lrrr}
\hline & P1.1-P1.3 & P2.1-P2.3 & P3.1-P3.3 \\
\hline Sort Variables & & & \\
\hline mean Coskew & -41.43 & -3.99 & 34.12 \\
mean $\widehat{R P}_{t+\tau}$ & 1.30 & 0.11 & 1.64 \\
\hline
\end{tabular}

(1) Equally-Weighted Portfolios

\begin{tabular}{lccc} 
Portfolio Returns & \multicolumn{3}{l}{} \\
\hline mean & $1.82^{* * *}$ & $1.72^{* * *}$ & $1.41^{* * *}$ \\
& $(3.63)$ & $(3.21)$ & $(2.85)$ \\
sd & 3.99 & 4.04 & 3.94 \\
SR & 1.58 & 1.48 & 1.24 \\
\hline \multirow{2}{*}{ Asset Pricing } & & & \\
\hline CAPM $\alpha$ & $1.84^{* * *}$ & $1.77^{* * *}$ & $1.39^{* *}$ \\
& $(3.62)$ & $(3.24)$ & $(2.44)$ \\
3-fac $\alpha$ & $1.83^{* * *}$ & $1.69^{* * *}$ & $1.32^{* *}$ \\
& $(3.97)$ & $(3.13)$ & $(2.42)$ \\
4-fac $\alpha$ & $1.86^{* * *}$ & $1.72^{* * *}$ & $1.35^{* * *}$ \\
& $(4.57)$ & $(3.84)$ & $(3.02)$ \\
\hline MKT & -0.11 & -0.23 & 0.04 \\
& $(-0.43)$ & $(-1.51)$ & $(0.26)$ \\
SMB & $0.27^{*}$ & 0.20 & $0.28^{*}$ \\
& $(1.90)$ & $(1.12)$ & $(1.83)$ \\
HML & -0.23 & 0.06 & -0.07 \\
& $(-1.23)$ & $(0.26)$ & $(-0.33)$ \\
\hline
\end{tabular}

(2) Value-Weighted Portfolios

\begin{tabular}{lccc} 
Portfolio Returns & \multicolumn{3}{l}{} \\
\hline mean & $1.06^{* * *}$ & $0.70^{*}$ & $1.21^{* * *}$ \\
& $(2.98)$ & $(1.85)$ & $(2.49)$ \\
sd & 3.62 & 3.62 & 4.39 \\
SR & 1.01 & 0.67 & 0.96 \\
\hline \multirow{2}{*}{ Asset Pricing } & & & \\
\hline CAPM $\alpha$ & $1.04^{* * *}$ & 0.67 & $1.17^{* *}$ \\
& $(2.81)$ & $(1.65)$ & $(2.38)$ \\
3-fac $\alpha$ & $0.97^{* * *}$ & 0.54 & $1.01^{* *}$ \\
& $(2.81)$ & $(1.35)$ & $(1.97)$ \\
4-fac $\alpha$ & $0.98^{* * *}$ & 0.57 & $1.03^{* *}$ \\
& $(2.97)$ & $(1.43)$ & $(2.17)$ \\
\hline MKT & 0.04 & 0.04 & 0.07 \\
& $(0.34)$ & $(0.31)$ & $(0.47)$ \\
SMB & 0.21 & $0.38^{* *}$ & $0.44^{* *}$ \\
& $(1.51)$ & $(1.98)$ & $(2.36)$ \\
HML & -0.02 & -0.00 & 0.04 \\
& $(-0.18)$ & $(-0.00)$ & $(0.18)$ \\
\hline
\end{tabular}




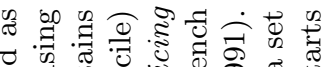

च 要

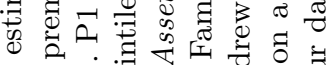

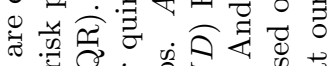

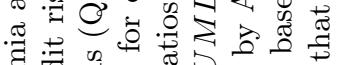
घี

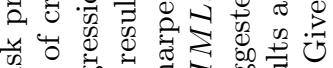

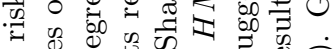

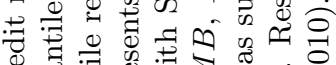

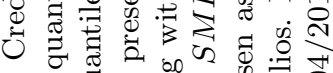
म

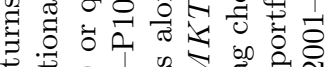

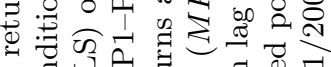
w U.

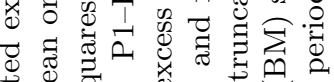

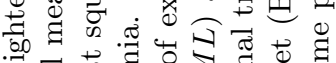

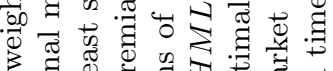

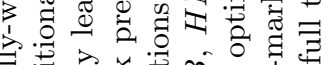

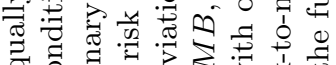

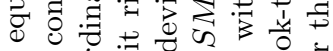

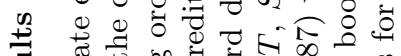

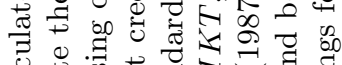

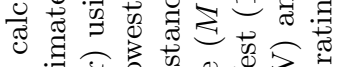

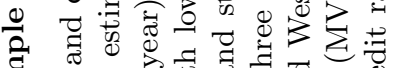

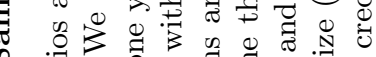

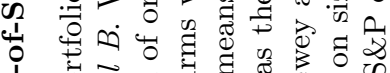

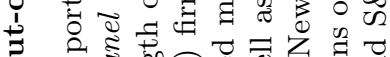

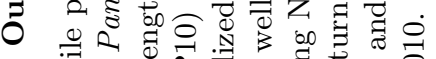

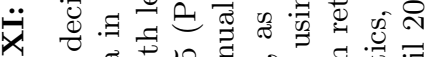

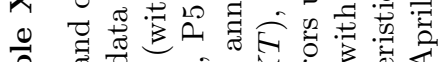
व

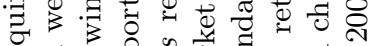
엽. ₹

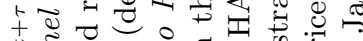

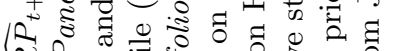

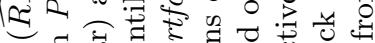

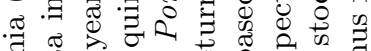
过 0 苛 至 च स्ति : U. in

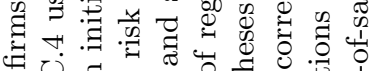

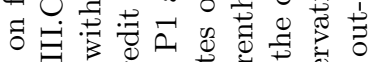

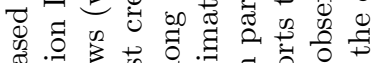

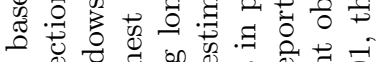

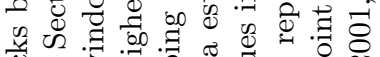

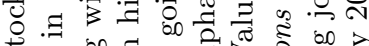
औ.

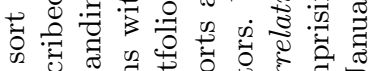

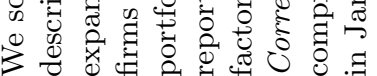




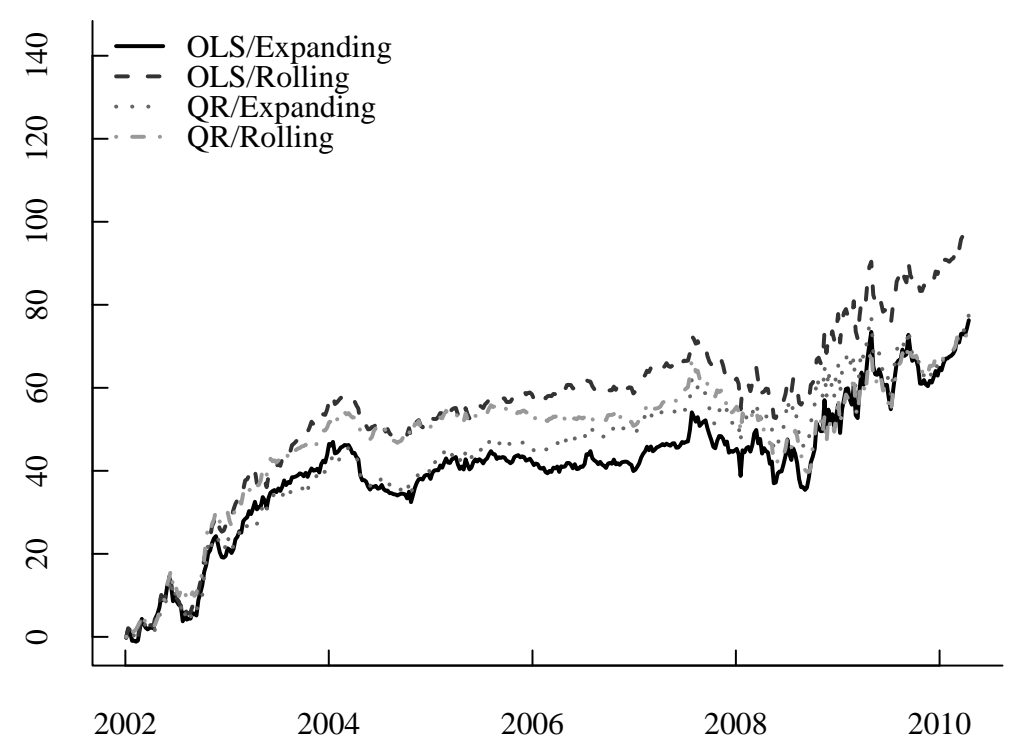

Panel B: Decile Portfolios

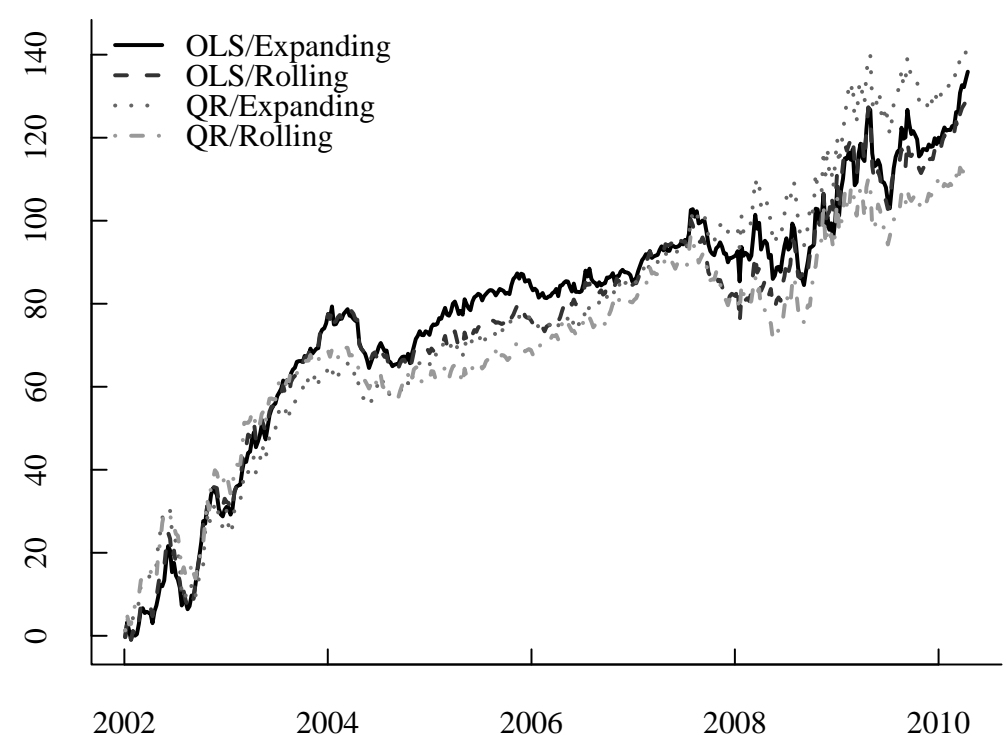

Figure 1: Cumulative 4-Factor Fama-French Alphas

We plot cumulative 4-factor $(M K T, S M B, H M L, U M D)$ Fama-French alphas of a high minus low credit risk premium strategy using weekly data for quintile portfolios in Panel $A$ and for decile portfolios in Panel B, respectively. We present results based on estimates of the conditional mean or conditional quantiles of credit risk premia using expanding windows (with initial length of one year) and rolling windows (with length of one year) using ordinary least squares (OLS) or quantile regressions (QR). Results are based on a data set comprising joint observations of CDS spreads, stock prices, firm characteristics, and S\&P credit ratings for the full time period (01/2001-04/2010). Given that our data starts in January 2001, the out-of-sample period is thus from January 2002 to April 2010. 


\title{
Internet Appendix for
}

\section{"The Cross-Section of Credit Risk Premia and Equity Returns"*}

\author{
Nils Friewald, Christian Wagner, and Josef Zechner
}

This document provides supplementary material for "The Cross-Section of Credit Risk Premia and Equity Returns". In Section III.C.5 of the paper, we discuss various robustness checks but, for space reasons, we do not report detailed results. This Internet Appendix contains Tables that present the results of the robustness analysis which form the basis for discussion in Section III.C.5.

\section{A. Pre-Crisis and Crisis Sub-Samples}

To explore whether the relation between risk premia in credit and equity markets is different prior as compared to during the crisis, we estimate credit risk premia for the two subperiods separately. Table IA.I and IA.II present results for the pre-crisis subsample from 01/2001 to 06/2007 and the crisis subsample from $07 / 2007$ to $04 / 2010$, respectively.

\section{B. Relevance of Interest Rate Risk}

To assess whether interest rate risk potentially affects our results, we repeat the empirical analysis by estimating credit risk premia forward CDS curves that are constructed under the assumption of zero riskless rates. Table IA.III reports the results.

\section{Default Probabilities and Equity Returns}

Table IA.IV reports results for sorting firms into portfolios based on the level of their 5-year CDS spread, which serves as a proxy for the firm's risk-neutral default probability. Tables IA.V and IA.VI present analogue results when firms are sorted into portfolios based on proxies for their physical default probability, using the firm's credit rating and its distance to default (following the procedure of Vassalou and Xing, 2004), respectively.

${ }^{*}$ Citation format: Friewald, Nils, Christian Wagner, and Josef Zechner, Internet Appendix for "The Cross-Section of Credit Risk Premia and Equity Returns," Journal of Finance, DOI STRING. Please note: Wiley-Blackwell is not responsible for the content or functionality of any supporting information supplied by the author. Any queries (other than missing material) should be directed to the authors of the article. 
Table IA.I: Returns on Stock Portfolios sorted by Credit Risk Premia: Prior to the Crisis

We sort stocks based on firms' estimates of their credit risk premia $\left(\widehat{C R P}_{t+\tau}\right)$ into quintile portfolios and calculate equally- and value-weighted excess returns in Panel $A(B)$. P1 contains firms with highest credit risk premia, P5 the ones with lowest. P1-P5 presents results for going long P1 and short P5. Portfolio Characteristics summarizes portfolio means of the market value ( $M V$ ), book-to-market $(B M), 5$-year CDS spread (S5), credit rating (Rating), number of CDS contributors reported by Markit (Liquid), and conditional coskewness with the market portfolio (Coskew) following Harvey and Siddique (2000). We assign integer numbers to the $\mathrm{S} \& \mathrm{P}$ credit ratings, i.e. $\mathrm{AAA}=1, \mathrm{AA}+=2, \ldots, \mathrm{C}=21$. Portfolio Returns reports monthly means and standard deviations of excess returns along with annualized Sharpe ratios. Asset Pricing reports alpha estimates of regressing excess returns on the market $(M K T)$, as well as the three $(M K T, S M B, H M L)$ and four ( $M K T, S M B, H M L, U M D)$ Fama-French factors. Values in parentheses are $t$-statistics based on HAC standard errors using Newey and West (1987) with optimal truncation lag chosen as suggested by Andrews (1991). Results are based on a data set comprising joint observations of CDS spreads, stock prices, firm characteristics, and S\&P credit ratings for the pre-crisis period (01/2001-06/2007).

\begin{tabular}{|c|c|c|c|c|c|c|}
\hline & $\mathrm{P} 1$ & P2 & P3 & $\mathrm{P} 4$ & $\mathrm{P} 5$ & $\overline{\mathrm{P} 1-\mathrm{P} 5}$ \\
\hline \multicolumn{7}{|c|}{ Sort Variable: Credit Risk Premium $\left(\widehat{R P}_{t+\tau}\right)$} \\
\hline mean & 22.07 & 4.20 & 1.65 & -0.16 & -14.13 & \\
\hline \multicolumn{7}{|c|}{ Portfolio Characteristics } \\
\hline$M V$ & 8.74 & 19.71 & 32.49 & 40.58 & 15.41 & \\
\hline$B M$ & 0.72 & 0.65 & 0.53 & 0.51 & 0.65 & \\
\hline$S 5$ & 213.54 & 78.01 & 50.69 & 47.42 & 129.85 & \\
\hline Rating & 10.00 & 7.84 & 6.74 & 6.48 & 8.62 & \\
\hline Liquid & 7.05 & 8.31 & 8.04 & 8.13 & 8.29 & \\
\hline Coskew & -2.77 & -3.03 & -2.48 & -1.80 & -3.15 & \\
\hline \multicolumn{7}{|c|}{ Panel A: Equally-Weighted Portfolios } \\
\hline \multicolumn{7}{|c|}{ Portfolio Returns } \\
\hline \multirow[t]{2}{*}{ mean } & $1.45^{* *}$ & 0.56 & 0.43 & 0.10 & -1.23 & $2.68^{* * *}$ \\
\hline & $(2.18)$ & (1.11) & $(0.98)$ & $(0.20)$ & $(-1.50)$ & $(6.31)$ \\
\hline $\mathrm{sd}$ & 5.35 & 4.11 & 3.59 & 4.03 & 5.66 & 3.14 \\
\hline SR & 0.94 & 0.47 & 0.41 & 0.09 & -0.75 & 2.95 \\
\hline \multicolumn{7}{|c|}{ Asset Pricing } \\
\hline \multirow[t]{2}{*}{ CAPM $\alpha$} & $1.13^{* * *}$ & 0.31 & 0.22 & -0.15 & $-1.55^{* * *}$ & $2.68^{* * *}$ \\
\hline & $(4.42)$ & $(1.32)$ & $(1.19)$ & $(-0.71)$ & $(-4.09)$ & $(6.57)$ \\
\hline \multirow[t]{2}{*}{3 -fac $\alpha$} & $0.78^{* * *}$ & -0.09 & -0.24 & $-0.32^{*}$ & $-2.35^{* * *}$ & $3.13^{* * *}$ \\
\hline & $(3.70)$ & $(-0.56)$ & $(-1.34)$ & $(-1.73)$ & $(-5.23)$ & $(6.08)$ \\
\hline \multirow[t]{2}{*}{4 -fac $\alpha$} & $0.79^{* * *}$ & -0.09 & -0.24 & -0.32 & $-2.35^{* * *}$ & $3.14^{* * *}$ \\
\hline & $(3.71)$ & $(-0.51)$ & $(-1.25)$ & $(-1.61)$ & $(-5.37)$ & $(6.24)$ \\
\hline \multirow[t]{2}{*}{ MKT } & $1.23^{* * *}$ & $1.00^{* * *}$ & $0.89^{* * *}$ & $0.94^{* * *}$ & $1.41^{* * *}$ & $-0.19^{*}$ \\
\hline & (19.24) & (16.95) & $(20.81)$ & $(18.47)$ & $(14.31)$ & $(-1.72)$ \\
\hline \multirow[t]{2}{*}{ SMB } & $0.26^{* * *}$ & 0.11 & 0.08 & 0.06 & 0.19 & 0.07 \\
\hline & $(3.34)$ & $(1.24)$ & $(1.40)$ & $(0.86)$ & $(1.63)$ & $(0.44)$ \\
\hline \multirow[t]{2}{*}{ HML } & $0.24^{* * *}$ & $0.38^{* * *}$ & $0.46^{* * *}$ & $0.16^{* *}$ & $0.77^{* * *}$ & $-0.53^{* * *}$ \\
\hline & $(4.24)$ & $(4.62)$ & $(8.23)$ & $(2.29)$ & $(5.32)$ & $(-3.70)$ \\
\hline
\end{tabular}

Panel B: Value-Weighted Portfolios

\begin{tabular}{|c|c|c|c|c|c|c|}
\hline mean & $\begin{array}{l}1.17^{* *} \\
(2.39)\end{array}$ & $\begin{array}{c}0.49 \\
(1.01)\end{array}$ & $\begin{array}{c}-0.09 \\
(-0.20)\end{array}$ & $\begin{array}{c}-0.44 \\
(-0.91)\end{array}$ & $\begin{array}{c}-1.50^{*} \\
(-1.87)\end{array}$ & $\begin{array}{l}2.67^{* * *} \\
(4.00)\end{array}$ \\
\hline $\mathrm{sd}$ & 4.84 & 4.24 & 3.77 & 3.91 & 5.48 & 3.98 \\
\hline SR & 0.84 & 0.40 & -0.08 & -0.39 & -0.95 & 2.33 \\
\hline \multicolumn{7}{|c|}{ Asset Pricing } \\
\hline CAPM $\alpha$ & $\begin{array}{l}0.89^{* * *} \\
(3.42)\end{array}$ & $\begin{array}{c}0.23 \\
(1.51)\end{array}$ & $\begin{array}{l}-0.30 \\
(-1.55)\end{array}$ & $\begin{array}{l}-0.68^{* * *} \\
(-3.13)\end{array}$ & $\begin{array}{l}-1.82^{* * *} \\
(-3.96)\end{array}$ & $\begin{array}{l}2.71^{* * *} \\
(4.02)\end{array}$ \\
\hline 3 -fac $\alpha$ & $\begin{array}{l}0.93^{* * *} \\
(2.79)\end{array}$ & $\begin{array}{c}0.17 \\
(1.30)\end{array}$ & $\begin{array}{l}-0.48^{* * *} \\
(-2.68)\end{array}$ & $\begin{array}{l}-0.65^{* * *} \\
(-2.93)\end{array}$ & $\begin{array}{l}-2.21^{* * *} \\
(-3.73)\end{array}$ & $\begin{array}{l}3.14^{* * *} \\
(3.94)\end{array}$ \\
\hline 4 -fac $\alpha$ & $\begin{array}{l}0.93^{* * *} \\
(2.72)\end{array}$ & $\begin{array}{c}0.18 \\
(1.41)\end{array}$ & $\begin{array}{l}-0.46^{* *} \\
(-2.49)\end{array}$ & $\begin{array}{l}-0.64^{* * *} \\
(-2.97)\end{array}$ & $\begin{array}{l}-2.21^{* * *} \\
(-3.78)\end{array}$ & $\begin{array}{l}3.14^{* * *} \\
(4.01)\end{array}$ \\
\hline MKT & $\begin{array}{c}1.02^{* * *} \\
(10.96)\end{array}$ & $\begin{array}{c}0.99^{* * *} \\
(12.19)\end{array}$ & $\begin{array}{l}0.91^{* * *} \\
(9.77)\end{array}$ & $\begin{array}{c}0.89^{* * *} \\
(13.81)\end{array}$ & $\begin{array}{c}1.35^{* * *} \\
(16.26)\end{array}$ & $\begin{array}{l}-0.33^{* *} \\
(-2.18)\end{array}$ \\
\hline SMB & $\begin{array}{c}0.01 \\
(0.10)\end{array}$ & $\begin{array}{c}-0.02 \\
(-0.24)\end{array}$ & $\begin{array}{l}-0.21^{* * *} \\
(-3.13)\end{array}$ & $\begin{array}{c}-0.09 \\
(-1.28)\end{array}$ & $\begin{array}{l}-0.12 \\
(-1.18)\end{array}$ & $\begin{array}{c}0.13 \\
(0.80)\end{array}$ \\
\hline HML & $\begin{array}{c}-0.05 \\
(-0.34)\end{array}$ & $\begin{array}{c}0.07 \\
(0.80)\end{array}$ & $\begin{array}{l}0.31^{* * *} \\
(3.76)\end{array}$ & $\begin{array}{c}0.01 \\
(0.18)\end{array}$ & $\begin{array}{l}0.49^{* * *} \\
(3.11)\end{array}$ & $\begin{array}{l}-0.53^{* *} \\
(-2.12)\end{array}$ \\
\hline
\end{tabular}


Table IA.II: Returns on Stock Portfolios sorted by Credit Risk Premia: During the Crisis Period

We sort stocks based on firms' estimates of their credit risk premia $\left(\widehat{C R P}_{t+\tau}\right)$ into quintile portfolios and calculate equally- and value-weighted excess returns in Panel $A(B)$. P1 contains firms with highest credit risk premia, P5 the ones with lowest. P1-P5 presents results for going long P1 and short P5. Portfolio Characteristics summarizes portfolio means of the market value ( $M V$ ), book-to-market $(B M), 5$-year CDS spread (S5), credit rating (Rating), number of CDS contributors reported by Markit (Liquid), and conditional coskewness with the market portfolio (Coskew) following Harvey and Siddique (2000). We assign integer numbers to the $\mathrm{S} \& \mathrm{P}$ credit ratings, i.e. $\mathrm{AAA}=1, \mathrm{AA}+=2, \ldots, \mathrm{C}=21$. Portfolio Returns reports monthly means and standard deviations of excess returns along with annualized Sharpe ratios. Asset Pricing reports alpha estimates of regressing excess returns on the market $(M K T)$, as well as the three $(M K T, S M B, H M L)$ and four ( $M K T, S M B, H M L, U M D)$ Fama-French factors. Values in parentheses are $t$-statistics based on HAC standard errors using Newey and West (1987) with optimal truncation lag chosen as suggested by Andrews (1991). Results are based on a data set comprising joint observations of CDS spreads, stock prices, firm characteristics, and S\&P credit ratings for the crisis period (07/2007-04/2010).

\begin{tabular}{|c|c|c|c|c|c|c|}
\hline & $\mathrm{P} 1$ & P2 & P3 & $\mathrm{P} 4$ & $\mathrm{P} 5$ & $\overline{\mathrm{P} 1-\mathrm{P} 5}$ \\
\hline \multicolumn{7}{|c|}{ Sort Variable: Credit Risk Premium $\left(\widehat{R P}_{t+\tau}\right)$} \\
\hline mean & 53.17 & 7.56 & 0.59 & -6.20 & -62.74 & \\
\hline \multicolumn{7}{|c|}{ Portfolio Characteristics } \\
\hline$M V$ & 11.74 & 20.01 & 25.45 & 22.49 & 14.59 & \\
\hline$B M$ & 0.93 & 0.61 & 0.56 & 0.57 & 0.97 & \\
\hline$S 5$ & 390.87 & 149.16 & 111.74 & 120.53 & 326.92 & \\
\hline Rating & 10.30 & 8.45 & 7.79 & 8.16 & 9.76 & \\
\hline Liquid & 7.53 & 7.16 & 7.53 & 7.84 & 8.15 & \\
\hline Coskew & -5.77 & -7.76 & -10.08 & -9.34 & -6.07 & \\
\hline \multicolumn{7}{|c|}{ Panel A: Equally-Weighted Portfolios } \\
\hline \multicolumn{7}{|c|}{ Portfolio Returns } \\
\hline \multirow[t]{2}{*}{ mean } & 0.78 & 0.19 & -0.50 & -1.46 & -4.75 & $5.53^{* * *}$ \\
\hline & $(0.27)$ & $(0.10)$ & $(-0.26)$ & $(-0.67)$ & $(-1.42)$ & $(3.94)$ \\
\hline $\mathrm{sd}$ & 11.29 & 7.81 & 7.21 & 8.02 & 12.68 & 6.21 \\
\hline SR & 0.24 & 0.08 & -0.24 & -0.63 & -1.30 & 3.09 \\
\hline \multicolumn{7}{|c|}{ Asset Pricing } \\
\hline \multirow[t]{2}{*}{ CAPM $\alpha$} & 1.23 & $0.52^{*}$ & -0.19 & $-1.12^{* *}$ & $-4.23^{* * *}$ & $5.46^{* * *}$ \\
\hline & (1.39) & (1.98) & $(-0.72)$ & $(-2.23)$ & $(-3.01)$ & $(3.18)$ \\
\hline \multirow[t]{2}{*}{3 -fac $\alpha$} & 0.85 & 0.37 & -0.19 & $-1.21^{* *}$ & $-4.44^{* * *}$ & $5.29^{* * *}$ \\
\hline & (1.13) & (1.45) & $(-0.62)$ & $(-2.48)$ & $(-4.47)$ & $(3.59)$ \\
\hline \multirow[t]{2}{*}{ 4-fac $\alpha$} & $0.46^{*}$ & 0.26 & -0.18 & $-1.15^{* * *}$ & $-4.38^{* * *}$ & $4.84^{* * *}$ \\
\hline & $(1.91)$ & $(1.54)$ & $(-0.61)$ & $(-3.03)$ & $(-5.32)$ & $(7.59)$ \\
\hline \multirow[t]{2}{*}{ MKT } & $1.36^{* * *}$ & $1.08^{* * *}$ & $1.06^{* * *}$ & $1.17^{* * *}$ & $1.62^{* * *}$ & -0.25 \\
\hline & $(9.86)$ & $(23.68)$ & (15.36) & $(8.40)$ & $(8.55)$ & $(-0.92)$ \\
\hline \multirow[t]{2}{*}{ SMB } & $0.77^{* * *}$ & $0.31^{* *}$ & -0.03 & 0.19 & 0.38 & 0.40 \\
\hline & $(2.87)$ & $(2.22)$ & $(-0.20)$ & $(1.52)$ & $(1.52)$ & $(1.40)$ \\
\hline \multirow[t]{2}{*}{ HML } & 0.36 & 0.06 & 0.04 & -0.07 & $0.52^{* * *}$ & -0.16 \\
\hline & $(0.96)$ & $(0.42)$ & $(0.25)$ & $(-0.58)$ & $(2.65)$ & $(-0.72)$ \\
\hline
\end{tabular}

Panel B: Value-Weighted Portfolios

\begin{tabular}{|c|c|c|c|c|c|c|}
\hline mean & $\begin{array}{c}-0.63 \\
(-0.26)\end{array}$ & $\begin{array}{c}-0.25 \\
(-0.16)\end{array}$ & $\begin{array}{c}-0.46 \\
(-0.31)\end{array}$ & $\begin{array}{c}-1.08 \\
(-0.76)\end{array}$ & $\begin{array}{c}-4.79 \\
(-1.53)\end{array}$ & $\begin{array}{l}4.16^{* * *} \\
(3.36)\end{array}$ \\
\hline $\mathrm{sd}$ & 9.04 & 6.50 & 5.67 & 5.99 & 10.58 & 5.79 \\
\hline SR & -0.24 & -0.14 & -0.28 & -0.62 & -1.57 & 2.49 \\
\hline \multicolumn{7}{|c|}{ Asset Pricing } \\
\hline CAPM $\alpha$ & $\begin{array}{c}-0.26 \\
(-0.45)\end{array}$ & $\begin{array}{c}0.02 \\
(0.07)\end{array}$ & $\begin{array}{c}-0.23 \\
(-0.59)\end{array}$ & $\begin{array}{c}-0.83^{* *} \\
(-2.45)\end{array}$ & $\begin{array}{l}-4.35^{* * *} \\
(-4.93)\end{array}$ & $\begin{array}{l}4.10^{* * *} \\
(3.43)\end{array}$ \\
\hline 3 -fac $\alpha$ & $\begin{array}{c}-0.32 \\
(-0.59)\end{array}$ & $\begin{array}{c}-0.01 \\
(-0.05)\end{array}$ & $\begin{array}{c}-0.13 \\
(-0.42)\end{array}$ & $\begin{array}{l}-0.83^{* *} \\
(-2.37)\end{array}$ & $\begin{array}{l}-4.25^{\text {*** }} \\
(-5.88)\end{array}$ & $\begin{array}{l}3.93^{* * *} \\
(3.83)\end{array}$ \\
\hline 4 -fac $\alpha$ & $\begin{array}{l}-0.52 \\
(-1.11)\end{array}$ & $\begin{array}{c}-0.05 \\
(-0.29)\end{array}$ & $\begin{array}{c}-0.02 \\
(-0.11)\end{array}$ & $\begin{array}{l}-0.74^{* * *} \\
(-3.42)\end{array}$ & $\begin{array}{l}-4.15^{\text {*** }} \\
(-5.82)\end{array}$ & $\begin{array}{l}3.62^{* * * *} \\
(3.99)\end{array}$ \\
\hline MKT & $\begin{array}{c}1.29^{* * *} \\
(12.99)\end{array}$ & $\begin{array}{c}0.95^{* * *} \\
(17.61)\end{array}$ & $\begin{array}{c}0.83^{* * *} \\
(18.59)\end{array}$ & $\begin{array}{c}0.88^{* * *} \\
(12.96)\end{array}$ & $\begin{array}{c}1.46^{* * *} \\
(11.08)\end{array}$ & $\begin{array}{c}-0.17 \\
(-0.90)\end{array}$ \\
\hline SMB & $\begin{array}{c}0.14 \\
(0.51)\end{array}$ & $\begin{array}{c}0.06 \\
(0.50)\end{array}$ & $\begin{array}{l}-0.24 \\
(-1.52)\end{array}$ & $\begin{array}{c}0.00 \\
(0.04)\end{array}$ & $\begin{array}{c}-0.29 \\
(-1.25)\end{array}$ & $\begin{array}{c}0.43 \\
(0.85)\end{array}$ \\
\hline HML & $\begin{array}{l}-0.02 \\
(-0.08)\end{array}$ & $\begin{array}{l}-0.00 \\
(-0.01)\end{array}$ & $\begin{array}{c}0.12 \\
(0.92)\end{array}$ & $\begin{array}{l}-0.08 \\
(-1.46)\end{array}$ & $\begin{array}{c}0.39 \\
(1.25)\end{array}$ & $\begin{array}{c}-0.41 \\
(-0.76)\end{array}$ \\
\hline
\end{tabular}


Table IA.III: Returns on Stock Portfolios sorted by Credit Risk Premia: Assuming Zero Interest Rates

We sort stocks based on firms' estimates of their credit risk premia $\left(\widehat{C R P}_{t+\tau}\right)$ into quintile portfolios and calculate equally- and value-weighted excess returns in Panel $A(B)$ while assuming zero riskless interest rates. P1 contains firms with highest credit risk premia, P5 the ones with lowest. P1-P5 presents results for going long P1 and short P5. Portfolio Characteristics summarizes portfolio means of the market value $(M V)$, book-to-market $(B M)$, 5-year CDS spread (S5), credit rating (Rating), number of CDS contributors reported by Markit (Liquid), and conditional coskewness with the market portfolio (Coskew) following Harvey and Siddique (2000). We assign integer numbers to the $\mathrm{S} \& \mathrm{P}$ credit ratings, i.e. $\mathrm{AAA}=1, \mathrm{AA}+=2, \ldots, \mathrm{C}=21$. Portfolio Returns reports monthly means and standard deviations of excess returns along with annualized Sharpe ratios. Asset Pricing reports alpha estimates of regressing excess returns on the market $(M K T)$, as well as the three $(M K T, S M B, H M L)$ and four $(M K T, S M B$, $H M L, U M D)$ Fama-French factors. Values in parentheses are $t$-statistics based on HAC standard errors using Newey and West (1987) with optimal truncation lag chosen as suggested by Andrews (1991). Results are based on a data set comprising joint observations of CDS spreads, stock prices, firm characteristics, and S\&P credit ratings for the full time period (01/2001-04/2010), the pre-crisis period $(01 / 2001-06 / 2007)$ and the crisis period $(07 / 2007-04 / 2010)$.

\begin{tabular}{|c|c|c|c|c|c|c|c|c|}
\hline & \multicolumn{6}{|c|}{ Full Period } & \multirow{2}{*}{$\begin{array}{c}\text { Pre-Crisis } \\
\text { P1-P5 }\end{array}$} & \multirow{2}{*}{$\begin{array}{l}\text { Crisis } \\
\text { P1-P5 }\end{array}$} \\
\hline & P1 & P2 & P3 & $\mathrm{P} 4$ & P5 & P1-P5 & & \\
\hline \multicolumn{9}{|c|}{ Sort Variable: Credit Risk Premium $\left(\widehat{R P}_{t+\tau}\right)$} \\
\hline mean & 32.28 & 4.92 & 1.13 & -2.25 & -31.92 & & & \\
\hline \multicolumn{9}{|c|}{ Portfolio Characteristics } \\
\hline$\overline{M V}$ & 12.25 & 19.20 & 29.16 & 32.00 & 17.61 & & & \\
\hline$B M$ & 0.78 & 0.60 & 0.53 & 0.55 & 0.78 & & & \\
\hline$S 5$ & 260.33 & 98.51 & 69.62 & 73.12 & 202.82 & & & \\
\hline Rating & 9.73 & 8.01 & 7.22 & 7.34 & 8.92 & & & \\
\hline Liquid & 7.16 & 7.62 & 7.88 & 8.29 & 8.36 & & & \\
\hline Coskew & -3.26 & -4.21 & -4.54 & -4.64 & -2.83 & & & \\
\hline
\end{tabular}

Panel A: Equally-Weighted Portfolios

\begin{tabular}{|c|c|c|c|c|c|c|c|c|}
\hline mean & $\begin{array}{c}0.70 \\
(0.67)\end{array}$ & $\begin{array}{c}0.29 \\
(0.51)\end{array}$ & $\begin{array}{c}0.05 \\
(0.08)\end{array}$ & $\begin{array}{c}-0.18 \\
(-0.28)\end{array}$ & $\begin{array}{c}-1.96^{*} \\
(-1.72)\end{array}$ & $\begin{array}{l}2.65^{* * *} \\
(4.02)\end{array}$ & $\begin{array}{l}2.77^{* * *} \\
(5.46)\end{array}$ & $\begin{array}{l}5.37^{* * *} \\
(3.80)\end{array}$ \\
\hline sd & 7.99 & 5.29 & 5.01 & 5.08 & 8.60 & 4.41 & 3.27 & 6.37 \\
\hline SR & 0.30 & 0.19 & 0.03 & -0.12 & -0.79 & 2.09 & 2.94 & 2.92 \\
\hline \multicolumn{9}{|c|}{ Asset Pricing } \\
\hline CAPM $\alpha$ & $\begin{array}{c}0.58^{*} \\
(1.75)\end{array}$ & $\begin{array}{c}0.22 \\
(1.19)\end{array}$ & $\begin{array}{c}-0.02 \\
(-0.13)\end{array}$ & $\begin{array}{l}-0.25 \\
(-1.20)\end{array}$ & $\begin{array}{l}-2.08^{* * *} \\
(-4.62)\end{array}$ & $\begin{array}{l}2.66^{* * *} \\
(3.87)\end{array}$ & $\begin{array}{l}2.78^{* * *} \\
(6.87)\end{array}$ & $\begin{array}{l}5.29^{* * *} \\
(3.13)\end{array}$ \\
\hline 3 -fac $\alpha$ & $\begin{array}{c}0.18 \\
(0.53)\end{array}$ & $\begin{array}{c}-0.05 \\
(-0.38)\end{array}$ & $\begin{array}{c}-0.19 \\
(-1.26)\end{array}$ & $\begin{array}{l}-0.47^{* * *} \\
(-2.72)\end{array}$ & $\begin{array}{l}-2.58^{* * *} \\
(-6.91)\end{array}$ & $\begin{array}{l}2.77^{* * *} \\
(5.44)\end{array}$ & $\begin{array}{l}3.25^{* * *} \\
(6.29)\end{array}$ & $\begin{array}{l}5.09^{* * *} \\
(3.42)\end{array}$ \\
\hline 4 -fac $\alpha$ & $\begin{array}{c}0.23 \\
(0.86) \\
\end{array}$ & $\begin{array}{l}-0.05 \\
(-0.26) \\
\end{array}$ & $\begin{array}{l}-0.20 \\
(-1.35) \\
\end{array}$ & $\begin{array}{l}-0.48^{* * *} \\
(-3.17)\end{array}$ & $\begin{array}{l}-2.59^{* * *} \\
(-5.57)\end{array}$ & $\begin{array}{l}2.82^{* * *} \\
(6.04)\end{array}$ & $\begin{array}{l}3.26^{* * *} \\
(6.39) \\
\end{array}$ & $\begin{array}{l}4.65^{* * *} \\
(7.44) \\
\end{array}$ \\
\hline MKT & $\begin{array}{c}1.42^{* * *} \\
(19.65)\end{array}$ & $\begin{array}{c}0.94^{* * *} \\
(14.60)\end{array}$ & $\begin{array}{c}0.93^{* * *} \\
(16.60)\end{array}$ & $\begin{array}{c}0.93^{* * *} \\
(17.08)\end{array}$ & $\begin{array}{c}1.55^{* * *} \\
(10.03)\end{array}$ & $\begin{array}{c}-0.13 \\
(-0.74)\end{array}$ & $\begin{array}{c}-0.24^{* *} \\
(-2.18)\end{array}$ & $\begin{array}{c}-0.30 \\
(-1.12)\end{array}$ \\
\hline SMB & $\begin{array}{l}0.39^{* * *} \\
(4.42)\end{array}$ & $\begin{array}{l}0.22^{* * *} \\
(4.57)\end{array}$ & $\begin{array}{c}0.03 \\
(0.78)\end{array}$ & $\begin{array}{c}0.06 \\
(0.65)\end{array}$ & $\begin{array}{c}0.14^{* *} \\
(2.37)\end{array}$ & $\begin{array}{l}0.26^{* * *} \\
(2.64)\end{array}$ & $\begin{array}{c}0.13 \\
(0.96)\end{array}$ & $\begin{array}{c}0.47 \\
(1.69)\end{array}$ \\
\hline HML & $\begin{array}{l}0.40^{* * *} \\
(4.11)\end{array}$ & $\begin{array}{l}0.30^{* * *} \\
(3.00)\end{array}$ & $\begin{array}{l}0.27^{* * *} \\
(3.66)\end{array}$ & $\begin{array}{l}0.35^{* * *} \\
(6.11)\end{array}$ & $\begin{array}{l}0.80^{* * *} \\
(7.30)\end{array}$ & $\begin{array}{l}-0.40^{* *} \\
(-2.39)\end{array}$ & $\begin{array}{l}-0.58^{* * *} \\
(-4.90)\end{array}$ & $\begin{array}{c}-0.21 \\
(-1.11)\end{array}$ \\
\hline
\end{tabular}

Panel B: Value-Weighted Portfolios

\begin{tabular}{|c|c|c|c|c|c|c|c|c|}
\hline \multicolumn{9}{|l|}{ Portfolio } \\
\hline mean & $\begin{array}{c}-0.12 \\
(-0.15)\end{array}$ & $\begin{array}{c}0.17 \\
(0.31)\end{array}$ & $\begin{array}{c}-0.48 \\
(-0.96)\end{array}$ & $\begin{array}{c}-0.51 \\
(-0.89)\end{array}$ & $\begin{array}{c}-1.74^{*} \\
(-1.77)\end{array}$ & $\begin{array}{l}1.61 \\
(3.43)\end{array}$ & $\begin{array}{l}2.78^{* * *} \\
(3.92)\end{array}$ & $\begin{array}{l}4.22^{* * *} \\
(3.14)\end{array}$ \\
\hline sd & 6.98 & 4.66 & 4.34 & 4.39 & 7.31 & 4.02 & 4.06 & 5.94 \\
\hline \multicolumn{9}{|c|}{ Asset Pricing } \\
\hline CAPM $\alpha$ & $\begin{array}{c}-0.22 \\
(-0.84)\end{array}$ & $\begin{array}{c}0.10 \\
(0.79)\end{array}$ & $\begin{array}{l}-0.54^{* * *} \\
(-2.77)\end{array}$ & $\begin{array}{l}-0.57^{* *} \\
(-2.29)\end{array}$ & $\begin{array}{l}-1.84^{* * *} \\
(-4.79)\end{array}$ & $\begin{array}{l}1.62^{* * *} \\
(3.06)\end{array}$ & $\begin{array}{l}2.81^{* * *} \\
(4.02)\end{array}$ & $\begin{array}{l}4.15^{* * *} \\
(3.47)\end{array}$ \\
\hline 3 -fac $\alpha$ & $\begin{array}{c}-0.34 \\
(-1.35)\end{array}$ & $\begin{array}{c}0.01 \\
(0.08)\end{array}$ & $\begin{array}{l}-0.49^{* * *} \\
(-2.99)\end{array}$ & $\begin{array}{l}-0.59^{* * *} \\
(-3.13)\end{array}$ & $\begin{array}{l}-1.95^{* * *} \\
(-5.97)\end{array}$ & $\begin{array}{l}1.60^{* * *} \\
(3.27)\end{array}$ & $\begin{array}{l}3.36^{* * *} \\
(3.84)\end{array}$ & $\begin{array}{l}4.00^{* * *} \\
(3.84)\end{array}$ \\
\hline 4 -fac $\alpha$ & $\begin{array}{c}-0.33 \\
(-1.18)\end{array}$ & $\begin{array}{c}0.01 \\
(0.07)\end{array}$ & $\begin{array}{l}-0.49^{* * *} \\
(-2.92)\end{array}$ & $\begin{array}{l}-0.61^{* * *} \\
(-3.21)\end{array}$ & $\begin{array}{l}-1.95^{* * *} \\
(-5.68)\end{array}$ & $\begin{array}{l}1.62^{* * *} \\
(3.61)\end{array}$ & $\begin{array}{l}3.35^{* * *} \\
(3.92)\end{array}$ & $\begin{array}{l}3.68^{* * *} \\
(4.18)\end{array}$ \\
\hline $\mathrm{MKT}$ & $\begin{array}{c}1.31^{* * *} \\
(27.03)\end{array}$ & $\begin{array}{l}0.88^{* * *} \\
(17.20)\end{array}$ & $\begin{array}{c}0.83^{* * *} \\
(21.47)\end{array}$ & $\begin{array}{c}0.81^{* * *} \\
(19.17)\end{array}$ & $\begin{array}{c}1.40^{* * *} \\
(10.92)\end{array}$ & $\begin{array}{c}-0.09 \\
(-0.89)\end{array}$ & $\begin{array}{c}-0.38^{* *} \\
(-2.43)\end{array}$ & $\begin{array}{c}-0.21 \\
(-1.05)\end{array}$ \\
\hline
\end{tabular}


Table IA.IV: Returns on Stock Portfolios sorted by 5-Year CDS Spreads

We sort stocks based on firms' 5-year CDS spreads (S5) into quintile portfolios and calculate equally- and value-weighted excess returns in Panel $A$ (B). P1 contains firms with highest 5-year CDS spreads, P5 the ones with lowest. P1-P5 presents results for going long P1 and short P5. Portfolio Characteristics summarizes portfolio means of the market value ( $M V)$, book-to-market $(B M)$, 5-year CDS spread (S5), credit rating (Rating), number of CDS contributors reported by Markit (Liquid), and conditional coskewness with the market portfolio (Coskew) following Harvey and Siddique (2000). We assign integer numbers to the S\&P credit ratings, i.e. $\mathrm{AAA}=1, \mathrm{AA}+=2, \ldots, \mathrm{C}=21$. Portfolio Returns reports monthly means and standard deviations of excess returns along with annualized Sharpe ratios. Asset Pricing reports alpha estimates of regressing excess returns on the market $(M K T)$, as well as the three $(M K T, S M B, H M L)$ and four $(M K T, S M B, H M L, U M D)$ Fama-French factors. Values in parentheses are $t$-statistics based on HAC standard errors using Newey and West (1987) with optimal truncation lag chosen as suggested by Andrews (1991). Results are based on a data set comprising joint observations of CDS spreads, stock prices, firm characteristics, and S\&P credit ratings for the full time period (01/2001-04/2010).

\begin{tabular}{|c|c|c|c|c|c|c|}
\hline & $\mathrm{P} 1$ & $\mathrm{P} 2$ & P3 & $\mathrm{P} 4$ & $\mathrm{P} 5$ & P1-P5 \\
\hline \multicolumn{7}{|c|}{ Sort Variable: 5-Year CDS Spread (S5) } \\
\hline mean & 414.85 & 134.89 & 76.00 & 48.48 & 29.27 & \\
\hline \multicolumn{7}{|c|}{ Portfolio Characteristics } \\
\hline$M V$ & 4.75 & 8.83 & 13.66 & 21.51 & 51.31 & \\
\hline$B M$ & 0.96 & 0.72 & 0.65 & 0.54 & 0.38 & \\
\hline$S 5$ & 414.85 & 134.89 & 76.00 & 48.48 & 29.27 & \\
\hline Rating & 11.69 & 9.23 & 8.19 & 7.07 & 5.43 & \\
\hline Liquid & 6.33 & 7.74 & 7.98 & 7.89 & 7.32 & \\
\hline Coskew & -2.89 & -4.30 & -4.05 & -4.35 & -3.04 & \\
\hline
\end{tabular}

Panel A: Equally-Weighted Portfolios

\begin{tabular}{|c|c|c|c|c|c|c|}
\hline mean & $\begin{array}{c}-0.29 \\
(-0.23)\end{array}$ & $\begin{array}{c}-0.25 \\
(-0.30)\end{array}$ & $\begin{array}{c}-0.09 \\
(-0.15)\end{array}$ & $\begin{array}{c}0.00 \\
(0.00)\end{array}$ & $\begin{array}{c}-0.15 \\
(-0.31)\end{array}$ & $\begin{array}{c}-0.14 \\
(-0.17)\end{array}$ \\
\hline sd & 10.29 & 6.88 & 5.24 & 4.69 & 4.22 & 6.95 \\
\hline SR & -0.10 & -0.12 & -0.06 & 0.00 & -0.12 & -0.07 \\
\hline \multicolumn{7}{|c|}{ Asset Pricing } \\
\hline CAPM $\alpha$ & $\begin{array}{c}-0.43 \\
(-1.00)\end{array}$ & $\begin{array}{l}-0.34 \\
(-1.17)\end{array}$ & $\begin{array}{c}-0.16 \\
(-0.92)\end{array}$ & $\begin{array}{c}-0.07 \\
(-0.34)\end{array}$ & $\begin{array}{l}-0.21^{* *} \\
(-2.05)\end{array}$ & $\begin{array}{c}-0.21 \\
(-0.53)\end{array}$ \\
\hline 3 -fac $\alpha$ & $\begin{array}{l}-1.29^{* * *} \\
(-8.26)\end{array}$ & $\begin{array}{l}-0.69^{* * *} \\
(-4.23)\end{array}$ & $\begin{array}{l}-0.45^{* * *} \\
(-4.46)\end{array}$ & $\begin{array}{c}-0.17 \\
(-0.99)\end{array}$ & $\begin{array}{l}-0.25^{* * *} \\
(-2.96)\end{array}$ & $\begin{array}{l}-1.04^{* * *} \\
(-4.95)\end{array}$ \\
\hline 4 -fac $\alpha$ & $\begin{array}{l}-1.24^{* * *} \\
(-3.91)\end{array}$ & $\begin{array}{l}-0.69^{* * *} \\
(-3.12)\end{array}$ & $\begin{array}{l}-0.44^{* * *} \\
(-3.94)\end{array}$ & $\begin{array}{l}-0.18 \\
(-1.56)\end{array}$ & $\begin{array}{l}-0.26^{* * *} \\
(-3.34)\end{array}$ & $\begin{array}{l}-0.98^{* * *} \\
(-2.86)\end{array}$ \\
\hline MKT & $\begin{array}{c}1.73^{* * *} \\
(21.41)\end{array}$ & $\begin{array}{c}1.28^{* * *} \\
(13.26)\end{array}$ & $\begin{array}{c}0.97^{* * *} \\
(21.03)\end{array}$ & $\begin{array}{c}0.90^{* * *} \\
(15.13)\end{array}$ & $\begin{array}{c}0.84^{* * *} \\
(20.16)\end{array}$ & $\begin{array}{c}0.89^{* * *} \\
(13.50)\end{array}$ \\
\hline SMB & $\begin{array}{l}0.61^{* * *} \\
(5.69)\end{array}$ & $\begin{array}{l}0.20^{* * *} \\
(3.67)\end{array}$ & $\begin{array}{l}0.17^{* * *} \\
(3.89)\end{array}$ & $\begin{array}{c}0.09 \\
(1.41)\end{array}$ & $\begin{array}{l}-0.09^{* *} \\
(-2.39)\end{array}$ & $\begin{array}{l}0.69^{* * *} \\
(7.98)\end{array}$ \\
\hline HML & $\begin{array}{c}1.04^{* * *} \\
(17.88)\end{array}$ & $\begin{array}{l}0.46^{* * *} \\
(6.33)\end{array}$ & $\begin{array}{l}0.37^{* * *} \\
(7.28)\end{array}$ & $\begin{array}{l}0.11^{* *} \\
(2.34)\end{array}$ & $\begin{array}{l}0.14^{* * *} \\
(2.50)\end{array}$ & $\begin{array}{l}0.90^{* * *} \\
(9.23)\end{array}$ \\
\hline
\end{tabular}

Panel B: Value-Weighted Portfolios

\begin{tabular}{lcccccc}
\multicolumn{7}{l}{ Portfolio Returns } \\
mean & -1.06 & -0.72 & -0.47 & -0.20 & -0.45 & -0.61 \\
& $(-0.80)$ & $(-0.86)$ & $(-0.73)$ & $(-0.36)$ & $(-1.05)$ & $(-0.74)$ \\
sd & 9.59 & 7.12 & 5.26 & 4.70 & 3.91 & 7.11 \\
SR & -0.38 & -0.35 & -0.31 & -0.15 & -0.40 & -0.30 \\
\hline \multirow{2}{*}{ Asset Pricing } & & & & & \\
\hline CAPM $\alpha$ & $-1.19^{* * *}$ & $-0.82^{* * *}$ & $-0.54^{* * *}$ & -0.27 & $-0.51^{* * *}$ & -0.68 \\
& $(-2.56)$ & $(-3.62)$ & $(-3.12)$ & $(-1.02)$ & $(-5.12)$ & $(-1.35)$ \\
3-fac $\alpha$ & $-1.58^{* * *}$ & $-0.92^{* * *}$ & $-0.75^{* * *}$ & -0.28 & $-0.41^{* * *}$ & $-1.17^{* * *}$ \\
& $(-3.99)$ & $(-4.13)$ & $(-4.68)$ & $(-1.15)$ & $(-4.62)$ & $(-3.18)$ \\
4-fac $\alpha$ & $-1.56^{* * *}$ & $-0.91^{* * *}$ & $-0.74^{* * *}$ & -0.30 & $-0.42^{* * *}$ & $-1.15^{* *}$ \\
& $(-3.52)$ & $(-4.20)$ & $(-4.68)$ & $(-1.64)$ & $(-5.11)$ & $(-2.42)$ \\
\hline MKT & $1.66^{* * *}$ & $1.40^{* * *}$ & $0.98^{* * *}$ & $0.90^{* * *}$ & $0.78^{* * *}$ & $0.88^{* * *}$ \\
& $(9.91)$ & $(18.63)$ & $(20.63)$ & $(21.41)$ & $(28.01)$ & $(5.84)$ \\
SMB & $0.28^{* *}$ & $-0.14^{*}$ & 0.02 & $-0.09^{*}$ & $-0.17^{* * *}$ & $0.45^{* * *}$ \\
& $(2.46)$ & $(-1.91)$ & $(0.30)$ & $(-1.91)$ & $(-4.53)$ & $(4.25)$ \\
HML & $0.48^{* *}$ & $0.30^{* * *}$ & $0.35^{* * *}$ & 0.09 & -0.03 & $0.51^{* * *}$ \\
& $(2.47)$ & $(4.43)$ & $(5.37)$ & $(1.56)$ & $(-0.65)$ & $(2.64)$ \\
\hline
\end{tabular}


Table IA.V: Returns on Stock Portfolios sorted by Credit Ratings

We sort stocks based on firms' credit ratings into quintile portfolios and calculate equally- and value-weighted excess returns in Panel $A(B)$. We assign integer numbers to the $\mathrm{S} \& \mathrm{P}$ credit ratings, i.e. $\mathrm{AAA}=1, \mathrm{AA}+=2, \ldots, \mathrm{C}=21$. $\mathrm{P} 1$ contains firms with lowest credit ratings, P5 the ones with highest. P1-P5 presents results for going long P1 and short P5. Portfolio Characteristics summarizes portfolio means of the market value $(M V)$, book-to-market $(B M)$, 5-year CDS spread $(S 5)$, credit rating (Rating), number of CDS contributors reported by Markit (Liquid), and conditional coskewness with the market portfolio (Coskew) following Harvey and Siddique (2000). Portfolio Returns reports monthly means and standard deviations of excess returns along with annualized Sharpe ratios. Asset Pricing reports alpha estimates of regressing excess returns on the market $(M K T)$, as well as the three $(M K T$, $S M B, H M L)$ and four $(M K T, S M B, H M L, U M D)$ Fama-French factors. Values in parentheses are $t$-statistics based on HAC standard errors using Newey and West (1987) with optimal truncation lag chosen as suggested by Andrews (1991). Results are based on a data set comprising joint observations of CDS spreads, stock prices, firm characteristics, and S\&P credit ratings for the full time period (01/2001-04/2010).

\begin{tabular}{|c|c|c|c|c|c|c|}
\hline & $\mathrm{P} 1$ & $\mathrm{P} 2$ & P3 & $\mathrm{P} 4$ & $\mathrm{P} 5$ & $\mathrm{P} 1-\mathrm{P} 5$ \\
\hline \multicolumn{7}{|c|}{ Sort Variable: Credit Rating (Rating) } \\
\hline mean & 12.70 & 10.08 & 8.77 & 7.28 & 4.92 & \\
\hline \multicolumn{7}{|c|}{ Portfolio Characteristics } \\
\hline$M V$ & 4.43 & 6.64 & 9.68 & 16.70 & 51.34 & \\
\hline$B M$ & 0.81 & 0.77 & 0.68 & 0.58 & 0.46 & \\
\hline$S 5$ & 393.07 & 162.33 & 101.04 & 72.97 & 50.47 & \\
\hline Rating & 12.70 & 10.08 & 8.77 & 7.28 & 4.92 & \\
\hline Liquid & 5.52 & 7.04 & 8.32 & 7.94 & 8.14 & \\
\hline Coskew & -2.07 & -5.75 & -3.25 & -4.39 & -2.45 & \\
\hline
\end{tabular}

Panel A: Equally-Weighted Portfolios

\begin{tabular}{|c|c|c|c|c|c|c|}
\hline mean & $\begin{array}{c}0.16 \\
(0.13)\end{array}$ & $\begin{array}{c}0.06 \\
(0.07)\end{array}$ & $\begin{array}{c}-0.10 \\
(-0.14)\end{array}$ & $\begin{array}{c}-0.06 \\
(-0.08)\end{array}$ & $\begin{array}{c}-0.42 \\
(-0.63)\end{array}$ & $\begin{array}{c}0.51 \\
(0.85)\end{array}$ \\
\hline sd & 9.44 & 6.46 & 5.78 & 5.42 & 5.29 & 5.49 \\
\hline SR & 0.06 & 0.03 & -0.06 & -0.04 & -0.28 & 0.32 \\
\hline \multicolumn{7}{|c|}{ Asset Pricing } \\
\hline CAPM $\alpha$ & $\begin{array}{c}-0.19 \\
(-0.42)\end{array}$ & $\begin{array}{c}-0.07 \\
(-0.26)\end{array}$ & $\begin{array}{c}-0.22 \\
(-1.09)\end{array}$ & $\begin{array}{c}-0.17 \\
(-0.84)\end{array}$ & $\begin{array}{l}-0.53^{* * *} \\
(-3.17)\end{array}$ & $\begin{array}{c}0.37 \\
(1.28)\end{array}$ \\
\hline 3 -fac $\alpha$ & $\begin{array}{l}-0.94^{* * *} \\
(-7.91)\end{array}$ & $\begin{array}{l}-0.54^{* * *} \\
(-3.96)\end{array}$ & $\begin{array}{l}-0.49^{* * *} \\
(-2.55)\end{array}$ & $\begin{array}{l}-0.34^{* * *} \\
(-2.55)\end{array}$ & $\begin{array}{l}-0.60^{* * *} \\
(-4.26)\end{array}$ & $\begin{array}{l}-0.35^{* *} \\
(-2.35)\end{array}$ \\
\hline 4 -fac $\alpha$ & $\begin{array}{l}-0.93^{* * *} \\
(-3.31)\end{array}$ & $\begin{array}{l}-0.54^{* * *} \\
(-2.70)\end{array}$ & $\begin{array}{l}-0.48^{* * *} \\
(-2.49)\end{array}$ & $\begin{array}{l}-0.35^{* * *} \\
(-2.65)\end{array}$ & $\begin{array}{l}-0.59^{* * *} \\
(-3.94)\end{array}$ & $\begin{array}{c}-0.33 \\
(-1.22)\end{array}$ \\
\hline MKT & $\begin{array}{c}1.52^{* * *} \\
(13.76)\end{array}$ & $\begin{array}{c}1.12^{* * *} \\
(16.69)\end{array}$ & $\begin{array}{c}1.06^{* * *} \\
(28.92)\end{array}$ & $\begin{array}{c}1.03^{* * *} \\
(19.35)\end{array}$ & $\begin{array}{c}1.03^{* * *} \\
(17.84)\end{array}$ & $\begin{array}{l}0.49^{* * *} \\
(8.85)\end{array}$ \\
\hline SMB & $\begin{array}{l}0.75^{* * *} \\
(7.86)\end{array}$ & $\begin{array}{l}0.32^{* * *} \\
(13.75)\end{array}$ & $\begin{array}{l}0.17^{* * *} \\
(2.53)\end{array}$ & $\begin{array}{c}0.07 \\
(1.31)\end{array}$ & $\begin{array}{l}-0.13^{* * *} \\
(-2.68)\end{array}$ & $\begin{array}{l}0.88^{* * *} \\
(9.11)\end{array}$ \\
\hline HML & $\begin{array}{l}0.88^{* * * *} \\
(8.79)\end{array}$ & $\begin{array}{l}0.54^{* * *} \\
(4.76)\end{array}$ & $\begin{array}{l}0.32^{* * *} \\
(4.15)\end{array}$ & $\begin{array}{l}0.24^{* * *} \\
(4.40)\end{array}$ & $\begin{array}{l}0.21^{* * *} \\
(3.77)\end{array}$ & $\begin{array}{l}0.68^{* * *} \\
(8.48)\end{array}$ \\
\hline
\end{tabular}

Panel B: Value-Weighted Portfolios

\begin{tabular}{lcccccc}
\multicolumn{7}{l}{ Portfolio Returns } \\
\hline mean & -0.22 & -0.27 & -0.51 & -0.12 & -0.62 & 0.29 \\
& $(-0.19)$ & $(-0.32)$ & $(-0.75)$ & $(-0.19)$ & $(-1.11)$ & $(0.45)$ \\
sd & 8.21 & 5.86 & 5.36 & 5.06 & 4.64 & 5.50 \\
SR & -0.09 & -0.16 & -0.33 & -0.08 & -0.47 & 0.18 \\
\hline \multirow{2}{*}{ Asset Pricing } & & & & & \\
\hline CAPM $\alpha$ & -0.52 & -0.38 & $-0.62^{* * *}$ & -0.22 & $-0.72^{* * *}$ & 0.17 \\
& $(-1.18)$ & $(-1.39)$ & $(-2.66)$ & $(-1.40)$ & $(-6.21)$ & $(0.44)$ \\
3-fac $\alpha$ & $-0.94^{* * *}$ & $-0.65^{* * *}$ & $-0.74^{* * *}$ & $-0.33^{* * *}$ & $-0.65^{* * *}$ & -0.30 \\
& $(-2.92)$ & $(-3.15)$ & $(-2.98)$ & $(-2.73)$ & $(-5.46)$ & $(-1.59)$ \\
4-fac $\alpha$ & $-0.95^{* * *}$ & $-0.67^{* *}$ & $-0.74^{* * *}$ & $-0.34^{* * *}$ & $-0.64^{* * *}$ & -0.31 \\
& $(-2.55)$ & $(-2.09)$ & $(-2.99)$ & $(-2.69)$ & $(-5.33)$ & $(-0.72)$ \\
\hline MKT & $1.34^{* * *}$ & $1.02^{* * *}$ & $1.01^{* * *}$ & $0.97^{* * *}$ & $0.92^{* * *}$ & $0.43^{* * *}$ \\
& $(7.72)$ & $(9.72)$ & $(40.21)$ & $(17.67)$ & $(23.24)$ & $(2.77)$ \\
SMB & $0.46^{* * *}$ & $0.17^{* *}$ & 0.07 & -0.03 & $-0.23^{* * *}$ & $0.70^{* * *}$ \\
& $(3.57)$ & $(2.00)$ & $(0.89)$ & $(-0.37)$ & $(-3.52)$ & $(5.02)$ \\
HML & $0.45^{*}$ & $0.32^{* *}$ & $0.14^{* * *}$ & $0.19^{* *}$ & 0.06 & 0.34 \\
& $(1.77)$ & $(2.32)$ & $(2.50)$ & $(2.46)$ & $(0.78)$ & $(0.97)$ \\
\hline
\end{tabular}


Table IA.VI: Returns on Stock Portfolios sorted by Distances-to-Default

We sort stocks based on firms' distances-to-default $(D D)$ into quintile portfolios and calculate equally- and value-weighted excess returns in Panel A (B). We compute the distance-to-default in analogy to Vassalou and Xing (2004). P1 contains firms with lowest distances-to-default, P5 the ones with highest. P1-P5 presents results for going long P1 and short P5. Portfolio Characteristics summarizes portfolio means of the market value $(M V)$, book-to-market $(B M)$, 5-year CDS spread $(S 5)$, credit rating $($ Rating), number of CDS contributors reported by Markit (Liquid), and conditional coskewness with the market portfolio (Coskew) following Harvey and Siddique (2000). We assign integer numbers to the S\&P credit ratings, i.e. AAA=1, AA+ $=2, \ldots, \mathrm{C}=21 . \quad$ Portfolio Returns reports monthly means and standard deviations of excess returns along with annualized Sharpe ratios. Asset Pricing reports alpha estimates of regressing excess returns on the market $(M K T)$, as well as the three $(M K T, S M B, H M L)$ and four $(M K T, S M B, H M L, U M D)$ Fama-French factors. Values in parentheses are $t$-statistics based on HAC standard errors using Newey and West (1987) with optimal truncation lag chosen as suggested by Andrews (1991). Results are based on a data set comprising joint observations of CDS spreads, stock prices, firm characteristics, and S\&P credit ratings for the full time period $(01 / 2001-04 / 2010)$.

\begin{tabular}{|c|c|c|c|c|c|c|}
\hline & $\overline{\mathrm{P} 1}$ & $\overline{\mathrm{P} 2}$ & P3 & $\mathrm{P} 4$ & $\mathrm{P} 5$ & $\mathrm{P} 1-\mathrm{P} 5$ \\
\hline \multicolumn{7}{|c|}{ Sort Variable: Distance-to-Default (DD) } \\
\hline mean & 4.51 & 6.87 & 8.65 & 10.58 & 14.87 & \\
\hline \multicolumn{7}{|c|}{ Portfolio Characteristics } \\
\hline$M V$ & 12.09 & 14.45 & 18.10 & 21.07 & 36.00 & \\
\hline$B M$ & 0.79 & 0.62 & 0.58 & 0.51 & 0.38 & \\
\hline$S 5$ & 268.28 & 132.19 & 92.10 & 60.56 & 40.62 & \\
\hline Rating & 10.75 & 9.31 & 8.44 & 7.62 & 6.40 & \\
\hline Liquid & 7.54 & 8.06 & 7.93 & 7.67 & 7.53 & \\
\hline Coskew & -6.66 & -3.80 & -2.22 & -2.14 & -2.42 & \\
\hline
\end{tabular}

Panel A: Equally-Weighted Portfolios

\begin{tabular}{|c|c|c|c|c|c|c|}
\hline mean & $\begin{array}{c}-0.61 \\
(-0.42)\end{array}$ & $\begin{array}{c}-0.29 \\
(-0.36)\end{array}$ & $\begin{array}{c}-0.54 \\
(-0.67)\end{array}$ & $\begin{array}{c}-0.17 \\
(-0.32)\end{array}$ & $\begin{array}{c}-0.46 \\
(-0.83)\end{array}$ & $\begin{array}{c}-0.15 \\
(-0.15)\end{array}$ \\
\hline $\mathrm{sd}$ & 8.75 & 5.83 & 5.20 & 4.60 & 3.84 & 6.91 \\
\hline SR & -0.24 & -0.17 & -0.36 & -0.13 & -0.41 & -0.08 \\
\hline \multicolumn{7}{|c|}{ Asset Pricing } \\
\hline CAPM $\alpha$ & $\begin{array}{c}-1.03 \\
(-1.57)\end{array}$ & $\begin{array}{c}-0.56 \\
(-1.31)\end{array}$ & $\begin{array}{c}-0.75 \\
(-1.60)\end{array}$ & $\begin{array}{c}-0.39^{*} \\
(-1.69)\end{array}$ & $\begin{array}{c}-0.58 \\
(-1.48)\end{array}$ & $\begin{array}{c}-0.44 \\
(-0.79)\end{array}$ \\
\hline 3 -fac $\alpha$ & $\begin{array}{l}-1.49^{* * *} \\
(-2.54)\end{array}$ & $\begin{array}{c}-0.70 \\
(-1.44)\end{array}$ & $\begin{array}{c}-0.76^{*} \\
(-1.76)\end{array}$ & $\begin{array}{l}-0.42^{* *} \\
(-2.06)\end{array}$ & $\begin{array}{c}-0.65 \\
(-1.48)\end{array}$ & $\begin{array}{c}-0.83 \\
(-1.44)\end{array}$ \\
\hline $4-f a c \alpha$ & $\begin{array}{l}-1.50^{* * *} \\
(-2.92)\end{array}$ & $\begin{array}{l}-0.74^{* * *} \\
(-2.57)\end{array}$ & $\begin{array}{l}-0.81^{* * *} \\
(-2.65)\end{array}$ & $\begin{array}{l}-0.44^{* * *} \\
(-2.77)\end{array}$ & $\begin{array}{l}-0.68^{* *} \\
(-2.35)\end{array}$ & $\begin{array}{c}-0.82 \\
(-1.37)\end{array}$ \\
\hline MKT & $\begin{array}{l}1.33^{* * *} \\
(7.76)\end{array}$ & $\begin{array}{l}0.90^{* * *} \\
(4.45)\end{array}$ & $\begin{array}{l}0.76^{* * *} \\
(3.25)\end{array}$ & $\begin{array}{l}0.82^{* * *} \\
(9.78)\end{array}$ & $\begin{array}{l}0.43^{* * *} \\
(3.62)\end{array}$ & $\begin{array}{l}0.90^{* * *} \\
(5.22)\end{array}$ \\
\hline SMB & $\begin{array}{l}0.44^{* * *} \\
(3.05)\end{array}$ & $\begin{array}{c}0.28^{* *} \\
(1.97)\end{array}$ & $\begin{array}{c}0.05 \\
(0.51)\end{array}$ & $\begin{array}{c}-0.11 \\
(-0.74)\end{array}$ & $\begin{array}{c}0.16^{*} \\
(1.76)\end{array}$ & $\begin{array}{c}0.28 \\
(1.61)\end{array}$ \\
\hline HML & $\begin{array}{l}0.91^{* * *} \\
(4.76)\end{array}$ & $\begin{array}{c}0.13 \\
(0.70)\end{array}$ & $\begin{array}{c}-0.00 \\
(-0.01)\end{array}$ & $\begin{array}{c}0.18^{* *} \\
(1.96)\end{array}$ & $\begin{array}{c}0.04 \\
(0.54)\end{array}$ & $\begin{array}{l}0.87^{* * *} \\
(4.74)\end{array}$ \\
\hline
\end{tabular}

Panel B: Value-Weighted Portfolios

\begin{tabular}{lcccccc}
\multicolumn{7}{l}{ Portfolio Returns } \\
\hline mean & -0.94 & -0.39 & -1.05 & -0.07 & -0.80 & -0.14 \\
& $(-0.82)$ & $(-0.44)$ & $(-1.14)$ & $(-0.18)$ & $(-1.22)$ & $(-0.18)$ \\
sd & 8.27 & 6.07 & 5.19 & 4.29 & 4.20 & 6.63 \\
SR & -0.40 & -0.22 & -0.70 & -0.06 & -0.66 & -0.08 \\
\hline \multirow{2}{*}{ Asset Pricing } & & & & & \\
\hline CAPM $\alpha$ & $-1.31^{*}$ & -0.66 & $-1.24^{* *}$ & -0.26 & $-0.92^{* *}$ & -0.39 \\
& $(-1.71)$ & $(-1.56)$ & $(-2.15)$ & $(-1.26)$ & $(-2.12)$ & $(-0.83)$ \\
3-fac $\alpha$ & $-1.50^{*}$ & -0.67 & $-1.23^{* *}$ & -0.21 & $-0.97^{* *}$ & -0.53 \\
& $(-1.79)$ & $(-1.44)$ & $(-2.32)$ & $(-1.40)$ & $(-2.04)$ & $(-1.07)$ \\
4-fac $\alpha$ & $-1.52^{* * *}$ & $-0.71^{* *}$ & $-1.28^{* * *}$ & -0.23 & $-1.01^{* * *}$ & -0.52 \\
& $(-2.71)$ & $(-2.16)$ & $(-3.20)$ & $(-1.20)$ & $(-2.48)$ & $(-0.99)$ \\
\hline MKT & $1.28^{* * *}$ & $0.99^{* * *}$ & $0.72^{* * *}$ & $0.73^{* * *}$ & $0.43^{* * *}$ & $0.85^{* * *}$ \\
& $(12.47)$ & $(5.70)$ & $(3.25)$ & $(8.19)$ & $(3.73)$ & $(5.63)$ \\
SMB & -0.11 & -0.01 & -0.14 & -0.26 & -0.03 & -0.08 \\
& $(-0.83)$ & $(-0.13)$ & $(-1.48)$ & $(-1.34)$ & $(-0.38)$ & $(-0.48)$ \\
HML & $0.67^{* *}$ & 0.04 & 0.12 & 0.10 & 0.17 & 0.50 \\
& $(2.30)$ & $(0.21)$ & $(0.44)$ & $(0.77)$ & $(1.19)$ & $(1.45)$ \\
\hline
\end{tabular}

